\title{
Influence of agronomic practices on the
}

\section{development of soil suppression against cyst- \\ forming plant-parasitic nematodes}

\author{
Dissertation \\ to obtain the $\mathrm{Ph}$. D. degree \\ in the Ph. D. Program for Agricultural Sciences in Göttingen (PAG) \\ at the Faculty of Agricultural Sciences, \\ Georg-August-University Göttingen, Germany
}

presented by

Caroline Eberlein

born in Viña del Mar, Chile

Göttingen, December 2015 
1. Examiner:

Prof. Dr. Stefan Vidal (Supervisor)

Department of Crop Sciences,

Division of Agricultural Entomology,

2. Examiner:

University of Göttingen, Germany

Prof. Dr. Johannes Hallmann (Co-supervisor)

Fachgebiet Ökologischer Pflanzenschutz

3. Examiner:

University of Kassel, Witzenhausen

Prof. Dr. Andreas von Tiedemann

Director of the Department of Crop Sciences,

Division of Plant Pathology and Crop Protection,

University of Göttingen, Germany

Place and date of dissertation: Göttingen, $9^{\text {th }}$ February 2016. 
To the memory of my grandparents 


\section{TABLE OF CONTENTS}

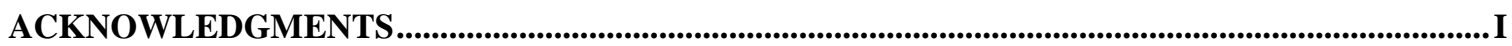

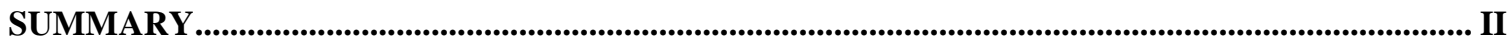

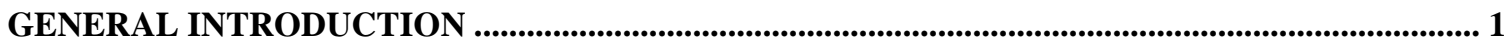

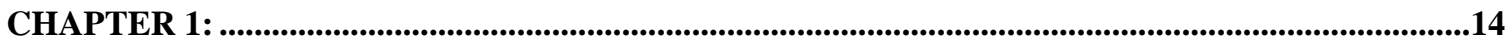

POPULATION DYNAMICS OF GLOBODERA PALLIDA UNDER POTATO MONOCULTURE14

ABSTRACT

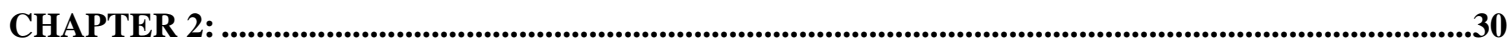

MICROBIAL COMMUNITIES IN GLOBODERA PALLIDA IN FEMALES RAISED IN POTATO

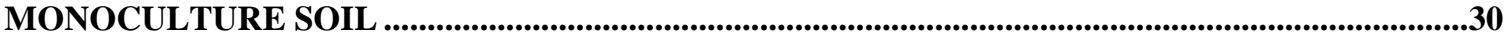

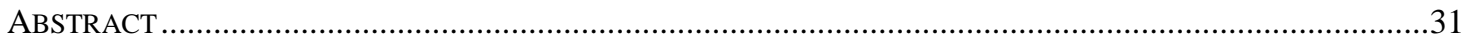

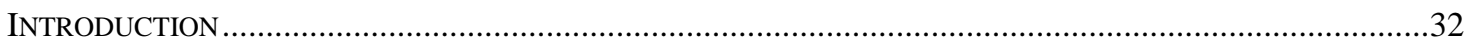

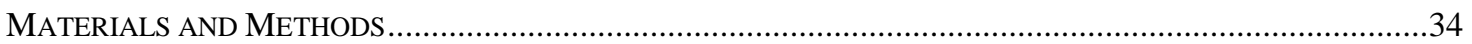

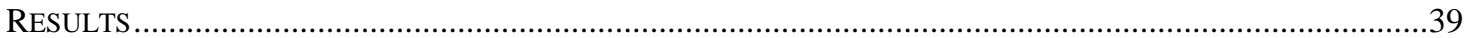

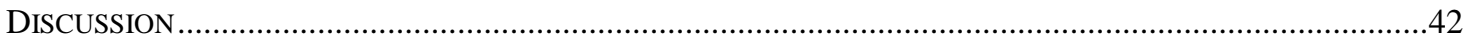

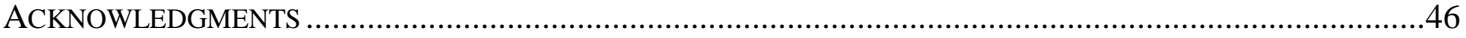

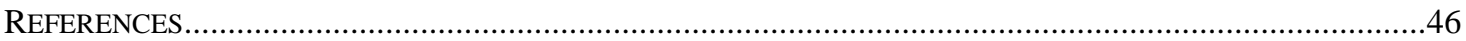

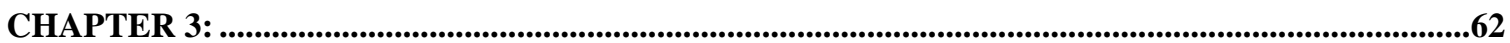

IMPACT OF CROPPING SEQUENCES AND PRODUCTION STRATEGIES ON SOIL

SUPPRESSIVENESS AGAINST CEREAL CYST NEMATODES ..................................................62

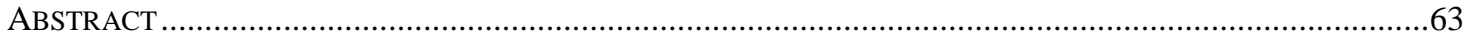

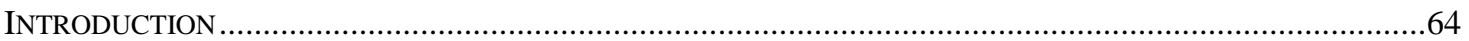

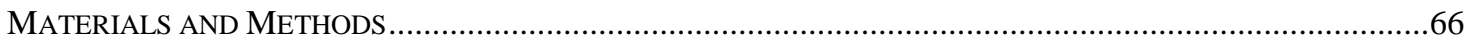

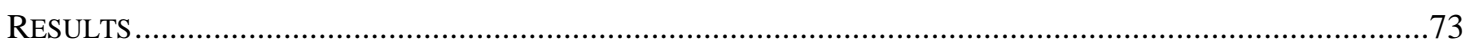

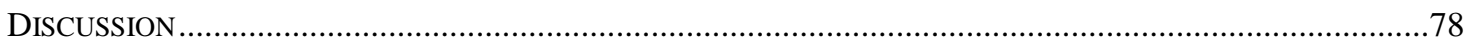

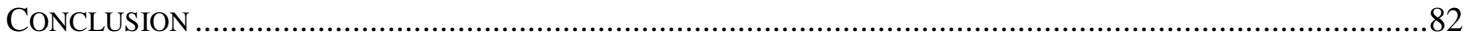

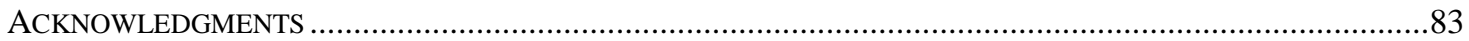

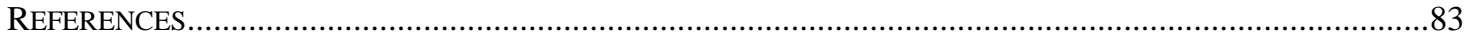

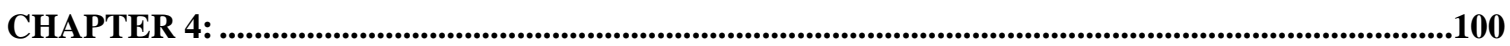

BIOLOGICAL SUPPRESSION OF POPULATIONS OF THE PLANT-PARASITIC NEMATODE

HETERODERA SCHACHTII ADAPTED TO DIFFERENT HOST GENOTYPES OF SUGAR

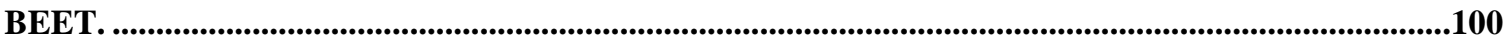

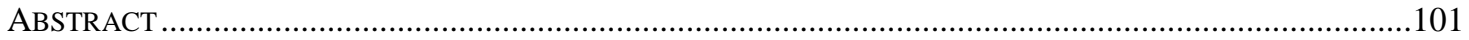

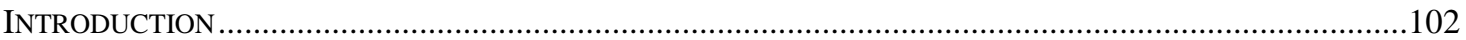

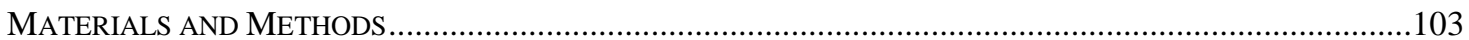

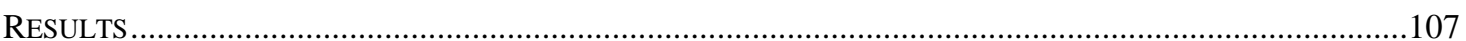

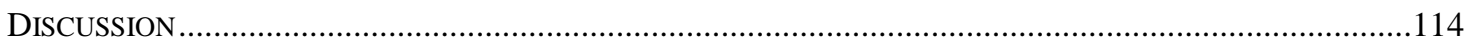

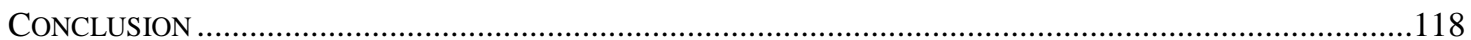

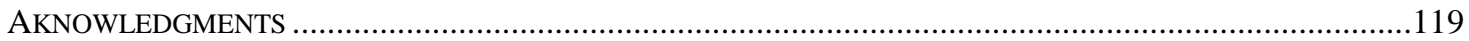

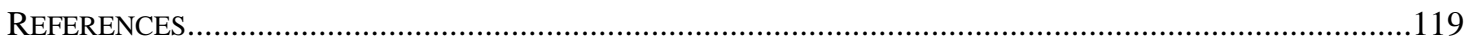




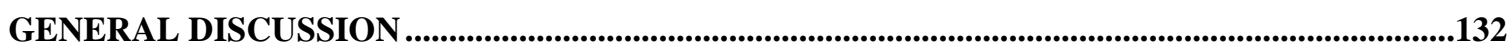

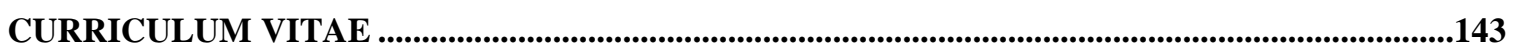

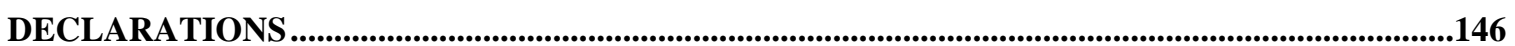




\section{LIST OF TABLES}

Table

Page

2.1 Means \pm SE of percentage of diseased eggs, number of eggs per cyst and eggs with fungal growth from the content of Globodera pallida females and cysts raised in root observation chambers in potato monoculture soil infested with one of two G. pallida populations.

2.2 Operational taxonomic units (OTU) of the most the dominant bacteria within females of Globodera pallida populations raised in non-heated potato monoculture of Chavornay and Delmsen soil based on the V3V4 region amplicon pyrosequencing.

2.3 Operational taxonomic units (OTU) of the most dominant fungi within females of Globodera pallida raised in non-heated potato monoculture of Chavornay and Delmsen soil based on ITS2 region amplicon pyrosequencing.

3.1 Cereal yields in a transfer study averaged for amendment with non-heated or heated portions of oat monoculture soil in a cereal monoculture with initial oat 'Nordstern' or 'Sang' compared to a sequence with sugar beet 'Beretta' at Münster 2010-2013. 


\section{LIST OF FIGURES}

Figure

1.1 Population densities of Globodera pallida Chavornay and Delmsen on susceptible potato 'Selma' in monoculture.

1.2 Tuber yield of potato 'Selma' in monoculture plots infested with Globodera pallida Pa3 populations Chavornay or Delmsen (lsmeans \pm lsmse) in years 2010 to 2014.

1.3 Relative proportions of potato tuber size classes in Globodera pallida $\mathrm{Pa} 3$ infested plots of nematode populations Chavornay and Delmsen in years 2010 to 2014.

2.1 Egg of Globodera pallida healthy and compromised, rated as diseased.

2.2 Number of females visible on potato roots 'Selma' during monitoring in root observation chambers from 36 dpi to 90 dpi of heated and nontreated portions of soil from Chavornay or Delmsen microplots during the first experiment.

2.3 Bacterial (16S rRNA gene) DGGE fingerprints for Globodera pallida females collected from heat-treated (HT) and non-heated soil (NT) at 64 dpi in 2012 and at 91 dpi in 2014 and corresponding UPGMA cluster.

2.4 Fungal (ITS) DGGE fingerprints for Globodera pallida females collected from heat-treated (HT) and non-heated soil (NT) at 64 dpi in 2012 and at 91 dpi in 2014 and respective UPGMA cluster.

2.5 Bacterial (16S rRNA gene) DGGE fingerprints for inoculation cysts 
(Cysts Pa3) and Globodera pallida females in heat-treated (HT) and nonheated soil (NT) in 2012 and corresponding UPGMA cluster.

2.6 Fungal (ITS) DGGE fingerprints for inoculation cysts (Cysts Pa3), for Globodera pallida females from heat-treated (HT_F) and from nonheated soil (NT_F), and for heat-treated soil (HT_S) in 2012 and respective UPGMA cluster.

3.1 Population densities of Heterodera avenae and H. filipjevi at harvest on different crop species following differential crops of sugar beet or oat in 2010 at Münster from 2010 to 2013.

3.2 Population densities of Heterodera avenae on oat/sugar beet and winter 92 wheat crops in H. avenae-infested soil at harvest in 2013 to 2014 at Braunschweig.

3.3 Females of Heterodera avenae on root systems of spring barley 'Hanka' 93 in root observation chambers.

3.4 Bacterial (16S rRNA gene) DGGE fingerprint and corresponding 94 UPGMA cluster for heat-treated (HT) and non-heated (NT) soil from oat monoculture, and non-infested control and Heterodera avenae microplots at Braunschweig after soil transfer and before sowing in 2013.

3.5 Fungal (ITS) DGGE fingerprints and respective UPGMA cluster for nonheated (NT) soil from oat monoculture and non-infested control and Heterodera avenae microplots at Braunschweig after amendment with heat-treated (HT) and non-heated (NT) oat monoculture soil and before sowing in 2013.

3.6 UPGMA dendrograms from bacterial (16S rRNA gene) and fungal (ITS) 
DGGE fingerprints for soil collected after harvest in 2013 from sub-plots where sugar beet Beretta (Ber) or Oat (Cer) were cropped in plots that received the heat-treated (HT) and non-heated (NT) amendment at Braunschweig, fungal (ITS) DGGE for cysts collected at harvest in 2013 and 2014 from microplots that received the heat-treated (HT) and nonheated $(\mathrm{NH})$ amendment at Braunschweig, and for Heterodera avenae females raised on non-heated $(\mathrm{NH})$ oat monoculture soil $(\mathrm{OM})$ and collected at 67 dpi in experiment 1 and 2, and fungal (ITS) DGGE for $H$. avenae females raised in heat-treated (HT) and non-heated (NT) oat monoculture $(\mathrm{OM})$, control/crop rotation $(\mathrm{CR})$ and intensive cereal cropping; organic farming (OF) and conventional farming (CF) soils and collected at 67 dpi in experiment 2.

3.7 Bacterial (16S rRNA gene) DGGE fingerprint, corresponding bacterial UPGMA cluster, and UPGMA cluster from fungal (ITS) DGGE fingerprint for heat-treated (HT) and non-heated (NT) oat monoculture $(\mathrm{OM})$, control/crop rotation $(\mathrm{CR})$ and intensive cereal cropping; organic farming (OF) and conventional farming (CF) soils before sowing in experiment 2 .

3.8 Bacterial (16S rRNA gene) DGGE fingerprint and corresponding 98 UPGMA cluster for Heterodera avenae females raised in heat-treated (HT) and non-heated (NT) oat monoculture (OM), control/crop rotation (CR) and intensive cereal cropping; organic farming (OF) and conventional farming (CF) soils and collected at $67 \mathrm{dpi}$ in experiment 2 .

4.1 Root penetration by second-stage juveniles (J2) of Heterodera schachtii Schach0 in a susceptible, resistant and tolerant sugar beet genotype at Münster, from 2010 to 2013 in untreated control, P. nishizawae, D. oviparasitica (2nd inoculation in 2011), and D. oviparasitica (single inoculation in 2011). 
4.2 Root penetration by second-stage juveniles (J2) of Heterodera schachtii 126

Schach1 in a susceptible, resistant and tolerant sugar beet genotype at Münster, from 2010 to 2013 in untreated control, P. nishizawae, Dazomet + D. oviparasitica, and Dazomet - D. oviparasitica.

4.3 Final population densities of Heterodera schachtii Schach0 at Münster, from 2010 to 2013 , at 0 - to 30-cm depth.

4.4 Final population densities of cysts of Heterodera schachtii Schach1 at 128 Münster, from 2010 to 2013, at 0- to 30-cm depth in untreated control, $P$. nishizawae, Dazomet + D. oviparasitica, and Dazomet - D. oviparasitica plots.

4.5 Final population densities of total eggs of Heterodera schachtii Schach1 at Münster, from 2010 to 2013, at 0- to 30-cm depth in untreated control, P. nishizawae, Dazomet + D. oviparasitica, and Dazomet $-D$. oviparasitica plots.

4.6 White sugar yield (WSY) of Heterodera schachtii Schach0 at Münster from 2010 to 2013.

4.7 White sugar yield (WSY) of Heterodera schachtii Schach1 at Münster from 2010 to 2013 in untreated control, P. nishizawae, Dazomet $+D$. oviparasitica, and Dazomet - D. oviparasitica plots. 


\section{ACKNOWLEDGMENTS}

I would like to express my deep appreciation and gratitude to my supervisor Dr. Andreas Westphal for the opportunity to work on these projects, for his guidance, support and challenges.

I am deeply indebted to Prof. Dr. Stefan Vidal for accepting me as a PhD student, for his support, and for his valuable suggestions and feedback.

I thank Prof. Dr. Johannes Hallmann for accepting to be my co-supervisor and for creating time to attend my defense despite tight schedules.

I thank Prof. Dr. Andreas von Tiedemann for accepting being a member of the committee.

I am indebted to Dr. Holger Heuer for his input in the molecular part of these studies, and for being accessible whenever I had questions or needed to discuss something.

I am very appreciative of Conicyt Chile for providing me with the Scholarship to undertake this PhD.

I am also thankful to the teams at the Institut of Plant Protection in Field Crops and Grassland, and the Institut for Epidemiology and Pathogen Diagnostics, Julius KühnInstitut, Münster and Braunschweig, for technical support. In particular I would like to thank Carolin Blümcke, Tanja Blöthe-Hartmann, Agnes Windt, Mechtild Neuhaus and Dorothee Suttorp who were very supportive in many facets of my $\mathrm{PhD}$.

I finally express my gratitude to Robert for his great support, encouragement and patience over these years. 


\section{SUMMARY}

Cyst-forming nematodes are a major group of plant pests of economic importance worldwide. There are well-documented cases of suppressive soils where plant-parasitic nematodes are maintained at very low population densities by one or more microorganisms that co-exist in the same environment. The role of agronomic practices in the establishment and support of soil suppressiveness offer new possibilities in the management of these pests.

To test if this specific suppressiveness would evolve under a five-year monoculture of susceptible potato in soil infested with Globodera pallida Pa3 populations Chavornay and Delmsen, a microplot study was conducted. Final populations of total eggs remained similar for Delmsen but oscillated for Chavornay. Proportions of diseased eggs increased dramatically at the first year after harvest and oscillated until the fifth year, especially for Chavornay. This suggested a predator - prey relationship of the nematode and a suppressive factor. Yields of total marketable potato tubers increased in Chavornay but decreased in Delmsen. In a greenhouse experiment, females developing in these soils were examined for inherent microbial communities through PCR-DGGE and pyrosequencing. Candidate microorganisms that possibly affected the egg health status of G. pallida were identified. The dominance of the fungus Malassezia, especially $M$. restricta, known for its pathogenic abilities on human and animal skin, a tissue that shares structural proteins with the nematodes cuticle, warrants further investigation.

To examine if susceptible crops were crucial for the successful establishment of suppressive transfer, population dynamics of Heterodera avenae and $H$. filipjevi were monitored in microplots amended with a nematode suppressive oat monoculture soil and cropped to susceptible cereal hosts during four years. Although no effect of the amendment was detected on $H$. avenae or $H$. filipjevi population densities, or in plant growth and yield parameters, percentage of diseased eggs increased up to $65.5 \%$ under the third cropping season, and yield was almost not constrained compared to the noninfested control plots. This suggested that the monoculture of susceptible crops was sufficient to induce and support the establishment of suppressive factors. In a climate chamber experiment, the suppressive potential of the oat monoculture and two soils from 
intensive cereal cropping systems (one from conventional, one from organic farming) was tested against $H$. avenae female populations. Results of this experiment indicated a suppressive potential of the monoculture and intensive cereal cropping soils. Furthermore, a high similarity in suppressive potential and microbial communities between organic and conventional farming soils suggested a stronger effect of the cropping rather than the farming system.

It was tested if tolerant sugar beet cultivars permit soil suppressiveness to establish by allowing some reproduction of the primary parasite, necessary for the increase of antagonists. Population dynamics and egg health status of Heterodera schachtii Schach0 and Schach1 were monitored under a four-year sugar beet monoculture of susceptible, resistant and tolerant genotypes. Pasteuria nishizawae and Dactylella oviparasitica were included in this study, as representative model organisms for an obligate bacterial parasite and a facultative antagonist, respectively. The ability of $D$. oviparasitica and $P$. nishizawae to suppress the populations of $H$. schachtii was inconsistent, compared to the corresponding controls. However, irrespective of the treatment and the cultivar, eggs became soon diseased, so by the third cropping cycle, diseased eggs represented over $90 \%$ of the total eggs. As expected, in each cropping season the tolerant genotype yielded the highest in both pathotypes. The presence of nematode-controlling factors in this monoculture of susceptible, resistant and tolerant sugar beet cultivars, that may be responsible for the dramatic increase of diseased eggs, was suggested.

Findings of these studies proportionate baseline data that complement the evidence of the potential of agronomic practices to induce and support the establishment of soil suppressiveness. In this study, monoculture or intensive cropping of susceptible host crops, and cultivation of resistant and tolerant host genotypes, supported the development of soil suppressive factors against different cyst-nematodes mostly in increased proportions of diseased eggs. 


\section{GENERAL INTRODUCTION}

"Plant parasitic-nematodes only reach unacceptable high population densities (i.e. become pests of economic concern) when they are no longer constrained by the biological mechanisms that normally keep them in check (Stirling, 1991)’”.

Cyst forming nematodes are a major group of plant pathogens of economic importance worldwide. Among others, considerable yield losses have been attributed to cyst nematodes attacking potatoes, cereals and sugar beet. Since eggs are contained within a cyst that protects them from biotic and abiotic factors such as predation or desiccation, eggs can remain viable for several years, which renders their control difficult. Potato cyst nematodes (PCN) Globodera pallida Stone and G. rostochiensis (Wollenweber) Skarbilovich, are among the most important limiting pests in potato production (Scurrah et al., 2005) and are listed as quarantine pests for EPPO, APPPC and NAPPO, and additionaly for CPPC and IAPSC in the case of G. rostochiensis (CABI/EPPO 1997). At very high levels of PCN populations, crop losses up to $80 \%$ can be expected (CABI/EPPO 1997). Cereal cyst nematodes (CCN) H. avenae Wollenweber and H. filipjevi (Madzhidov) Stelter are considered major yield constraints affecting the cereal production in many countries (reviewed by Nicol and Rivoal 2008; Riley et al., 2009). It has been estimated that high population densities of CCN under highly nematode-conducive conditions cause up to $89 \%$ yield losses in winter wheat (Rivoal and Cook, 1993; Evans and Rowe, 1998; Nicol et al., 2003). The sugar beet cyst nematode Heterodera schachtii Schmidt is one of the most significant pests in sugar beet production in Europe and worldwide (Williamson and Hussey, 1996; Evans and Rowe, 1998; Müller, 1999; Greco and Esmenjaud, 2004). It is the first cyst nematode recognized and yield losses up to $50 \%$ have been attributed to this nematode (Schlang, 1991; Müller, 1999; D’Addabbo et al., 2005; Hallmann et al., 2009).

Management options of varying levels of efficacy against these cyst nematodes include crop rotations, nematicides, trap cropping and the use of resistant cultivars. In the case of PCN, preventive methods such as the mandatory use of certified seed tuber and 
the avoidance of infestation of healthy areas are of particularly importance (Mugniery and Phillips, 2007).

Since cysts can remain viable for several years in the soil, non-host crops should be grown for many years before populations have been reduced to non-damaging levels, presumably by natural population density decline and spontaneous nematode hatch without a new feeding opportunity for this obligate parasite. In the case of PCN in northern Europe, rotations of four or even seven years can be an effective management strategy, but such long rotations often seems incompatible with modern intensive agriculture and is not economically practical (Müller, 1999; McDonald and Nicol, 2005; Mugniery and Phillips, 2007). Rotations may be shortened under warm conditions or if the rotations are complemented with the use of resistant potato cultivars and soil disinfestations (Mugniery and Phillips, 2007). For H. avenae, one of the most efficient control methods is the use of grass-free rotations. While a four-year rotation can be implemented in Europe, in most subtropical and tropical countries such long rotations are not suitable due to economical reasons (Nicol and Rivoal, 2008). For sugar beet nematode $H$. schachtii, until 1950, long-term rotations were the only feasible measure to control this nematode in Europe (Müller, 1999). Although growing sugar beet one year in five is considered an effective control measure, three-year rotations are possible when nematode resistant catch-crops are included. In Germany resistant oilseed radish Raphanus sativus oleiformis and mustard, Sinapis alba are regularly included in sugar beet rotations to reduce population densities of $H$. schachtii (Müller, 1999).

Nematicides have been used since the introduction of the fumigant carbon disulphide in the late $19^{\text {th }}$ century. Thereafter further fumigants such as 1,3dichloropropene (1,3-D), methyl bromide, metam sodium and dazomet were developed (Haydock et al., 2006). The use of methyl bromide has been phased out for developed countries in 2005 under the Montreal Protocol. Also effective nematicides such as dibromocholopropane (DBCP) and ethylene dibromide (EDB) have been withdrawn from the market due to their adverse effects on humans and the environment (Oka et al., 2000). In the second-half of the $20^{\text {th }}$ century, the use of fumigants was followed by the development of non-fumigants nematicides, such as organophosphates (e.g. fenamiphos, ethoprophos and fosthiazate) and carbamates (e.g. carbofuran, aldicarb and oxamyl), 
which have a nematostatic rather than a nematicidal effect (Haydock et al., 2006). As a result of human and environmental concerns, pesticide reduction to a minimum and the use of integrated plant protection measures became part of German legislation and international programmes (Burth et al., 2002). Since 1990, nematicides for controlling beet cyst nematodes are no longer allowed in Germany, and fosthiazate is the only registered nematicide for use in potato, but since it does not have a long-lasting effect, it does not fulfil the regulatory requirement of reductions of PCN (Müller, 1999; Woods et al., 1999).

As a consequence, alternative strategies like the use of resistant cultivars to reduce nematode populations became an essential part of integrated control management for these pests. Since the registration of the first sugar beet variety with resistance to $H$. schachtii in 1998 in Germany following registration of the first cultivar in France in 1996 (Müller, 1999), the use of genetic host resistance is considered one of the most economical, environmentally friendly, accessible and effective method to manage the nematode when the population densities exceed the damage thresholds. Commercial acceptance of resistant cultivars has been limited though because of a lower yield potential of resistant cultivars (Bürcky, 2013). Much more successful was the introduction of nematode-tolerant cultivars. These modern sugar beets have yield advantages over susceptible and sensitive high yield cultivars under increasing nematode population densities (Heinrichs, 2013; Kaemmerer et al., 2014).

Plant resistance to certain populations of the plant-parasitic nematode species may lead to an increase of the populations that are not suppressed by the resistant cultivars (Roberts, 2002). Since the resistance to $H$. schachtii is monogenic and dominantly inherited, it can break down when the corresponding virulence gene is present (Müller, 1992), thus the resistance can only be used for a limited period of time (Müller, 1999). In addition, the yield potential of resistant cultivars is usually lower than non-resistant varieties, so in the case of sugar beet, resistant cultivars have been only grown to a limited extent (<2\%; Märländer et al., 2003). The recent release of nematode-tolerant sugar beet cultivars provides novel management strategies, since they can withstand higher initial population densities of $H$. schachtii than susceptible cultivars before they incurr nematode damage while allowing more nematode reproduction than resistant 
cultivars. Tolerant cultivars also carry some resistance compared with susceptible cultivars.

The use of resistant cultivars against PCN has also faced difficulties. The cropping of the resistant cultivars against G. rostochiensis in almost all infested areas resulted in the replacement of this species by G. pallida. Although the first resistant varieties against $G$. pallida have been released, the durability of this resistance remains uncertain (Mugniery and Phillips, 2007). Resistance to PCN has mainly been derived from Solanum vernei. This resistance source is assumed to be polygenetic, and has resulted in the release of partially resistant varieties that allow the development of some females to maturity (Mugniery and Phillips, 2007). Another problem has been the lack of resistant cultivars for some pathotypes.

Several sources of resistance have been reported against $H$. avenae, but high variability within the species and among regional populations in terms of virulence and reproductive capacity impede their uniform effectiveness. This makes the control of $H$. avenae difficult (Rivoal et al., 2001; Mokabli et al, 2002). Many of the resistant sources that are conferred by a single dominant gene became ineffective when virulent pathotypes were selected by the repeated use of the same resistant cultivars. Evidence of this has been reported for $H$. avenae and H. filipjevi in Denmark and in Sweden (Cook and Noel, 2002).

Public concerns about the detrimental effects of chemical control on the environment and human health, along with its questionable effectiveness, long-term crop rotations, the lack of resistant or tolerant cultivars for some pathotypes, and the breakdown of host resistance by virulent populations continuously encourages the search for alternative management strategies. Natural enemies of cyst nematodes, mainly fungi, have been recognized since Kühn in 1877 reported that Catenaria auxiliaries (Kühn) Tribe (=Tarichium auxiliare Kühn) parasitized females of Heterodera schachtii (MorganJones and Rodríguez-Kábana, 1987). The potential of parasitic fungi as nematode control agents has been repeatedly reviewed (Mankau, 1980; Jatala, 1986; Kerry, 1988; Siddiqui and Mahmood, 1996). Inconsistent field performance has prevented their exploitation on a field scale. As a consequence, the number of commercial products registered for biological control of plant-parasitic nematodes is narrow (Dong and Zhang 2006), and 
most of them are formulations of the same fungal species such as Purpureocillium lilacinus and Pochonia chlamydosporia. Although few antagonists have been developed into an effective commercial product to manage plant-parasitic nematodes, welldocumented cases support the hypothesis that some level of biological control is naturally occurring in many agricultural fields. Such suppressive soils have been defined by Baker and Cook (1974) as "soils in which the pathogen does not establish or persist, establishes but causes little or no damage, or establishes and causes disease for a while but thereafter the disease is less important, although the pathogen may persist in the soil". Soils suppressive to pests and diseases caused by the most important soil-borne pathogens have been described. They include fungal and bacterial pathogens (Menzies 1959; Shipton, 1975; Cook and Baker, 1983; Alabourette, 1986; Shiomi et al., 1999) as well as nematodes (Gair et al., 1969; Kluepfel et al., 1993; Weibelzahl-Fulton et al., 1996; Westphal and Becker, 1999; Westphal and Xing, 2011). In suppressive soils, plantparasitic nematodes are maintained at very low population densities due to the action of one or more microorganisms that co-exist in the same environment (Stirling 1991). Cyst nematode-suppressive soils were first reported in Great Britain, where after an initial increase of nematode populations and plant damage, $H$. avenae populations declined after three to four cropping cycles of susceptible host crops (Gair et al., 1969). Other cystnematode suppressive soils have been described for $H$. schachtii (Thielemann and Steudel, 1973; Heijbroek, 1983; Crump and Kerry 1987; Westphal and Becker, 1999), H. glycines Ichinohe (Chen, 2007; Westphal and Xing, 2011) and Globodera spp. (Roessner, 1987).

Two compatible types of soil suppressiveness are distinguished: (I) general suppression is related to the total amount of microbiological activity that constrains the pathogen, and (II) specific suppression is due to the effects of a single microorganism or specific group of antagonists to the pathogen during some stage in its life cycle (Cook and Baker, 1983). Transferability is the key characteristic of specific suppression (Westphal and Becker, 2000). Different methods to detect and characterized a nematodesuppressive soil have been proposed (Stirling, 1991; Westphal 2005). They include the elimination of suppressiveness by biocidal treatments (i.e. pasteurization, fumigation) to demonstrate the biological basis of suppression, the transfer of suppressiveness to a 
conducive soil by addition of small amounts of the suppressive soil ( $0.1 \%$ to $10 \%$ or less), and the use of baiting techniques with different nematode life stages to transmit the suppressiveness. The decline of $H$. avenae in the UK caused by the parasitic fungi Nematophthora gynophila and Pochonia chlamydosporium (Kerry et al., 1982), and the reduction of $H$. schachtii in California by Brachyphoris (syn. Dactylella) oviparasitica (Westphal and Becker, 1999; Borneman and Becker, 2007) are good illustrations of specific suppressiveness.

The organisms associated with suppression have traditionally been determined using cultural, biochemical and microscopic methods, but molecular tools have provided new insights into the identification and characterization of soil microbial populations involved in soil suppressiveness (Weller et al., 2002; Garbeva et al., 2004; Mazzola 2004; van Elsas et al., 2008). Molecular techniques have been also of increasing importance in the characterization of specific suppression against plant-parasitic nematodes (Yin et al., 2003a, 2003b; Borneman and Becker 2007), and were used in the quantification and tracking of the nematode and its suppressive agents (Borneman and Becker 2007).

Once the mechanisms underlying the suppresiveness have been identified, the second step should be to maintain or even enhance the specific suppressive factors. In contrast to inundative approaches involving the release of large amounts of non-native biological agents to suppress a pathogen, recent emphasis has been put on adopting or modifying different agricultural practices in order to manipulate the resident rhizosphere microflora so that specific microorganisms involved in soil suppresiveness can be conserved or enhanced. Such practices include the cropping system, the growing of specific plant species or genotypes, tillage regime, or the application of soil amendments (Mazzola, 2007). The cultivation of annual or perennial host-crops for an extended time has been the common factor of all of the well-documented nematode-suppressive soils (Stirling 1991; Kluepfel et al., 1993; Westphal and Becker 1999; Timper et al., 2001). Hypothetically, the continuous presence of a particular plant-parasitic nematode with a surge to high population densities, leads to the build-up of specialized antagonists of that nematode (Kerry and Crump 1998). From a coevolutionary point of view, by providing a limited diversity of nutrient sources to microbial communities, it is likely that long-term monocultures generate the conditions for a strong directional selection for specialized 
antagonists, instead of a niche differentiation, thus maximizing the fitness benefit of antagonistic phenotypes (Kinkel et al., 2011).

In the experiments of this project, current general hypotheses were tested: (1) Does a five-year monoculture lead to soil suppressiveness to Globodera pallida? (2) Does host cropping facilitate the transfer and establishment of soil suppressiveness? (3) Does monoculture of host plant of different host plant genotypes (susceptible, resistant, tolerant) influence facultative and obligate nematode parasites differently?

To test whether a five-year monoculture of susceptible potato leads to suppresiveness of the soil against G. pallida, population dynamics of this nematode species and the impact of this cropping system on the health status of the nematode were evaluated. Microbial communities associated with the eggs of G. pallida raised in this monoculture soil were further investigated with culture-independent methods.

To examine if susceptible crops were crucial for the successful establishment of suppressiveness transfer, population dynamics of $H$. avenae and $H$. filipjevi were monitored in microplots amended with a nematode suppressive oat monoculture soil and cropped to susceptible hosts during four years. In a climate chamber experiment, the suppressive potential of the oat monoculture and two soils from intensive cereal cropping systems (one from conventional, one from organic farming) was tested against $H$. avenae female populations.

During the period that suppresiveness needs to establish, the nematode causes considerable damage and it seems unlikely that farmers would be prepared to suffer significant yield losses in the eventual hope of obtaining long-term nematode suppression. To overcome this problem, the use of tolerant genotypes would avert severe yield losses of susceptible cultivars in the initiating phase of the suppressiveness. In our hypothesis the tolerant crop would preserve yield while permitting soil suppressiveness to develop. Further, the limited reproduction of the primary parasite may allow for the increase of specific antagonists. To test this hypothesis, population dynamics and egg health status of $H$. schachtii were monitored under a four-year sugar beet monoculture of susceptible, resistant and tolerant genotypes. Pasteuria nishizawae and Dactylella oviparasitica were included in this study, as representative model organisms for an obligate bacterial parasite and a facultative antagonist, respectively. 


\section{References}

Alabouvette C. 1986. Fusarium wilt suppressive soils from the Chateaurenard region: review of a 10-year study. Agronomie 6: 273-84.

Baker, K.F. and Cook, R.J. 1974. Biological Control of Plant Pathogens. American Phytopathology Society, San Francisco, 433pp.

Borneman, J. and Becker, J.O. 2007. Identifying microorganisms involved in specific pathogen suppression in soil. Annu Rev Phytopathol 45:153-172.

Bürcky, K. 2013. Aktuelle Sortenergebnisse und Empfehlungen. Deut Zuckerrübenz 49: 14-19.

Burth, U., V. Gutsche, B. Freier, and D. Roßberg. 2002. Das notwendige Maß bei der Anwendung chemischer Pflanzenschutzmittel. Nachrichtenbl Deut Pflanzenschutzd 54: 297-303.

CABI/EPPO (1997). Data sheets on quarantine organisms: Globodera rostochiensis and Globodera pallida. In: Smith, I. M., McNamara, D. G., Scott, P. R., Holderness, M., and Burger, B. (Eds) Quarantine Pests for Europe. CAB International, Wallingford, UK, pp. 601-606.

Chen, S.Y. 2007. Suppression of Heterodera glycines in soils from fields with long-term soybean monoculture. Biocontrol Sci Technol 17: 125-134.

Cook, R.J., Baker, K.F., 1983. The Nature and Practice of Biological Control of Plant Pathogens. American Phytopathological Society, St. Paul, Minnesota, 539 pp.

Cook , R., Noel, G.R. 2002. Cyst nematodes: Globodera and Heterodera species. In: Starr, J.L., Cook, R. \& Bridge, J. (Eds). Plant resistance to parasitic nematodes . CAB International, Wallingford, UK, pp. 71-105.

Crump, D.H. and Kerry, B.R. 1987. Studies on the population dynamics and fungal parasitism of Heterodera schachtii in soil from sugar beet monoculture. Crop Prot 6: 49-55.

D’Addabbo, T., Sasanelli, N., Greco, N., Stea, V., Brandonisio, A. 2005. Effect of water, soil temperatures, and exposure times on the survival of the sugar beet cyst nematode, Heterodera schachtii. Phytopathology 95: 339-344.

Dong, L.Q., Zhang, K.Q. 2006. Microbial control of plant-parasitic nematodes: a fiveparty interaction. Plant Soil 288: 31-45. 
Evans, K. and Rowe, J.A. 1998. Distribution and economic importance. In: Sharma, S.B. (Ed.), The cyst nematodes, Chapman and Hall, London, UK, pp. 1-30.

Gair R., Mathias, P.L., Harvey, P.N. 1969. Studies of cereal nematode populations and cereal yields under continuous or intensive culture. Ann Appl Biol 63: 503-12.

Garbeva, P., van Veen, J.A., van Elsas, J.D. 2004. Microbial diversity in soil: selection of microbial populations by plant and soil type and implications for disease suppressiveness. Annu Rev Phytopathol 42: 243-270.

Greco, N., Esmenjaud, D., 2004. Management strategies for nematode control in Europe. In: Cook, R., Hunt, D.J. (Eds.), Nematology Monographs and Perspectives. Proceedings of the Fourth International Congress of Nematology, 2002. Tenerife, Spain, pp. 33-43.

Hallmann, J., M. Daub, F. Grundler, and A. Westphal. 2009. 150 Jahre Heterodera schachtii: Ein Überblick der frühen Arbeiten. [150 years Heterodera schachtii: A historical review of the early work]. Journal of Cultivated Plants 61:429-439.

Haydock, P. P. J., Woods, S. R., Grove, I. G., Hare, M. C. 2006. Chemical control of nematodes. In: Perry, R.N. and Moens, M. (Eds.), Plant nematology. CAB International, Wallingford, UK, pp. 392-410.

Heijbroek, W. 1983. Some effects of fungal parasites on the population development of the beet cyst nematode (Heterodera schachtii Schm.) Mededelingen Faculteit van de Landbouwwetenshappen Rijksuniversiteit Gent 48: 433-439.

Heinrichs, C. 2013. Der Acker lebt auch in der Tiefe. Zuckerrübenjournal 02/2013, 14-15. Jatala, P. 1986. Biological control of plant-parasitic nematodes. Ann Rev Phytopathol 24:453-489.

Kaemmerer, D., Meinecke, A., Hermann, A., Anselstetter, M., Göbel, E., Bürcky, K., Ziegler, K. and Westphal, A. 2014. Nematodenvermehrung und Ertragslesitung verschiedener Zuckerrüben-Genotypen. In: Maßnahmen zur Schadensminderung von Heterodera schachtii im Zuckerrübenbau. Bayerische Landesanstalt für Landwirtschaft. Freising-Tüntenhausen, Germany. pp. 44-54.

Kerry, B.R. 1988. Fungal parasites of cyst nematodes. Agriculture, Ecosystems and Environment 24: 293-305. 
Kerry, B. R., Crump, D. H., and Mullen, L. A. 1982. Studies of the cereal cyst-nematode, Heterodera avenae under continuous cereals, 1975-1978. II. Fungal parasitism of nematode females and eggs. Ann Appl Biol 100: 489-499.

Kerry, B.R., Crump, D.H. 1998. The dynamics of the decline of the cereal cyst nematode, Heterodera avenae, in four soils under intensive cereal production. Fund Appl Nematol 21: 617-625.

Kinkel, L. L., Bakker, M. G., \& Schlatter, D. C. 2011. A coevolutionary framework for managing disease-suppressive soils. Annu Rev Phytopathol 49: 47-67.

Kluepfel, D.A., McInnis, T.M., Zehr, E.I. 1993. Involvement of root-colonizing bacteria in peach rchard soils suppressive of the nematode Criconemella xenoplax. Phytopathology 83: 1240-1245.

Mankau, R. 1980. Biocontrol: Fungi as nematode control agents. J Nematol 12: 244-252.

Märländer, B., Hoffmann, C., Koch, H. J., Ladewig, E., Merkes, R., Petersen, J., \& Stockfisch, N. 2003. Environmental situation and yield performance of the sugar beet crop in Germany: heading for sustainable development. Journal of Agronomy and Crop Science 189: 201-226.

Mazzola, M. 2004. Assessment and management of soil microbial community structure for disease suppression. Annu Rev Phytopathol 42: 35-59.

Mazzola, M. 2007. Manipulation of rhizosphere bacterial communities to induce suppressive soils. J Nematol 39: 213-220.

McDonald, A.H. and Nicol, J.M. 2005. Nematode Parasites of Cereals. In: Luc, M., Sikora, R.A., Bridge, J. (Eds.), Plant parasitic nematodes in subtropical and tropical agriculture, $2^{\text {nd }}$ Edition. CAB International, Wallingford, UK, pp.131-191.

Menzies, J.D. 1959. Occurrence and transfer of a biological factor in soil that suppresses potato scab. Phytopathology 49: 648-52.

Mokabli, A., Valette, S., Gauthier, J. P., \& Rivoal, R. 2002. Variation in virulence of cereal cyst nematode populations from North Africa and Asia. Nematology 4: 521525 .

Morgan-Jones, G., Rodríguez-Kábana, R., 1987. Fungal biocontrol for the management of nematodes. In: Veech, J.A., Dickson, D.W. (Eds.), Vistas on Nematology. Painter Printer, Hyatt, MD, pp. 94-99. 
Mugniery, D. and Phillips, M.S. 2007. The Nematode Parasites of Potato. In: Vreugdenhil, D. (Ed.), Potato Biology and Biotechnology: Advances and Perspectives. Elsevier B. V., pp. 569-594.

Müller, J., 1992: Detection of pathotypes by assessing the virulence of Heterodera schachtii populations. Nematologica 38: 50-64.

Müller, J., 1999: The economic importance of Heterodera schachtii in Europe. Helminthologia 36: 205-213.

Nicol, J., Rivoal, R., Taylor, S. and Zaharieva, M. 2003. Global importance of cyst (Heterodera spp.) and lesion nematodes (Pratylenchus spp.) on cereals: Distribution, yield loss, use of host resistance and integration of molecular tools. Nematol Monogr Perspect 2: 1-19.

Nicol, J.M., Rivoal, R. 2008. Global knowledge and its application for the integrated control and management of nematodes on wheat. In: Ciancio, A. and Mukerji, K.G. (Eds.), Integrated management and biocontrol of vegetable and grain crops nematodes. Springer Academic Publishing, Dordrecht, The Netherlands, pp. 243287.

Oka, Y., Nacar, S., Putievsky, E., Ravid, U., Yaniv, Z., Spiegel, Y. 2000. Nematicidal activity of essential oils and their components against the root-knot nematode. Phytopathology 90: 710-715.

Riley, I. T., Nicol, J. M., \& Dababat, A. A. (Eds.) 2009. Cereal cyst nematodes: status, research and outlook. (CIMMYT: Ankara, Turkey).

Rivoal, R., Cook, R. 1993. Nematode pests of cereals. In: Evans, K., Trudgill, D.L., Webster, J.M. (Eds.), Plant parasitic nematodes in temperate agriculture, CAB International, Wallingford, UK, pp. 259-303.

Rivoal, R., Bekal, S., Valette, S., et al. 2001. Variation in reproductive capacity and virulence on different genotypes and resistance genes of Triticeae, in the cereal cyst nematode species complex. Nematology 3: 581-592.

Roberts, P.A. 2002. Concepts and Consequences of Resistance. In: Starr, J.L., Cook, R. and Bridge, J. (Eds.), Plant Resistance to Parasitic Nematodes. CAB International, Wallingford, UK, pp. 23-41. 
Roessner, J. 1987. Pilze als Antagonisten von Globodera rostocheinsis. Nematologica 33: 106-118.

Schlang, J. 1991. Anbau resistenter Zwischenfruchte zur biologischen Bekampfung des Rubenzystennematoden. Zuckerrübe 40: 476-488.

Scurrah, M. I., Niere, B., and Bridge, J. 2005. Nematode parasites of Solanum and sweet potatoes. In: Luc, M., Sikora, R. A., Bridge, J. (Eds.), Plant parasitic nematodes in subtropical and tropical agriculture. CAB International, Wallingford, UK, pp. 193220.

Shiomi Y, Nishiyama M, Onizuka T, Marumoto T. 1999. Comparison of bacterial community structures in the rhizoplane of tomato plants grown in soils suppressive and conducive toward bacterial wilt. Appl Environ Microbiol 65: 3996-4001.

Shipton PJ. 1975. Take-all decline during cereal monoculture. In: Bruehl GW (Ed). Biology and Control of Soil-Borne Plant Pathogens. Am Phytopathol Soc St. Paul, pp. 137-44.

Siddiqui, Z.A. \& Mahmood, I. 1996. Biological control of plant parasitic nematodes by fungi: A review. Bioresource Technology 58: 229-239.

Stirling, G.R. 1991. Biological control of plant-parasitic nematodes: progress problems and prospects. CAB International, Wallingford, UK, $282 \mathrm{pp}$.

Thielemann, R. \& Steudel, W. 1973. Nine years experience with monocultures of sugar beet in soil infested with Heterodera schachtii (Schmidt). Nachrichtenbl Deut Pflanzenschutzd 25: 145-149.

Timper, P., Minton, N.A., Johnson, A.W. et al. 2001. Influence of cropping systems on stem rot (Sclerotium rolfsii), Meloidogyne arenaria, and the nematode antagonist Pasteuria penetrans in peanut. Plant Dis 85: 767-772.

Van Elsas, J. D., Speksnijder, A. J., and van Overbeek, L. S. 2008. A procedure for the metagenomics exploration of disease-suppressive soils. J Microbiol Meth 75: 515522.

Weibelzahl-Fulton E, Dickson DW, Whitty EB. 1996. Suppression of Meloidogyne incognita and M. javanica by Pasteuria penetrans in field soil. J Nematol 28: 43-49. 
Weller, D. M., Raaijmakers, J. M., Gardener, B. B. M., Thomashow, L. S. 2002. Microbial populations responsible for specific soil suppressiveness to plant pathogens. Annu Rev Phytopathol 40: 309-348.

Westphal, A. 2005. Detection and description of soils with specific nematode suppressiveness. J Nematol 37: 121-130.

Westphal A, Becker JO. 1999. Biological suppression and natural population decline of Heterodera schachtii in a California field. Phytopathology 89: 434-40.

Westphal A, Becker JO. 2000. Transfer of biological soil suppressiveness against Heterodera schachtii. Phytopathology 90: 401-406.

Westphal, A. \& Xing, L.J. 2011. Soil suppressiveness against the disease complex of the soybean cyst nematode and sudden death syndrome of soybean. Phytopathology 101: 878-886.

Williamson, V.M., Hussey, R.S. 1996. Nematode pathogenesis and resistance in plants. The Plant Cell 8: 1735-1745.

Woods, S. R., Haydock, P. P. J., and Edmunds, C. 1999. Mode of action of fosthiazate used for the control of the potato cyst nematode Globodera pallida. Ann Appl Biol 135: 409-415.

Yin, B., Valinsky, L., Gao, X., Becker, J. O., and Borneman, J. 2003a. Bacterial rRNA genes associated with soil suppressiveness against the plant-parasitic nematode Heterodera schachtii. Appl Environ Microbiol 69:1573-1580.

Yin, B., Valinsky, L., Gao, X., Becker, J. O., and Borneman, J. 2003b. Identification of fungal rDNA associated with soil suppressiveness against Heterodera schachtii using oligonucleotide fingerprinting. Phytopathology 93: 1006-1013. 


\section{Chapter 1:}

\section{Population dynamics of Globodera pallida under potato monoculture}

\section{Caroline Eberlein $^{1,2}$, Holger Heuer ${ }^{3}$, Stefan Vidal $^{2}$, Andreas Westphal ${ }^{\text {* }}$}

\footnotetext{
${ }^{1}$ Julius Kühn-Institut, Institute for Plant Protection in Field Crops and Grassland, Messeweg 11/12, 38104 Braunschweig, Germany

${ }^{2}$ Department of Crop Sciences, University of Göttingen, Grisebachstrasse 6, 37077

Göttingen, Germany

${ }^{3}$ Julius Kühn-Institut, Institute for Epidemiology and Pathogen Diagnostics, Messeweg 11/12, 38104 Braunschweig, Germany

*Current address: University of California Riverside, Department of Nematology, Kearney Agricultural Research and Extension Center, 9240 S. Riverbend Ave., Parlier, CA 93648, U.S.
}

This chapter is a reprint of similar material already published in Nematropica.

Eberlein, C., H. Heuer, S. Vidal, and A. Westphal. 2016. Population dynamics of Globodera pallida under potato monoculture. Nematropica 46:114-120.

Online access: http://journals.fcla.edu/nematropica/article/view/90786 


\begin{abstract}
Globodera spp. are under strict quarantine in many countries. Quarentines can hamper international trade, restrict the exchange and transport of agricultural goods, and require comprehensive in-state regulatory efforts. Often, the development of soil suppressiveness to cyst nematodes under monoculture of susceptible hosts is observed. In this research, the development of soil suppressive to Globodera pallida was evaluated over a five-year monoculture of susceptible potato in soil infested with G. pallida $\mathrm{Pa}$. Microplots infested with cyst nematode populations "Chavornay" or "Delmsen" were continuously cropped with susceptible potato 'Selma'. Final cyst populations did not increase from 2010 to 2014. Final populations of total eggs remained similar for Delmsen but oscillated for Chavornay. This dynamic was also observed in the multiplication rate of cysts and total eggs of both nematode populations. Multiplication rates of cysts decreased by $60 \%$ for the Delmsen population. In both nematode populations, final proportions of diseased eggs increased pronounced in 2010 and oscillated until 2014, especially for Chavornay. This suggested a predator - prey relationship of the nematode and a suppressive factor. Yields of total marketable potato tubers increased in Chavornay but decreased in Delmsen. In this first report, numerical changes of cysts, diseased and healthy eggs of G. pallida under a potato monoculture were monitored. It remained unclear if organisms interfered with nematode activity, and if these could be beneficial in reducing the risk for nematode damage in potato production.
\end{abstract}

Keywords: Globodera pallida; population dynamics; potato monoculture; suppressive soil 


\section{Introduction}

Worldwide, potato (Solanum tuberosum L.) serves not only as one of the most important vegetable crops but also provides renewable raw material, e.g., for the production of starch (FAO, 2008). Potato cyst nematodes (PCN; Globodera pallida Stone and G. rostochiensis (Wollenweber) Skarbilovich strongly limit productivity of potato (Scurrah et al., 2005). This severe damage potential of Globodera spp., resulted in the classification of PCN as quarantine pests in the European Union, the Asia and Pacific Plant Protection Commission (APPPC), and the North American Plant Protection Organization (NAPPO; CABI/EPPO, 1997). Legislative control measures are in place to contain the spread of these pests (European Union, 2007). In Europe, fields must be checked for and found to be free of infestations with PCN prior to production of seed potatoes. In the presence of Globodera spp., cropping nematode-resistant cultivars of consumption potatoes may be prescribed by the local plant protection service.

Common nematode management strategies are difficult to implement. For example, crop rotations of non-hosts would need to be excessively long because of the very low decline rates of G. pallida (Evans and Haydock, 2000). A number of cover crop options are being explored, but the effectiveness of these in suppression of nematodes is unclear. The use of Solanum sisymbriifolium Lam has been demonstrated to reduce PCN in the Netherlands (Scholte 2000). More recently, brassica cover crops were found to reduce population densities by biofumigation (Ngala et al., 2015). Due to their costs, toxicology or because they have been banned from the market, only a limited number of fumigants and non-fumigant nematicides have been used commercially against Globodera spp. In Germany as of 2014, only the nematicide fosthiazate is registered in potato. It may protect yields but it does not decrease numbers of Globodera spp. during the crop cycle (Woods et al., 1999). Thus, this material does not fulfil the regulatory requirement of nematode reduction to be a permitted management strategy, and may not be used as fulfilment of the mandatory management requiremet.

In light of these limited strategies, potato production systems depend on the use of resistant cultivars. The usefulness of resistant cultivars is limited by the number of cultivars available against Globodera species and pathotypes (CABI/EPPO, 1997). The evolution of new pathotypes together with the selection of nematode populations that are 
not controlled by the frequently used $H_{1}$ gene of resistance to G. rostochiensis may result in a shift in pathotype or nematode species (Schouten and Beniers 1997; Evans and Haydock, 2000). Based on these challenges, additional management strategies are urgently needed.

PCN like other nematodes inhabit the complex environment of the soil where they are in constant interaction with potentially antagonistic microorganism found in undisturbed soils or in soils with continued cropping of susceptible hosts (Stirling, 1991; Westphal, 2005). The Current view is that monoculture of susceptible host plants of the specific nematode pest is a prerequisite for the development of suppressive soil (Gair et al., 1969). Several cyst nematode-suppressive soils have been reported (Kerry and Crump, 1998; Westphal and Becker, 1999; Westphal and Xing, 2011). In these induced suppressive soils, continuous increase of the primary parasite, the nematode, was followed by a build-up of antagonists that then reduced nematode reproduction. In cereal cyst nematode in the UK, the parasitic fungi Nematophthora gynophila and Pochonia chlamydosporium (syn. Verticillium chlamodosporium) kept the nematode below economic threshold levels (Kerry et al., 1982). In another agricultural cropping system, Brachyphoris (syn. Dactylella) oviparasitica was the key player in suppressiveness against Heterodera schachtii Schm. in California (Borneman and Becker, 2007). In comparison, limited research efforts have focused on suppressive soils against Globodera spp. (Roessner, 1987; Crump and Flynn, 1995).

The objectives of the current study were to test whether continued culture of susceptible potato leads to suppressiveness of the soil against G. pallida, and how such culture would impact the health status of the nematode. Numbers of cysts, total and diseased eggs of two populations of $G$. pallida under potato monoculture were monitored.

\section{Materials and Methods}

The experiments were conducted in microplots of $1 \mathrm{~m}^{2}$ surface area containing sandy soil (90.0\% sand, $5.4 \%$ silt, $2.4 \%$ clay, $2.2 \%$ O.M., pH 6.2). These plots had been originally infested with G. pallida $\mathrm{Pa}$, populations of two different origins: Chavornay and Delmsen, and used for different nematode management studies. For both nematode 
populations, replicate plots were available constituting two experiments (Chavornay: four replications; Delmsen: three replications). In April 2010, microplots with the Delmsen population were treated with Dazomet at $500 \mathrm{~kg} / \mathrm{ha}$ (Tetrahydro-3,5-dimethyl-1,3,5thiadiazine-2-thione; Basamid, BASF, Ludwigshafen, Germany), whereas plots with Chavornay were left non-treated. The biocide treatment was applied as previous studies had shown that such treatment rendered field soil conducive to Heterodera glycines (Xing and Westphal, 2006). Here, it was used to perturb microbial populations. Every year prior to planting, plots were fertilized with varying combinations of calcium ammonium nitrate and multi-nutrient NPK fertilizer to deliver 54 to $120 \mathrm{~kg} / \mathrm{ha} \mathrm{N}, 30,6$ to $34,9 \mathrm{Kg} / \mathrm{ha} \mathrm{P}$, and $132,8 \mathrm{Kg} / \mathrm{ha} \mathrm{K}$ in support of optimum plant growth. Sprouted tubers of potato 'Selma', susceptible to populations of G. pallida were planted to two evenly spaced parallel ridges at a total of six plants per microplot. Plants were maintained following standard regional cultivation recommendations including watering as needed and fungicide applications for suppression of potato late blight Phytophthora infestans (Mont.) de Bary. At harvest, potato tubers were dug, washed, and weighed. Fresh weights of marketable and total tubers were determined. Additionally, potato tubers were graded into diameter classes: $<30,31-35,36-55$ and $>55 \mathrm{~mm}$.

To determine initial and final population densities of G. pallida, twelve of 2-cm diameter cores of soil were collected per plot from the upper $30 \mathrm{~cm}$ prior to planting (19 days after treatment with Dazomet for Delmsen plots) and after harvest from the plot area where the root zone of the potatoes was. Subsamples of $400 \mathrm{~g}$ of soil were used for extracting cysts by density centrifugation with $\mathrm{MgSO}_{4}$ (Müller, 1980). Cysts were counted using a dissecting microscope before being crushed in a custom-made tissue grinder to release the eggs and juveniles. These were suspended in water and counted under an inverted transmitted light microscope (63 x magnification). Eggs and juveniles were classified into diseased (abnormal development or obviously colonized by microbes) or healthy (normally developed, intact $\mathrm{J} 2$ inside). Population densities of cysts and eggs were reported per $100 \mathrm{~g}$ of soil. 


\section{Data analysis}

Analyses of variance were conducted in GLIMMIX procedure of SAS (version 9.3, SAS Institute, Cary, NC, USA). Data including the independent variables nematode population and year, and the response variables related to the initial and final population densities of cysts and eggs and yield parameters were analyzed as repeated measures. Statistical significance was set at $P \leq 0.05$. Results are presented as backtransformed lsmeans \pm lsmse.

\section{Results}

In G. pallida Chavornay, final population densities of cysts slightly increased from 2012 (160.2 \pm 30.0) to 2014 (230.3 \pm 43.0; $P=0.04$; Fig. 1.1a). In Delmsen, final population of cysts decreased by $40 \%$ from 2010 to $2012(P<0.01)$, and then slightly increased from $2012(105.6 \pm 23.0)$ to $2014(177.2 \pm 38.3 ; P=0.02$; Fig. 1.1a). As a result, no significant increase was observed from 2010 to $2014(P=0.81)$. Final population densities of total eggs oscillated with large amplitudes in Chavornay, increasing 4.8-fold from 2010 to 2013 ( $P<0.01$ ), and then decreasing by 50\% from 2013 to 2014 ( $P=0.01$; Fig. 1.1b). In Delmsen, final population of total eggs did not change significantly between 2010 and 2014 (Fig. 1.1b). A pronounced unusual seasonal increase of 35.8- and 26.7-fold in the proportion of diseased eggs was observed from planting to harvest in 2010 for Chavornay and Delmsen, respectively (Fig. 1.1c). In Chavornay, cyclic oscillations were observed in final proportion of diseased eggs, which decreased from 2010 to 2011 ( $P<0.01)$, then increased to $2012(P<0.01)$, decreased again in 2013 $(P<0.01)$ and eventually increased in $2014(P=0.02$; Fig. 1.1c). In Delmsen, final proportion of diseased eggs remained similar until 2012, and then decreased until 2014 ( $P$ $<0.01$; Fig. 1.1c). The multiplication rate $\left(\mathrm{P}_{\mathrm{f}} / \mathrm{P}_{\mathrm{i}}\right)$ for cysts in Chavornay declined from $2011(1.5 \pm 0.2)$ to $2012(1.1 \pm 0.2 ; P=0.05)$, thereafter remained similar until 2014. In Delmsen, the multiplication rate of cysts decreased from $2010(2.6 \pm 0.4)$ to $2014(1.1 \pm$ $0.2 ; P<0.01)$. The multiplication rate $\left(\mathrm{P}_{\mathrm{f}} / \mathrm{P}_{\mathrm{i}}\right)$ of total eggs in Chavornay oscillated in a cyclic manner during the evaluated period. It increased from $2010(0.5 \pm 0.2)$ to 2011 (4.6 $\pm 0.7 ; P<0.01)$, then decreased to $2012(1.1 \pm 0.2 ; P<0.01)$, increased again in 2013 
(5.2 $\pm 0.7 ; P<0.01)$, and eventually decreased in $2014(0.7 \pm 0.2 ; P<0.01)$. For Delmsen, multiplication rate of total eggs increased from $2010(1.0 \pm 0.3)$ to $2011(2.7 \pm 0.5 ; P<$ $0.01)$, and then declined to $2014(0.9 \pm 0.3 ; P<0.01)$. A positive correlation between initial densities of healthy eggs and final densities of diseased eggs was found for Chavornay ( $r=0.46, P=0.04$ ), whereas a positive correlation between final densities of diseased eggs and final densities of total eggs was found for Delmsen $(r=0.73, P<0.01$; data not shown).

Fresh weight of total marketable potato tubers per plant in Chavornay increased 2.7-fold from 2010 to $2013(P=0.02)$ and then remained similar until 2014 (Fig. 1.2). In Delmsen, total marketable potato tubers per plant decreased by $80 \%$ from 2010 to 2014 $(P<0.01$; Fig. 1.2). In Chavornay, fresh weight of potato tubers per plant $<30 \mathrm{~mm}$ size increased 3.1-fold from 2010 to 2014 ( $P<0.01$; Fig. 1.3a). In Delmsen, this tuber category increased 3.0-fold from 2010 to $2013(P<0.01)$ and then decreased by 60\% from 2013 to 2014 ( $P=0.04$; Fig. 1.3b). Potato tuber yield per plant $31-35 \mathrm{~mm}$ in Chavornay significantly increased 3.5-fold from 2010 to $2013(P=0.02)$, but decreased by $60 \%$ from 2013 to $2014(P=0.05$; Fig. 1.3a). In Delmsen, this tuber category remained similar between 2010 and 2013 and decreased 70\% from 2013 to $2014(P=$ 0.04; Fig. 1.3b). Yield per plant 36-55 mm did not change significantly in Chavornay and Delmsen (Fig. 1.3a,b). Yield per plant >55 mm was only obtained in 2012 in one replicate of Chavornay (1.7 \pm 1.0$)$, and only registered in 2010 in Delmsen (172.8 \pm 73.1 ; Fig. 1.3b).

\section{Discussion}

Under this five-year monoculture of susceptible potato, G. pallida egg populations became diseased and egg numbers oscillated in a cyclic manner. This suggested density-dependent regulation of nematodes and their antagonists. There was no pronounced and continuous decline of the population densities of G. pallida, as had been observed in some other suppressive soil systems but many members of the nematode population became diseased. Full expression of suppressiveness may take longer to fully develop than was monitored in the current project. 
A large increase in numbers of diseased eggs, especially in Delmsen population was observed in 2010 and also in 2012. Diseased eggs exhibited fungal hyphae or physiologically disordered content. Diseased eggs of unknown etiology were described by Tribe (1977) as oily degenerated, lysed, shriveled, coagulated, or decayed. Bursnall and Tribe (1974), Morgan-Jones et al. (1981) and Dackman (1990) who also found high proportions of these eggs, proposed that this disorder was caused by fungal metabolites or depletion of oxygen by fungi growing in the cyst, or even viral infections.

Fluctuations showing a cyclic behavior, with increases followed by decreases were also reported by Heijbroek (1983) in long-term observations of $H$. schachtii population densities under a sugar beet monoculture. This population dynamics may indicate a density-dependent predator (parasite) - prey (host) interaction (Lotka, 1925; Volterra, 1926) where a stabilizing effect should be expected, as antagonists destroy an increasing proportion of the prey (host) population as their abundance increases. However, the pronounced increase of healthy eggs in 2013 for Chavornay, exceeded the amplitude of previous fluctuations. This observation differs from those by Heijbroek (1983) who detected oscillations not significantly different from the tolerance limit that never reached the initial maximum density. As in most natural populations, these oscillations may be shaped by a combined action of density-dependent, densityproportional and density-independent forces. Large oscillations occur where densitydependent actions are ineffective (Odum, 1954) but in contrast the predominance of density-dependent factors should lead to stability. We speculate that the experiment did not cover a sufficiently long period allowing a final decline of the nematode populations under this potato monoculture. Population densities can be maintained at equilibrium levels for several years, as has been seen under different monocultures of cysts nematodes (Gair et al., 1969; Thielemann and Steudel, 1973; Heijbroek, 1983; Westphal and Becker, 1999; Noel and Wax, 2003). In these studies, the number of cropping periods necessary for the decline of cyst nematode populations ranged from three to several more years (Gair et al., 1969; Thielemann and Steudel, 1973; Kerry et al., 1982; Heijbroek, 1983; Westphal and Becker, 1999). Perhaps the number of generations that a nematode completes during one growing season is more important than the number of years for the population density decline. For example, nematodes like $H$. schachtii or H. glycines that 
complete more than one generation per year (Thomason and Fife, 1962) may decline quicker than nematodes that have a single generation per growing period. The biocidal pre-plant treatment that was aimed at perturbing soil microbial communities did not seem to impact the development of high levels of diseased eggs.

When comparing with other long-term experiments with G. rostochiensis under susceptible potato monocultures, the increase of our populations (eggs $\mathrm{g}^{-1}$ soil) from the first to the fourth year; 4.1-fold for Chavornay and 1.4-fold for Delmsen (first to fifth year: Chavornay: 2.2-fold; Delmsen: 1.3-fold) are similar to the increases found by Jones and Parrot (1969) in the UK (first to fourth year: 1.9-fold; first to fifth year: 1.3-fold), and below increases found by Zawiślak et al. (1989) in Poland (first to fourth year: 245-fold; first to fifth year: 1000-fold) and by Tiilikkala (1991) in Finland (first to fourth year: 2650-fold; second-stage juveniles $\mathrm{g}^{-1}$ soil). Interestingly, in the monocultures of Tiillikala (1991) and Jones and Parrot (1969), the densities decreased after the fourth year, with fluctuations becoming smaller with repeated cropping, tending to an equilibrium at which an intermediate root size was balanced by an intermediate population density (Jones and Parrot, 1969).

Findings of this study present base line data for the dynamics of G. pallida under monoculture conditions. The monoculture did not lead to a severe and persistent decline as reported for other cyst nematode-suppressive soils. However, many members of the nematode population became diseased and a decline of the overall damage caused by this parasite was surmised. In a companion study, the microbial colonization of the cysts was further examined (Eberlein et al., 2016).

\section{Acknowledgments}

The authors wish to thank Conicyt for financial support of the first author. Partial support was obtained by the Norwegian Research Council, together with the Foundation for Research Levy on Agricultural Products, the Agricultural Agreement Research Fund, and the Norwegian Food Safety Authority. The support of the Weed Science group and the Institute for Epidemiology and Pathogen Diagnostics of Julius Kühn-Institut during the conduct of this study is appreciated. The technical support by J. Banyari, T. Bloethe- 
Hartmann, C. Blümcke, H. Grosse-Lengerich, F. Lange and A. Windt is greatly appreciated. Discussions with J.O. Becker, B. Niere and K. Smalla are appreciated. The experimental portion of this project was conducted during employment of A. Westphal in the Institute of Plant Protection in Field Crops and Grassland of the Julius Kühn-Institut.

\section{References}

Borneman, J., and J. O. Becker. 2007. Identifying Microorganisms Involved in Specific Pathogen Suppression in Soil. Annual Review of Phytopathology 45:153-172.

Bursnall, L. A., and H. T. Tribe. 1974. Fungal parasitism in cysts of Heterodera II. Egg parasites of H.schachtii. Transactions of the British Mycological Society 62:595-601.

CABI/EPPO. 1997. Data sheets on quarantine organisms: Globodera rostochiensis and Globodera pallida. Pp. 601-606 in I. M. Smith, D. G. McNamara, P. R. Scott, M. Holderness, and B. Burger, Eds. Quarantine Pests for Europe. CAB International, Wallingford, UK.

Crump, D. H., and C. A. Flynn. 1995. Isolation and screening of fungi for biological control of potato cyst nematodes. Nematologica 41:628-638.

Dackman, C. 1990. Fungal parasites of the potato cyst nematode Globodera rostochiensis: isolation and reinfection. Journal of Nematology 22:594-597.

Eberlein, C., H. Heuer, S. Vidal, and A. Westphal. 2016. Microbial communities in Globodera pallida females raised in potato monoculture soil. Phytopathology 106:581-590.

European Union. 2007. Council Directive 2007/33/EC of 11 June 2007 on the control of potato cyst nematodes and repealing Directive 69/465/EEC. Official Journal of the European Union L 156:12-22.

Evans, K., and P. P. J. Haydock. 2000. Potato cyst nematode management - present and future. Aspects of Applied Biology 59:91-97.

FAO. 2008. International Year of the Potato. Food and Agriculture Organization of the United Nations (FAO). Online. http://www.fao.org/potato-2008 (accessed 12.05.2014). 
Gair, R., P. L. Mathias, and P. N. Harvey. 1969. Studies of cereal nematode populations and cereal yields under continuous or intensive culture. Annals of Applied Biology 63:503-512.

Heijbroek, W. 1983. Some effects of fungal parasites on the population development of the beet cyst nematode (Heterodera schachtii Schm.) Mededelingen Faculteit van de Landbouwwetenshappen Rijksuniversiteit Gent 48:433-439.

Jones, F. G. W., and D. M. Parrott. 1969. Population fluctuations of Heterodera rostochiensis Woll. when susceptible potato varieties are grown continuously. Annals of Applied Biology 63:175-181.

Kerry, B. R., D. H. CRuMP, and L. A. Mullen. 1982. Studies of the cereal cyst-nematode, Heterodera avenae under continuous cereals, 1975-1978. II. Fungal parasitism of nematode females and eggs. Annals of Applied Biology 100:489-499.

Kerry, B. R., and D. H. Crump. 1998. The dynamics of the decline of the cereal cyst nematode, Heterodera avenae, in four soils under intensive cereal production. Fundamental and Applied Nematology 21:617-625.

Lotka, A. J. 1925. Elements of Physical Biology. Williams \& Wilkins, Baltimore, US.

Morgan-Jones, G., B. O. Gintis, and R. Rodriguez-Kabana. 1981. Fungal colonization of Heterodera glycines cysts in Arkansas, Florida, Mississippi and Missouri soils. Nematropica 11:155-163.

Müller, J. 1980. Ein verbessertes Extraktionsverfahren für Heterodera schachtii. [An improved method for the extraction of Heterodera schachtii.] Nachrichtenblatt des Deutschen Pflanzenschutzdienstes 32:21-24.

Ngala, B. M., P. P. J. Haydock, S. Woods, and M. A. Back. 2015. Biofumigation with Brassica juncea, Raphanus sativus, and Eruca sativa for the management of field populations of the potato cyst nematode Globodera pallida. Pest Management Science 71:759-769. Online DOI:10.1002/ps.3849

Noel, G. R., and L. M. Wax. 2003. Population dynamics of Heterodera glycines in conventional tillage and no-tillage soybean/corn cropping systems. Journal of Nematology 35:104-109.

Odum, E. P. 1954. Fundamentals of Ecology. W. B. Saunders Company, Philadelphia, US. 
Roessner, J. 1987. Pilze als Antagonisten von Globodera rostochiensis. Nematologica 33:106-118.

Scholte, K. 2000. Screening of non-tuber bearing Solanaceae for resistance and induction of juvenile hatch of potato cyst nematodes and their potential for trap cropping. Annals of Applied Biology 136:239-246.

Schouten, H. J. and J. E. Beniers. 1997. Durability of resistance to Globodera pallida I. Changes in pathogenicity, virulence, and aggressiveness during reproduction on partially resistant potato cultivars. Phytopathology 87:862-867.

Scurrah, M. I., B. Niere, and J. Bridge. 2005. Nematode parasites of Solanum and sweet potatoes. Pp. 193-220 in M. Luc, R.A. Sikora, J. Bridge, Eds. Plant Parasitic Nematodes in Subtropical and Tropical Agriculture. CAB International, Wallingford, UK.

Stirling, G. R. 1991. Biological control of plant-parasitic nematodes: progress problems and prospects. CAB International, Wallingford, UK. $282 \mathrm{pp}$.

Thielemann, R. and W. Steudel. 1973. Nine years experience with monocultures of sugar beet in soil infested with Heterodera schachtii (Schmidt). Nachrichtenblatt des Deutschen Pflanzenschutzdienstes 25:145-149.

Thomason, I. J. and D. Fife. 1962. The effect of temperature on development and survival of Heterodera schachtii Schm. Nematologica 7:139-145.

Tilikkala, K. 1991. Effect of crop rotation on Globodera rostochiensis and on potato yield. EPPO Bull. 21:41-47.

Tribe, H. T. 1977. Pathology of cyst-nematodes. Biolological Reviews 52:477-507.

Volterra, V. 1926. Variazione e fluttuazini del numero d'individui in specie animali conviventi. Memmorie dell’Accademia Nazionale dei Lincei 2:31-113.

Westphal, A. 2005. Detection and description of soils with specific nematode suppressiveness. Journal of Nematology 37:121-130.

Westphal, A., and J. O. Becker. 1999. Biological suppression and natural population decline of Heterodera schachtii in a California field. Phytopathology 89:434-440.

Westphal, A., and L.J. Xing. 2011. Soil suppressiveness against the disease complex of the soybean cyst nematode and sudden death syndrome of soybean. Phytopathology 101:878-886. 
Woods, S. R., P. P. J. Haydock, and C. Edmunds. 1999. Mode of action of fosthiazate used for the control of the potato cyst nematode Globodera pallida. Annals of Applied Biology 135:409-415.

Xing, L. J. and A. Westphal. 2006. Transferring soil suppressiveness against Heterodera glycines under field conditions. Journal of Nematology 38:302 (abstract).

Zawislak, K., J. Tyburski, and B. Rychik. 1989. Significance of crop rotation and cultivars resistant to potato cyst nematode on potato production. Pp. 111-119 in J. Vos, C. D. Van Loon, and G. J. Bollen, Eds. Effects of Crop Rotation on Potato Production in the Temperate Zones. Springer, The Netherlands. 


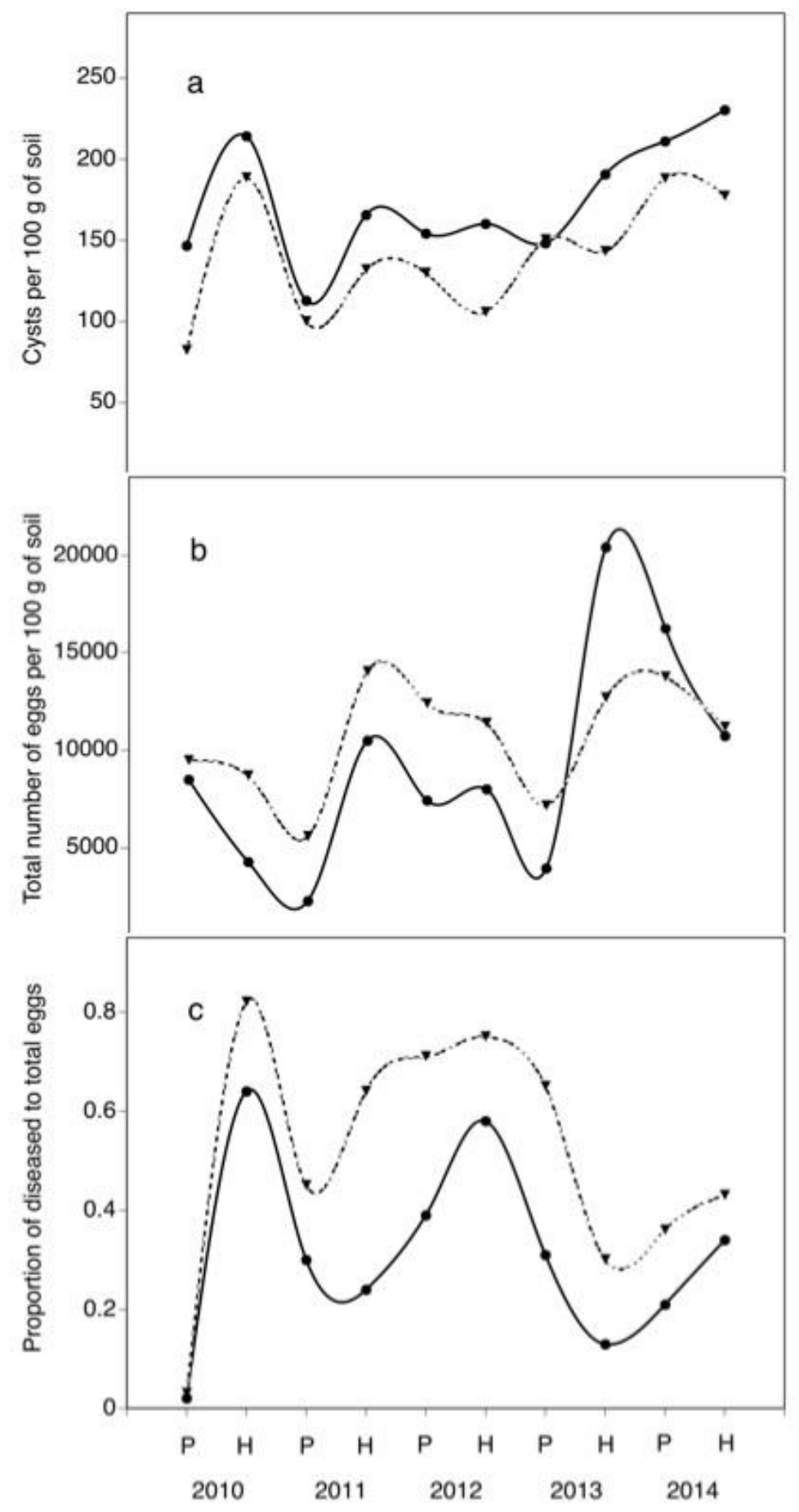

Fig. 1.1 Population densities of Globodera pallida Chavornay ( $)$ and Delmsen ( $\boldsymbol{\nabla})$ on susceptible potato 'Selma' in monoculture (a) number of cysts, (b) number of total eggs, and (c) proportion of diseased eggs of total eggs. Population densities determined at planting $(\mathrm{P})$ and harvest $(\mathrm{H})$ each year. Chavornay: 4 replicates; Delmsen: 3 replicates. 


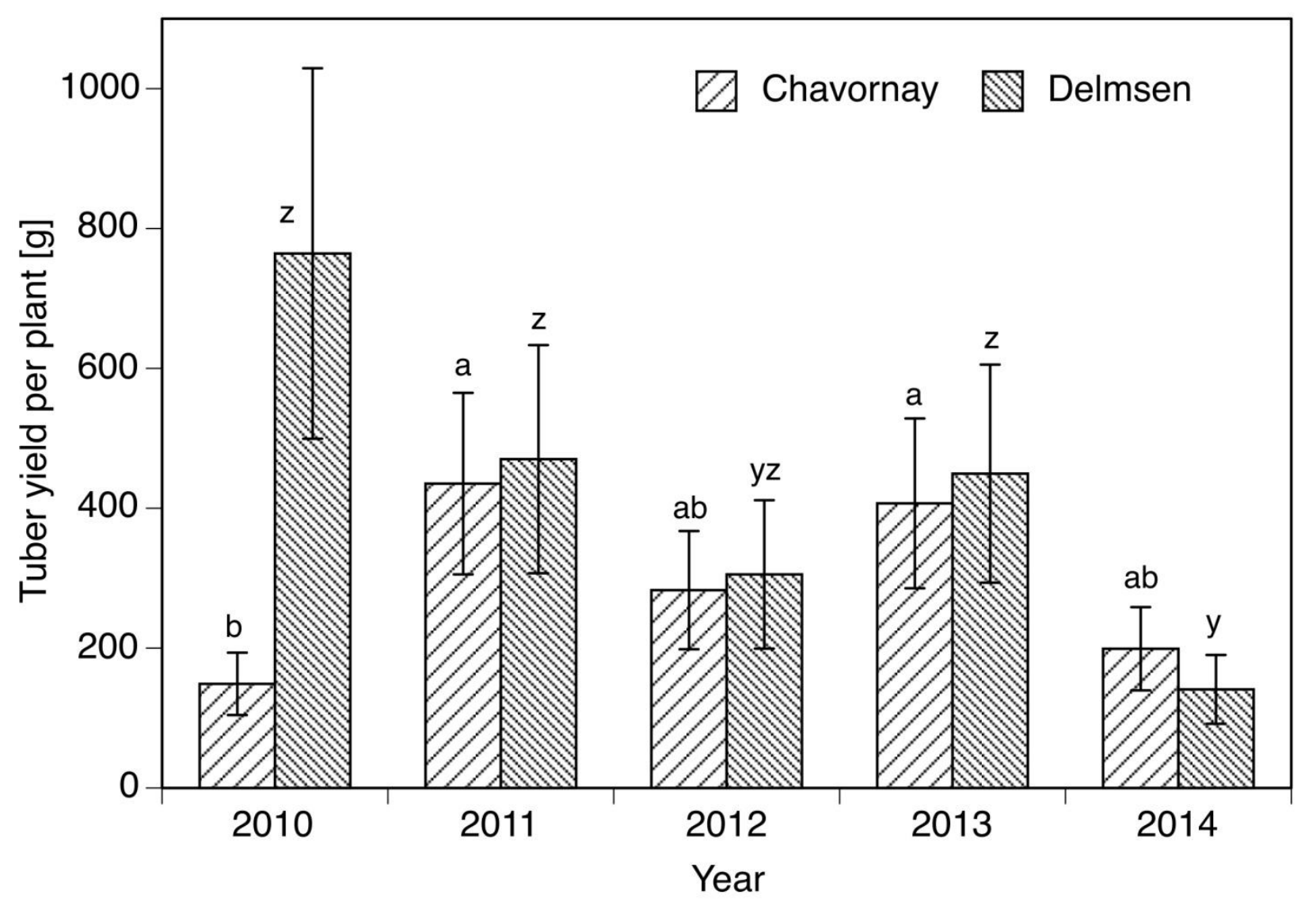

Fig. 1.2 Tuber yield of potato 'Selma' in monoculture plots infested with Globodera pallida Pa3 populations Chavornay or Delmsen (lsmeans \pm lsmse) in years 2010 to 2014 . Bars indexed with the same letter were not significantly different at $P=0.05$; Chavornay: a,b; Delmsen: z,y. 


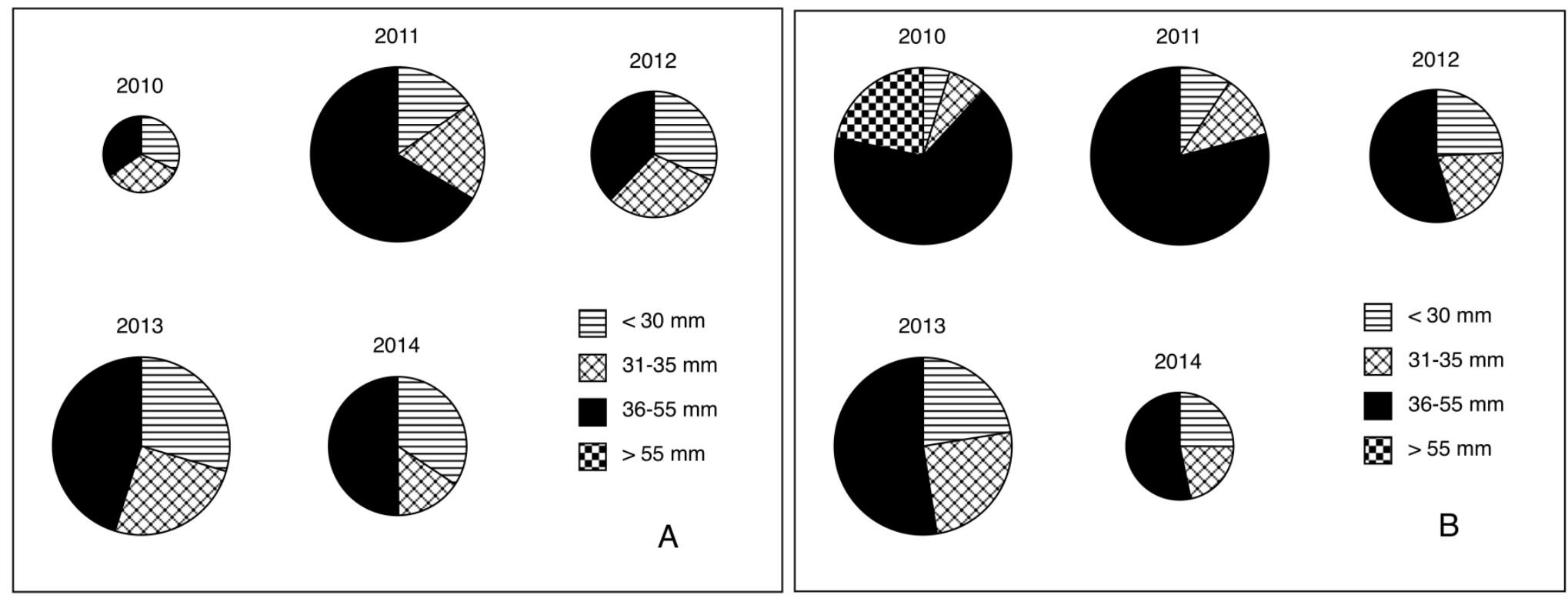

Fig. 1.3 Relative proportions of potato tuber size classes in Globodera pallida Pa3 infested plots of nematode populations (A) Chavornay and (B) Delmsen in years 2010 to 2014. 


\title{
Chapter 2:
}

\section{Microbial communities in Globodera pallida in females raised in potato monoculture soil}

\author{
Caroline Eberlein $^{1,2}$, Holger Heuer ${ }^{3}$, Stefan Vidal $^{2}$, Andreas Westphal ${ }^{*}$
}

${ }^{1}$ Julius Kühn-Institut, Federal Reasearch Centre for Cultivated Plants, Institute for Plant

Protection in Field Crops and Grassland, Messeweg 11/12, 38104 Braunschweig, Germany

${ }^{2}$ Department of Crop Sciences, University of Göttingen, Grisebachstrasse 6, 37077 Göttingen, Germany

${ }^{3}$ Julius Kühn-Institut, Institute for Epidemiology and Pathogen Diagnostics, Messeweg 11/12, 38104 Braunschweig, Germany

*Current address: University of California Riverside, Department of Nematology, Kearney

Agricultural Research and Extension Center, 9240 S. Riverbend Ave., Parlier, CA 93648, U.S.

This chapter is a reprint of similar material already published in Phytopathology.

Eberlein, C., Heuer, H., Vidal, S. and Westphal, A. 2015. Microbial communities in Globodera pallida females raised in potato monoculture soil. Phytopathology 106: 581-590.

Online access: http://apsjournals.apsnet.org/doi/pdf/10.1094/PHYTO-07-15-0180-R 


\section{Abstract}

PCN are under strict quarantine in many countries. Suppressiveness to cyst nematodes can evolve under monoculture of susceptible hosts. Females developing in potato monoculture soil infested with G. pallida populations Chavornay or Delmsen, were examined for inherent microbial communities. In the greenhouse, non-heated and heat-treated $\left(134{ }^{\circ} \mathrm{C}\right.$ for $10 \mathrm{~min}$.) portions of this soil were placed in root observation chambers, planted to Solanum tuberosum 'Selma', and inoculated with G. pallida Pa3 Chavornay. At harvest in Delmsen soil, cysts had fewer eggs in non-heated than heat-treated soil. In denaturing gradient gel electrophoresis (DGGE) analysis, bacterial and fungal fingerprints were characterized by a high variability between replicates; non-heated soils displayed more dominant bands than heated soils indicating more bacterial and fungal populations. In amplicon pyrosequencing, females from non-heated portions frequently contained ITS sequences of the fungus Malassezia. Specific for the Chavornay and Delmsen population, ribosomal sequences of the bacteria Burkolderia and Ralstonia were abundant on eggs. In this report of microbial communities in G. pallida raised in potato monoculture, candidate microorganisms perhaps associated with the health status of the eggs of G. pallida were identified. If pathologies on cyst nematodes can be ascertained, these organisms could improve the sustainability of production systems.

Keywords: Globodera pallida; potato monoculture; suppressive soil; microbial communities; DGGE; pyrosequencing 


\section{Introduction}

Potato (Solanum tuberosum L.) is one of the most consumed vegetable crops worldwide, and also serves as an important source of biological renewable raw material, e.g., starch (FAO, 2008). Of the factors that constrain the production of potatoes, nematodes, especially the potato cyst nematodes (PCN) Globodera pallida Stone and G. rostochiensis (Wollenweber) Skarbilovich, are among the most important limiting pests (Scurrah et al., 2005). The severe yield reduction potential of Globodera spp. has resulted in classification of PCN as quarantine pests within the European Union, for member countries of the Asia and Pacific Plant Protection Commission (APPPC), and the North American Plant Protection Organization (NAPPO; CABI/EPPO, 1997). In North America, after detected in 1941 on Long Island, New York, G. rostochiensis was subjected to strict quarantine regulations under the Golden Nematode Act. In 2006, G. pallida was discovered in northern Bingham County, Idaho. Currently, G. rostochiensis and G. pallida are of limited distribution in New York and Idaho states, respectively, and under official control (USDA/APHIS, 2015). In Europe, legislative control measures aim at preventing further spread and multiplication to damaging levels (European Union, 2007). Consequently, all fields scheduled for production of seed potatoes must be inspected and found to be free of infestations with Globodera spp. before the crop may be grown. If any of these nematodes are found, seed potato production is prohibited, and management options are put in place that aim at reducing population densities of the nematode. For example, cropping of consumption potatoes with resistance to the specific Globodera spp. can be prescribed by the local plant protection service.

Currently, few alternatives other than the use of resistant cultivars are available for the management of these nematodes. Effectiveness of crop rotation is limited, particularly for $G$. pallida, due to the slow decline of populations in the absence of a host crop (Evans and Haydock, 2000), resulting in the mandating of long and impractical rotations. The use of trap crops like Solanum sisymbriifolium Lam. has been successful to reduce PCN in the Netherlands (Scholte 2000) but implementation remains slow because of undesirable thorns on the plants, such as slow growth, and the risk that this plant produces seeds that could germinate within potato crops where weeds of Solanum spp. are difficult to control. Use of brassica cover crops seems promising but is still in experimental stages (Ngala et al., 2015). When available and cost 
effective, fumigant nematicides such as 1,3-dichloropropene or methyl bromide were used for PCN control. Currently, fumigant nematicides are generally banned in Europe. In developed countries, methyl bromide is banned since 2005 except for some highly restricted critical uses. Non-fumigant granular nematicides, e.g., fosthiazate, can reduce yield loss but do not suppress nematode population densities throughout the growing season (Woods et al., 1999). Nematode population density reduction is a mandatory regulatory requirement for prescribed management strategies, and thus nematostatic, non-fumigant nematicides may not be used. As a result, potato production systems rely heavily on resistant cultivars. The utility of resistant cultivars is widely recognized but there is a lack of sufficient cultivars against some pathotypes of PCN, especially for G. pallida (CABI/EPPO, 1997). The use of resistant cultivars also exerts a selection pressure. For example in Europe, the use of resistant cultivars that incorporate the $H_{l}$ gene resistance to $G$. rostochiensis facilitate the increase of $G$. pallida from previously mixed populations, shifting predominance to the species that is not suppressed by the potato cultivar (Evans and Haydock, 2000). A shift in nematode virulence could also occur, where the evolution of a new pathotype on a previously effective nematode resistance gene in potato threatens the sustainability of resistance as a management strategy (Schouten and Beniers 1997). Overcoming these risks of current management strategies demands alternative methods for growing potato in infested PCN fields.

PCN live in a microbiologically complex soil environment. Equilibrium of plant-parasitic nematode population density and antagonistic microorganisms is hypothetically found in undisturbed soils or in soils with continued cropping of a susceptible host (Stirling, 1991; Westphal, 2005). Since the discovery of soils suppressive to Heterodera avenae Woll. in the UK, monoculture of susceptible host plants of the specific nematode pest is viewed as a prerequisite for the evolution of suppressive soil (Gair et al., 1969). Several examples of suppressive soils have been reported for cyst nematodes (Kerry and Crump, 1998; Westphal and Becker, 1999; Westphal and Xing, 2011). In most of these soils, the reproduction of plant-parasitic nematodes was constrained by the activity of antagonistic microorganisms. In the specific case of the cereal cyst nematode, suppressiveness was caused by Nematophthora gynophila and Pochonia chlamydosporium, two parasitic fungi that rendered this nematode a non-problem in years of suitable soil moisture conditions in the UK (Kerry et al., 1982). In soils with Heterodera schachtii Schm. in California, Brachyphoris (syn. Dactylella) oviparasitica was identified as the 
key player in suppressiveness (Borneman and Becker, 2007). Research on potential suppressive soils against Globodera spp. has received limited attention (Roessner, 1987; Crump and Flynn, 1995).

The objective of this study was to test whether an unusually high number of diseased $G$. pallida eggs found under potato monoculture (Eberlein et al., 2016) was associated with specific microbial communities in the eggs of G. pallida raised in this monoculture soil. The microbial communities present within the eggs of females developing in this monoculture soil were characterized using cultivation-independent techniques.

\section{Materials and Methods}

Development of Globodera pallida females in root observation chambers. Soils from a potato monoculture at the Julius Kühn-Institut at Münster were collected from a microplot study, where potatoes 'Selma' were grown from 2009 until 2014 in plots filled with sandy soil (90.0\% sand, $5.4 \%$ silt, $2.4 \%$ clay, 2.2\% O.M., pH 6.2) infested with G. pallida populations (1) Chavornay or (2) Delmsen. In this monoculture, microbial communities in the Delmsen plots had been perturbed with the application of dazomet at $500 \mathrm{~kg} / \mathrm{ha}$ in April of 2010 (Tetrahydro-3,5dimethyl-1,3,5-thiadiazine-2-thione; Basamid, BASF, Ludwigshafen, Germany) (C. Eberlein, unpublished). The nematode populations are both classified as $\mathrm{Pa} 3$ but the Chavornay population is generally viewed as more aggressive than the Delmsen population. Two independent greenhouse experiments were set up in a randomized complete block design with five replications, with a factorial arrangement of soil infestation (1) or (2), and two treatments: (i) non-heated, and (ii) steam heat-treated at $134{ }^{\circ} \mathrm{C}$ for $10 \mathrm{~min}$ in an autoclave. The heating was done to perturb microbial communities possibly associated with diseased eggs detected in this monoculture soil (Westphal, 2005). For the first of these experiments, soil samples were collected during the fall of 2011, from microplots of both G. pallida populations at a depth of 30 $\mathrm{cm}$. For the replication of this experiment soil samples from the same microplots were collected in spring 2014. In the second run of the experiment, a loam soil $(50.3 \%$ sand, $30.2 \%$ silt, $9.5 \%$ clay, 1.42\% O.M., pH 6.6) with no potato crop history was included as a control.

At initiation of the respective experiments, soils were separated into two portions, one was left non-heated, and the other steam heat-treated. Both portions were then placed in separate 
root observation chambers with a $18 \mathrm{~cm} \times 13 \mathrm{~cm}$ transparent side and $6 \mathrm{~cm}$ depth. Each chamber was inoculated with cysts of G. pallida $\mathrm{Pa} 3$ population Chavornay obtained fom pure culture at the equivalent of 12,000 eggs per box, and planted with a sprouted seed piece of potato 'Selma'. The cysts were placed in the soil at the site were the piece of potato was planted. The boxes were leaned at a 45-degree angle with the transparent side down, so roots grew preferentially against this side to allow for observation of the root system and developing females. The experiments were maintained under ambient light with day and night averaged temperatures of $23^{\circ}$ and $22{ }^{\circ} \mathrm{C}$ (first experiment) and $25^{\circ}$ and $23^{\circ} \mathrm{C}$ (second experiment), in a temperature controlled greenhouse. The chambers were watered daily with tap water and fertilized with nutrient solution (NPK: 5.3\% N, 3.9\% P, 19.7\% K; Steiner, 1968) as needed once a week. Starting at 36 and 35 days post inoculation (dpi), in the first and second experiment, respectively, females visible on the root surface were counted weekly. At 64 dpi and 91 dpi in the first and second experiment, respectively, ten individual females were hand-picked from the root system of each box, washed with sterile water and stored at $-20{ }^{\circ} \mathrm{C}$ for microbial community analysis. At the termination of the first experiment (101 dpi) and second experiment (91 dpi), females and cysts hand-picked from the roots were used for examination of the egg contents. The visible root length per root box was determined using the line intersection method (Tennant, 1975) at 86 dpi and 77 dpi in the first and second experiment, respectively.

Examination of the egg content of females and cysts. Females and cysts picked from the root system at $101 \mathrm{dpi}$ and $91 \mathrm{dpi}$ in the first and second experiment, respectively, were thoroughly washed with sterile water and divided into two groups for different examinations. Females and cysts belonging to the first group were crushed to release eggs and second-stage juveniles (J2) that were spread onto water agar (5\%) amended with the antibiotic rifampicin (100 $\mathrm{mg} / \mathrm{kg}$ ) in $9-\mathrm{cm}$ diameter petri plates. After three days of incubation at room temperature, eggs and $\mathrm{J} 2$ with visible fungal infestation were counted and numbers expressed as percentages of the total number of eggs and J2 observed. Females and cysts of the second group were also crushed, and the obtained egg suspensions were examined and categorized into healthy (normally developed, intact J2 inside; Fig. 2.1A) or diseased (abnormal development or obviously colonized by microbes; Fig. 2.1B) under an inverted transmitted light microscope (63x 
magnification). Percentages of diseased or healthy eggs and $\mathrm{J} 2$ of the total number of eggs and $\mathrm{J} 2$ examined were calculated.

DNA extraction and PCR amplification of bacterial 16S rRNA gene and fungal ITS fragments from G. pallida females. Genomic microbial DNA from the egg content of ten females per root chamber was extracted with the FastDNA SPIN Kit for Soil by using the FastPrep-24 bead beating system (MP Biomedicals, Santa Ana, CA, USA) according to manufacturer recommendations. Extracted DNA was checked by electrophoresis (80 V, $45 \mathrm{~min}$ ) on a $0.8 \%$ agarose gel followed by ethidium bromide staining, and viewing under UV light. DNA was stored at $-20{ }^{\circ} \mathrm{C}$ until further use.

The bacterial specific primers F984GC and R1378-1401 were used for amplification of 16S rRNA gene fragments (Heuer et al., 1997). PCR reactions were performed in $25 \mu 1$ reaction volumes, containing $5 \mu \mathrm{l} 5 \mathrm{x}$ GoTaq buffer, $2.5 \mu \mathrm{l} 2 \mathrm{mM}$ dNTPs, $3.75 \mu 125 \mathrm{mM} \mathrm{MgCl}, 2 \mu 150 \%$ (w/v) acetamide, $0.5 \mu 110 \mu \mathrm{M}$ of each primer, $0.125 \mu \mathrm{l} \mathrm{GoTaq}$ polymerase $5 \mathrm{U} / \mu \mathrm{l}$ (Promega, Madison, Wisconsin, USA), $9.625 \mu \mathrm{l}$ distilled water and $1 \mu$ l template DNA. After 5 min of denaturation at $94{ }^{\circ} \mathrm{C}, 35$ thermal cycles including $1 \mathrm{~min}$ at $94{ }^{\circ} \mathrm{C}, 1 \mathrm{~min}$ at $53{ }^{\circ} \mathrm{C}$ and $2 \mathrm{~min}$ at $72{ }^{\circ} \mathrm{C}$ were performed, followed by a final extension at $72{ }^{\circ} \mathrm{C}$ for $10 \mathrm{~min}$. Positive amplification was confirmed by electrophoresis on $1 \%$ agarose gels with ethidium bromide staining.

The fungal internal transcribed spacer (ITS) fragments were amplified using a nested PCR with primer pairs ITS1F/ITS4 and ITS1FGC/ITS2 according to the PCR conditions described by Weinert et al. (2009) with slight modifications. Aliquots of $2 \mu \mathrm{l}$ of the first stage PCR products were used as template for the subsequent PCR. Amplicons were analysed by $1 \%$ agarose gel electrophoresis, ethidium bromide staining and UV light.

DGGE analysis of the amplified bacterial and fungal amplicons from G. pallida females. Denaturing gradient gel electrophoresis (DGGE; Muyzer et al., 1993) was used to assess the composition of the dominant bacterial and fungal communities present in the eggs recovered from the extracted females. PCR products were separated by DGGE based on the protocol of Weinert et al. (2009). Briefly, polyacrylamide gels with denaturing gradients of 46.5 to $65 \%$ and 23 to $58 \%$ ( $100 \%$ denaturant is defined as $7 \mathrm{M}$ urea and $40 \%$ de-ionized formamide) were used for 16S rRNA and ITS fragments of bacteria and fungi, respectively. Electrophoresis was 
performed using the IngenyphorU system (Ingeny, Goes, The Netherlands). The volume of PCR products loaded on the gel was adjusted according to the amplicon concentration as assessed by agarose gel electrophoresis ( 3 to $10 \mu \mathrm{l}$ ). The electrophoresis was run in $1 \mathrm{x}$ tris-acetate-EDTA buffer for $17 \mathrm{~h}$ at $58{ }^{\circ} \mathrm{C}$ and $140 \mathrm{~V}$ for PCR-amplified 16S rRNA gene fragments, and for $18 \mathrm{~h}$ at $60{ }^{\circ} \mathrm{C}$ and $100 \mathrm{~V}$ for ITS fragments. The gels were silver stained (Heuer et al., 2001), dried at room temperature and scanned with a digital flat bed scanner.

Cluster analysis of bacterial and fungal community profiles was conducted with the software package GelCompar II 6.5 (Applied Maths, Gent, Belgium) to evaluate the percentage of similarity shared among samples. Lanes were normalized and similarities for each pair of lanes within a gel were determined using Pearson's correlation. A cluster analysis was performed by the un-weighted pair group method using arithmetic averages (UPGMA).

The bacterial and fungal fingerprints of non-heated and heat-treated soil from the experiment consisting of Chavornay and Delmsen microplots soils and those of inoculum cysts were compared. This was done to test whether the microorganisms in the females that developed in the non-heated and the heat-treated soils were acquired from the soil environment rather than being transmitted from the cyst inoculum.

Pyrosequencing and sequence analysis of DNA from G. pallida females raised in nonheated potato monoculture soil. In preparation of the pyrosequencing process, bacterial 16S rRNA gene fragments were amplified in $25 \mu 1$ of PCR mixtures of $2.5 \mu 1$ TrueStart buffer, 3.75 $\mu 125 \mathrm{mM} \mathrm{MgCl}_{2}, 2.5 \mu \mathrm{l} 2 \mathrm{mM}$ dNTPs, $1.25 \mu \mathrm{l}$ DMSO, $0.75 \mu 1$ 10 $\mu \mathrm{M}$ primers $356 \mathrm{~F}$ and 1064R,

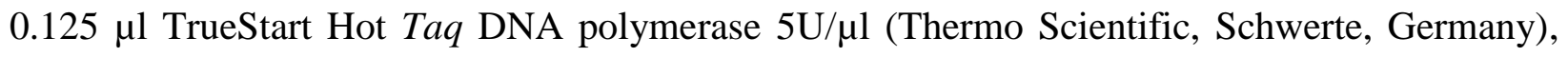
$10.37 \mu 1$ distilled water and $1 \mu \mathrm{l}$ of template DNA. The following thermocycling program was used: 5 min denaturation at $95{ }^{\circ} \mathrm{C}$, followed by 35 cycles of $30 \mathrm{~s}$ denaturation at $95{ }^{\circ} \mathrm{C}, 30 \mathrm{~s}$ annealing at $60{ }^{\circ} \mathrm{C}, 1 \mathrm{~min}$ extension at $72{ }^{\circ} \mathrm{C}$, and a final extension step of $10 \mathrm{~min}$ at $72{ }^{\circ} \mathrm{C}$. These PCR products and those from the first step of the nested ITS-PCR were purified with the DNA Clean \& Concentrator-5 Zymo Kit (Zymo Research Corporation, Irvine, CA, USA) before being submitted for pyrosequencing. Sequencing of the hypervariable V3-V4 region of the $16 \mathrm{~S}$ rRNA gene was conducted at the Biotechnology Innovation Centre (BIOCANT, Cantanhede, Portugal) with fusion primers containing the Roche-454 A and B Titanium sequencing adapters, an eight-base barcode sequence in fusion primer $A$, the forward primer 5'- 
ACTCCTACGGGAGGCAG-3' and the reverse primer 5'- TACNVRRGTHTCTAATYC -3' (Wang and Qian, 2009). For the ITS2 region of fungal ribosomal DNA, amplifications were performed with fusion primers containing the Roche-454 A and B Titanium sequencing adapters, an eight-base barcode sequence in fusion primer $A$, the forward primer 5'GCATCGATGAAGAACGC-3' and reverse primer 5'-CCTCCGCTTATTGATATGC-3' (White et al., 1990). Sequencing was performed with GS 454 FLX Titanium chemistry, according to manufacturer's instructions (Roche, 454 Life Sciences, Brandford, CT, USA).

In the case of bacteria, quality filtered sequences were assigned to operational taxonomic units (OTUs) defined at 97\% sequence similarity according to Ding et al. (2012). Briefly, sequences matching the barcode and primer were selected for blastn searches in the database SILVA 115 SSU Ref (Quast et al. 2013). Chimera were truncated, barcodes and primers were removed, and sequences shorter than $200 \mathrm{bp}$ were discarded. Multiple alignments and OTU assignment were performed using the software package Mothur v1.14.0 (Schloss et al. 2009). Fungal ITS2 sequences were assigned to the most similar ITS of "species hypotheses" (SH) as defined in the database UNITE v6 (Kõljalg et al., 2013), for sequences with an identity of at least 95\%. For ITS sequences that had the same similarity to more than one SH, the SH with highest frequency in all blastn hits was chosen.

Statistical analysis. Analyses of variance were used to analyse the data with the MIXED and GLIMMIX procedures of SAS (version 9.3, SAS Institute, Cary, NC, USA). Count data was $\log _{10}$-transformed, whereas any percentage data was arcsine-transformed before analysis in PROC MIXED. Females counted at weekly time intervals (response variable) were analyzed as repeated measures with PROC GLIMMIX. The model included the effects of soil, treatment and time. For the examination of the egg content of females and cysts, the effects of soil and treatment (independent variables) were tested on the dependent variables: percentages of healthy or disease eggs, eggs per cyst, and percentages of eggs presenting fungal growth. Statistical significance was set at $P \leq 0.05$. Results obtained from PROC MIXED are presented as means \pm se. Results obtained from PROC GLIMMIX are presented as backtransformed lsmeans \pm lsmse. 


\section{Results}

Development of Globodera pallida females in root observation chambers. In the first experiment consisting of microplot soils where potato was repeatedly grown (from 2009 to 2014) in the presence of Chavornay or Delmsen G. pallida populations, no significant differences in numbers of females were found between the two soils (Chavornay: $38.2 \pm 5.8$, Delmsen: $31.0 \pm$ 4.5, $P=0.2841$ ), or between the two treatments (heat-treated: $35.6 \pm 5.4$, non-heated: $33.3 \pm 4.8$, $P=0.7215$; data not shown) during the monitoring time. The root length measurements per observation area were similar in non-heated and heat-treated soils, or between Chavornay and Delmsen soils (data not shown). Maximum numbers of females visible on the roots were reached at $50 \mathrm{dpi}$, and declined until completion of the experiment (Fig. 2.2). In the replication of the experiment including a control soil lacking of a potato cropping history in the heat-treated soil, no significant differences were observed among soils. Within non-heated soils, female numbers were similar between the control $(5.8 \pm 1.9)$ and Chavornay $(11.6 \pm 3.5 ; P=0.1232)$, and higher in Delmsen $(52.5 \pm 15.0)$ than in the control $(P<0.01)$ and Chavornay $(P<0.01)$. In non-heated soil, female numbers in Chavornay remained similar at 35 dpi (126.2 \pm 57.8$)$ and 42 dpi (79.8 \pm 33.7; $P=0.2101)$, and thereafter decreased until 77 dpi $(2.2 \pm 0.9 ; P<0.01)$ to remain similar through 91 dpi $(1.5 \pm 0.7 ; P=0.4064)$. In the Delmsen population soil (in non-heated portion), female numbers remained similar from 35 dpi $(302.1 \pm 137.9)$ to 49 dpi $(216.7 \pm 110.5 ; P=$ $0.4160)$, thereafter decreasing until $91 \mathrm{dpi}(5.1 \pm 1.6 ; P<0.01)$. For both populations, maximum numbers of females were found at 35 dpi (data not shown).

Examination of the egg content of females and cysts of G. pallida. In the first experiment, the total number (healthy and diseased) of eggs per cyst in Delmsen population soil were only about half in the non-heated soil $(81.5 \pm 26.4)$ than in the heat-treated $(157.5 \pm 20.4, P<0.01)$. In non-heated soil, fewer eggs per cyst were found in Delmsen soil $(81.5 \pm 26.4)$ than in Chavornay soil $(143.6 \pm 10.9, P=0.0146)$. However, no significant effect of the treatment was detected on the percentages of diseased eggs. After incubation on water agar, only a few eggs showed fungal hyphae and no significant differences were found with regard to the percentages of eggs with fungi from different soils (both experiments) or between the treatments (first experiment; Table 2.1). 
DGGE analysis of the amplified bacterial and fungal amplicons from G. pallida females. In the DGGE fingerprints of bacterial communities, different profiles for non-heated and heattreated soil indicated the presence of different bacterial populations (Fig. 2.3A). DGGE fingerprints of $16 \mathrm{~S}$ rRNA genes from heat-treated soil displayed a highly uniform pattern. In the UPGMA-cluster analysis, samples from the heat-treated soil shared more than $80 \%$ similarity and clustered separately from the non-heated soil (Fig. 2.3B). In non-heated soil, a different and complex pattern for the bacterial community was attributed to the high variability among replicates. A larger number of dominant bands compared to the heat-treated soil indicated an increase in dominant bacterial species (Fig. 2.3A). The high variability among replicates and the lack of separation between the two populations or experiments precluded detection of specific ribotypes enriched in the non-heated soil. These results were confirmed by UPGMAdendrograms, where a mixed clustering between the G. pallida populations and the two experiments within the non-heated soil was observed (Fig. 2.3B).

In the community analysis of fungal ITS fragments, a different pattern was observed for the non-heated compared to the heat-treated soil (Fig. 2.4A). In contrast to the bacterial profiles, a high variability within populations was observed in the heat-treated soil, where few highintensity bands indicated that a few fungal species were dominant (Fig. 2.4A). In the ITS UPGMA-dendrogram, with the exception of one replication, the heat-treated soil formed a separate cluster but shared a low similarity (Fig. 2.4B). In non-heated soil, the highly complex banding resulted in no consistent clustering (Fig. 2.4B). In both experiments, higher abundance of dominant bands in nematodes from non-heated than heat-treated soil samples indicated an increase in dominant fungal ribotypes. The control soil displayed fewer dominant bands than soil from the two G. pallida populations (Fig. 2.4A). Despite the high internal variability of nonheated soils from each of the experiments, four dominant bands with identical electrophoretic mobility (A, B, C and D) were observed in almost all samples from both populations (Fig. 2.4A). The ITS fragments pattern did not allow distinguishing the two populations and the two experiments. A higher abundance of dominant bands reflecting enhanced sequence diversity was observed in the fungal DGGE than in the bacterial DGGE.

Distinct fingerprints and clusters for bacterial DGGE results were observed for inoculum cysts and for females from heat-treated soil (Fig. 2.5A,B). Despite a high variability among years within inoculum cysts and the females from non-heated soil, bacterial DGGE fingerprints from 
most samples of females from non-heated soil clustered separately from the inoculum cysts and shared a low similarity with them (Fig. 2.5B). Different fungal fingerprints were observed for inoculum cysts and females from non-heated soil (Fig. 2.6A). However, due to a high internal variability, no separate cluster was observed for the inoculum cysts, which shared a low similarity with females and soil of both treatments (Fig. 2.6B).

Pyrosequencing and sequence analysis. Acquired bacterial sequences from females raised in non-heated soil from both G. pallida population microplots were grouped into 333 OTUs (>97\% sequence similarity), after excluding OTUs with less than $96 \%$ rRNA gene sequence identity or with only one sequence. An average of 797 total sequences was obtained for females raised in Chavornay soil, while 1194 were obtained for females raised in Delmsen soil. The OTUs were classified in 10 phyla, 19 classes, 36 orders, 55 families and 77 genera. Most of the OTUs were affiliated with Proteobacteria (212), followed by Actinobacteria (48) and Bacteroidetes (39). Proteobacteria were dominated by OTUs assigned to Betaproteobacteria (117) and Alphaproteobacteria (71). The phylum Actinobacteria were strongly dominated by the class Actinobacteria (41), and Bacteroidetes by Sphingobacteria (25) and Flavobacteria (11). Of 272 OTUs belonging to 77 genera, 21\% were affiliated to Burkholderia (Betaproteobacteria), 14\% to Ralstonia (Betaproteobacteria), 6\% to Devosia (Alphaproteobacteria), 4\% to Rhizobium (Alphaproteobacteria) and 4\% to Streptomyces (Actinobacteria). A list of the most dominant bacterial OTUs is shown in Table 2.2.

In females from the non-heated Chavornay and Delmsen soils, a total of 948 and 1231 fungal sequences were acquired, respectively. Sequences were grouped into 24 OTUs after excluding OTUs with less than 95\% SH identity, or with only one sequence. The OTUs could be classified to 2 phyla, 3 classes, 7 orders, 4 families and 9 genera. 15 of 24 OTUs were affiliated with Ascomycota, 7 with Basidiomycota and 2 with unidentified uncultured fungi. Within the Ascomycota (15), the majority accounted for Sordariomycetes (8), followed by Dothideomycetes (4) and Euromycetes (3), whereas for Basidiomycota, all were related to Malasseziales (Incertae sedis). At the genus level, the majority was associated with Malassezia (Basidiomycota Incertae sedis), followed by Colletotrichum (Sordariomycetes) and Penicillium (Eurotiomycetes).

Within Malassezia, OTUs containing high number of sequences affiliated with Malassezia restricta, M. sympodialis and M. globosa were detected in females raised in soil from 
Chavornay and Delmsen microplots. Among Ascomycota, dominant OTUs assigned to Hirsutella rhossiliensis (Hypocreales), Microdochium bolleyi (Xylariales) and Monographella cucumerina were found in females raised in Chavornay soil but not in Delmsen soil (Table 2.3). Due to the high variability among replicates within each of the two G. pallida microplot soils (Chavornay and Delmsen), a statistical comparison between these two soils was not conducted.

\section{Discussion}

In this study, the presence of microorganisms associated with females of G. pallida was demonstrated. An association of these organisms with the high levels of diseased eggs that were found in the potato monoculture microplots remains to be proven. The content of these eggs appeared coagulated, lysed, degenerated or decayed, as described by Tribe (1977), who referred to such symptoms as eggs diseased by unknown causes. The high abundance of organisms found by culture-independent methods could point to the importance of microbial activities for such pathology. Further identified organisms found at high abundance or reported to be parasitic on nematodes, e. g., H. rhossiliensis, may be key players in the dynamic and reduced nematode health observed under this monoculture. The dominance of Malassezia spp. within females from soils of both populations of $G$. pallida suggests an interaction that needs to be further explored. Overall, DGGE fingerprints displayed a high degree of variability among replicates in the nonheated soils suggesting that specific bacterial and fungal ribotypes were not abundant enough to be PCR-amplified, which could mean that no stable and reproducible populations were associated with the females developed in these soils. The low similarity between inoculum cysts and newly formed females in bacterial and fungal fingerprints supported that the vast majority of the microorganisms found associated with G. pallida females did not derive from the inoculum cysts but from the microplot soil filled in the root observation chambers.

By eliminating most of the soil microbiota, heat treatments have been used to demonstrate the biological nature of specific suppressiveness (Westphal, 2005). Potato cyst nematodes generally complete only one generation per growing season; this could explain the lack of significant differences between percentages of diseased eggs in non-heated and heattreated soil, suggesting that more time may be necessary for measurable suppressiveness. In similar experiments with Heterodera schachtii (Crump and Kerry, 1987; Westphal and Becker, 
2001), differences in population development between suppressive and conducive soils were first observed in the second generation of the nematode.

Despite the great percentage of healthy eggs, it appeared that a biotic component may have negatively impacted female fecundity of Delmsen population during the monitoring time rather than the nematode eggs directly. Such pathology was also reported for other suppressive soils. Fungal parasites affected the population dynamics of Heterodera avenae Woll. by reducing the fecundity of females (Kerry et al., 1982). Brachyphoris oviparasitica was first isolated from nematode eggs but later was recognized as a female parasite because the numbers of eggs per female were reduced by almost $60 \%$ as compared to females developing in the absence of the fungus (Becker et al., 2013).

Next-generation sequencing complemented the diversity and abundance profiling of females' bacterial and fungal communities obtained by DGGE with the added benefit of time reduction to complete the procedure and without the bias of cultivation. Results obtained by pyrosequencing differed greatly from the species frequently found in other cyst nematodes, which may be mainly explained by differences in isolation procedure, since cyst-colonizing microorganisms have been traditionally determined with culture-dependent methods. Since only a minute proportion of the microbial community can be cultivated on laboratory media, the population size and microbial diversity can be substantially underestimated (Bridge and Spooner, 2001). DNA-based methods not only detected a greater part of microbial communities, but they also provided further approximation into their structure and functional role, and facilitate the identification of microorganisms involved in suppressiveness against soil-borne pathogens (van Elsas et al., 2008). Different DNA fingerprinting approaches like DGGE, cloning, sequencing, and oligonucleotide fingerprinting of rRNA genes (OFRG), with focus on the bacterial and fungal communities associated with cyst nematodes or implicated in their suppressiveness have been used (Nour et al. 2003, Yin et al. 2003a, 2003b, Borneman and Becker 2007). This is the first report of egg health status and associated microbial communities within females of $G$. pallida based on a cultivation-independent approach.

Although a considerable number of investigations have been conducted on fungal colonization of cyst nematodes, comparatively little is known about the cyst-associated bacterial flora. Most studies have focused on the antagonistic capacities of Pasteuria nishizawae, and rhizobacteria like Bacillus spp. and Pseudomonas spp., (reviewed by Tian et al., 2007). When 
evaluating the effect of bacteria isolated from cysts against G. pallida, Racke and Sikora (1992) found that $5 \%$ of the bacteria exhibited antagonistic activity against this nematode species. Based on the pyrosequencing data, most OTUs belonged to Alphaproteobacteria, Betaproteobacteria, Actinobacteria and Sphingobacteria-Flavobacteria groups, which were also frequently detected through DNA-based techniques within cysts of Heterodera glycines Ichinohe (Nour et al., 2003), and H. schachtii Schm. (Yin et al., 2003a). In our study, high proportions of OTUs affiliated with Ralstonia and Burkholderia were found; the last one reported to show antagonistic effects against nematodes (Meyer and Roberts, 2002). Ralstonia pickettii, enhanced in females raised in soil from Delmsen microplots, had been reported to significantly reduce soybean damage by root-knot and cyst nematodes (Kloepper et al., 1992). OTUs assigned to some plant pathogens, like Ralstonia solanacearum and $R$. syzygii (Jackson, 2009) were also detected. Pantoea agglomerans, a bacterial endophyte isolated from tomato, is capable of reducing penetration by Meloidogyne incognita juveniles, and reducing root galls of tomato (Munif et al., 2013), and was also enriched in females raised in soil from Delmsen microplots. A high number of sequences affiliated with Devosia chinhatensis and Rhodobacter blasticus detected in females isolated from Delmsen microplot soil were also found on baiting juveniles of Meloidogyne hapla Chitwood in three arable soils from Germany (Adam et al., 2014). Brevundimonas vesicularis and Moraxella osloensis, dominant in females from the Delmsen soil, have been reported in the literature to cause human infections (Han and Tarrand, 2004; Shang et al., 2012). M. osloensis, was also parasitic on the mucous membranes of other warm-blooded animals, nematodes and slugs (Holt et al., 1994, Tan and Grewal, 2001).

The mycoflora of Heterodera spp. has been intensively examined (Kerry, 1988; Carris and Glawe, 1989; Yin et al., 2003b), but few studies have examined the fungi associated with potato cyst nematodes. This nematode was believed not to have effective fungal antagonists in agricultural soils until the most commonly occurring fungi in Heterodera spp. were also found in Globodera spp. (Crump, 1991). The mycoflora associated with Globodera spp. from potato fields in Europe and South America included the known nematophagous fungi Cylindrocarpon destructans, Fusarium oxysporum, Gliocladium roseum, Paecilomyces lilacinus, Phoma exigua, Pochonia chlamidosporium, and other fungal species found to grow saprophytically or showing parasitic abilities erratically (Morgan-Jones and Rodriguez-Kabana, 1986; Roessner, 1987; Dackman, 1990; Sikora et al., 1990; Crump and Flynn, 1995; Yu and Coosemans, 1998; Jacobs, 
2000). This was corroborated by higher abundance of dominant bands observed in fungal compared to bacterial community profiles, suggesting a higher diversity of predominant ribotypes. These findings were not consistent with the results obtained from the pyrosequencing, where an enhanced number of species was found for bacteria. This inconsistency may be due to the lower resolution power of the ITS2 region compared to the V3V4 hypervariable region. On the other hand, according to Muyzer and Smalla (1998), bands having the same melting behaviour and therefore located at the same position, do not necessarily have the same sequence. This could explain the increased number of species found for bacteria from the pyrosequencing. It may be possible that fewer fungi can concomitantly colonize cysts than bacteria. It was once presumed that only one species of fungus could colonize females or cysts of $\mathrm{H}$. glycines (Gintis et al., 1983). While this hypothesis no longer holds, our data supports a scarcer occurrence of fungi compared with bacteria.

Most remarkable was the high abundance of Malassezia, especially M. restricta in G. pallida females from non-heated microplot soils of either Chavornay or Delmsen populations. Although being part of the benign skin flora of humans and animals, yeasts of Malassezia may become pathogenic under certain conditions (Guého-Kellerman et al., 2011). Some described nematophagous fungi, e.g., isolates of $P$. lilacinus can also cause cutaneous infections in humans (Hall et al., 2004). The colonization by Malassezia spp. of substrates high in collagen, a component of the cuticle of G. pallida (Abrantes and Curtis, 2002), suggested a potential pathogenic capacity of Malassezia spp. toward G. pallida. The initial neutral lipid content of Globodera spp. (Storey, 1983) further supported this hypothesis, since a lipid dependency was suggested for Malassezia species (Guého-Kellerman et al., 2011). Malassezia globosa and M. restricta were also detected in nematodes living in forests (Renker et al., 2003). Moreover, Adam et al. (2014), found DGGE dominant bands related to sequences of $M$. restricta in samples of three arable soils in Germany and associated to juveniles of Meloidogyne hapla baited in those soils, suggesting an intimate relation with nematodes. In females from Chavornay microplot soil, a high number of sequences were affiliated with Hirsutella rhossiliensis, a fungal pathogen of several cyst nematodes, including G. pallida (Chen and Liu, 2005). Sequences affiliated with Microdochium bolleyi and Monographella (syn. Plectosphaerella) cucumerina, were also found in high number in samples of this population. Whereas $M$. bolleyi has been isolated from eggs of the cereal cyst nematode H. avenae (Dackman and Nordbring-Hertz, 1985), Monographella 
cucumerina has been shown to have potential as a biological control agent against potato cyst nematodes (Jacobs, 2000; Atkins et al., 2003).

Findings of this study illustrated the vast diversity and abundance of microbes on PCN females by culture-independent methods. It remained unclear if some of these organisms may be involved in the unknown pathology of "diseased eggs", and such a hypothesis remains to be comprehensively tested. A specific microbiome occupying the micro-environmental niche within G. pallida females may be useful for managing G. pallida population densities. Exploiting their activities would have potential of supporting suppression of this nematode and sustainable production of potato.

\section{Acknowledgments}

The authors wish to thank Conicyt for financial support of the first author. Partial support was obtained by the Norwegian Research Council, together with the Foundation for Research Levy on Agricultural Products, the Agricultural Agreement Research Fund, and the Norwegian Food Safety Authority. The support of the Weed Science group and the Institute for Epidemiology and Pathogen Diagnostics of Julius Kühn-Institut during the conduct of this study is appreciated. The technical support by J. Banyari, T. Bloethe-Hartmann, C. Blümcke, H. Grosse-Lengerich, F. Lange and A. Windt is greatly appreciated. Discussions with J.O. Becker, B. Niere, K. Smalla and S. Schreiter are appreciated. The experimental portion of this project was conducted during employment of A. Westphal at the Institute of Plant Protection in Field Crops and Grassland of the Julius Kühn-Institut.

\section{References}

Abrantes, I. D. O., and Curtis, R. H. C. 2002. Immunolocalization of a putative cuticular collagen protein in several developmental stages of Meloidogyne arenaria, Globodera pallida and G. rostochiensis. J. Helminthol. 76:1-6.

Adam, M., Westphal, A., Hallmann, J., and Heuer, H. 2014. Specific microbial attachment to root knot nematodes in suppressive soil. Appl. Environ. Microbiol. 80:2679-2686. 
Atkins, S. D., Clark I. M., Sosnowska, D., Hirsch, P.R., and Kerry, B.R. 2003. Detection and quantification of Plectosphaerella cucumerina, a potential biological control agent of potato cyst nematodes, by using conventional PCR, real-time PCR, selective media, and baiting. Appl. Environ. Microbiol. 69:4788-4793.

Becker, J. S., Borneman, J., and Becker, J. O. 2013. Dactylella oviparasitica parasitism of the sugar beet cyst nematode observed in trixenic culture plates. Biol. Contr. 64:51-56.

Borneman, J., and Becker, J. O. 2007. Identifying microorganisms involved in specific pathogen suppression in soil. Annu. Rev. Phytopathol. 45:153-172.

Bridge P., and Spooner, B. 2001. Soil fungi: diversity and detection. Plant Soil 232:147-54.

CABI/EPPO. 1997. Data sheets on quarantine organisms: Globodera rostochiensis and Globodera pallida. Pages 601-606 in: Smith, I. M., McNamara, D. G., Scott, P. R., Holderness, M., and Burger, B. eds. Quarantine Pests for Europe. CAB International, Wallingford, UK.

Carris, L. M., and Glawe, D. A. 1989. Fungi colonizing cysts of Heterodera glycines. Bulletin 786, University of Illinois, Urbana-Champaign, Agric. Exp. Station, USDA.

Chen, S., and Liu, X. 2005. Control of the soybean cyst nematode by the fungi Hirsutella rhossiliensis and Hirsutella minnesotensis in greenhouse studies. Biol. Contr. 32:208-219.

Crump, D. H. 1991. Fungal species isolated from beet, cereal and potato cyst nematodes. Pages 58-64 in: Kerry, B. R., and Crump, D. H. eds. Methods for studying nematophagous fungi. IOBC/ WPRS Bulletin XIV.

Crump, D.H., and Kerry, B.R. 1987. Studies on the population dynamics and fungal parasitism of Heterodera schachtii in soil from sugar-beet monoculture. Crop Prot. 6:49-55.

Crump, D.H., and Flynn C.A. 1995. Isolation and screening of fungi for biological control of potato cyst nematodes. Nematologica 41:628-638.

Dackman, C. 1990. Fungal parasites of the potato cyst nematode Globodera rostochiensis: isolation and reinfection. J. Nematol. 22:594-597.

Dackman, C., and Nordbring-Hertz, B. 1985. Fungal parasites of the cereal cyst nematode Heterodera avenae in southern Sweden. J. Nematol. 17:50-55.

Ding, G. C., Heuer, H., and Smalla, K. 2012. Dynamics of bacterial communities in two unpolluted soils after spiking with phenanthrene: soil type specific and common responders. Frontiers Microbiol. 3:290; doi: 10.3389/fmicb.2012.00290 
Eberlein, C., H. Heuer, S. Vidal, and A. Westphal. 2016. Population dynamics of Globodera pallida under potato monoculture. Nematropica 46:114-120.

European Union. 2007. Council Directive 2007/33/EC of 11 June 2007 on the control of potato cyst nematodes and repealing Directive 69/465/EEC. Off. J. Eur. Union L 156:12-22.

Evans, K., and Haydock, P. P. J. 2000. Potato cyst nematode management - present and future. Aspects Appl. Biol. 59:91-97.

FAO. 2008. International Year of the Potato. Food and Agriculture Organization of the United Nations (FAO). http://www.fao.org/potato-2008 (accessed 12.05.2014).

Gair R., Mathias P. L., and Harvey, P. N. 1969. Studies of cereal nematode populations and cereal yields under continuous or intensive culture. Ann. Appl. Biol. 63:503-512.

Gintis, B. O., Morgan-Jones, G., and Rodriguez-Kabana, R. 1983. Fungi associated with several developmental stages of Heterodera glycines from Alabama soybean field soil. Nematropica 13:181-200.

Guého-Kellerman, E., Batra, R., and Boekhout, T. 2011. Malassezia Baillon (1889). Pages 18071832 in: Kurtzman, C., Fell, J. W., Boekhout, T. eds. The yeasts: a taxonomic study. Elsevier.

Hall, V. C., Goyal, S., Davis, M. D., and Walsh, J. S. 2004. Cutaneous hyalohyphomycosis caused by Paecilomyces lilacinus: report of three cases and review of the literature. Intern. J. Dermatol. 43:648-653.

Han, X. Y., and Tarrand, J. J. 2004. Moraxella osloensis blood and catheter infections during anticancer chemotherapy clinical and microbiologic studies of 10 cases. Ameri. J. Clin. Pathol. 121:581-587.

Heuer, H., Krsek, M., Baker, P., Smalla, K., and Wellington, E. M. 1997. Analysis of actinomycete communities by specific amplification of genes encoding16SrRNA and gelelectrophoretic separation in denaturing gradients. Appl. Environ. Microbiol. 63:3233-3241.

Heuer, H., Wieland, G., Schoenfeld, J., Schoenwaelder, A., Gomes, N. C. M., and Smalla, K., 2001. Bacterial community profiling using DGGE or TGGE analysis. Pages 177-190 in: Rouchelle, P. ed. Environmental Molecular Microbiology: Protocols and Applications. Horizon Scientific Press, Wymondham, UK.

Holt, J. G., Krieg, N. R., Sneath P. H. A., Staley, J., et al. 1994. Bergey's Manual of Determinative Bacteriology, 9th ed. Williams \& Wilkins, Baltimore, US. 
Jackson, R. W. 2009. Plant pathogenic bacteria: genomics and molecular biology. Caister Academic Press, Norfolk, UK.

Jacobs, H. 2000. Development of a fungal biological control agent for potato cyst nematodes. Ph.D. Thesis. University of Luton, Luton, UK.

Kerry, B. 1988. Fungal parasites of cyst nematodes. Agric. Ecosyst. Environ. 24:293-305.

Kerry, B. R., Crump, D. H., and Mullen, L. A. 1982. Studies of the cereal cyst-nematode, Heterodera avenae under continuous cereals, 1975-1978. II. Fungal parasitism of nematode females and eggs. Ann. Appl. Biol. 100:489-499.

Kerry, B. R., and Crump, D. H. 1998. The dynamics of the decline of the cereal cyst nematode, Heterodera avenae, in four soils under intensive cereal production. Fund. Appl. Nematol. 21:617-625.

Kloepper, J. W., Rodríguez-Kábana, R., McInroy, J. A., and Young, R. W. 1992. Rhizosphere bacteria antagonistic to soybean cyst (Heterodera glycines) and root-knot (Meloidogyne incognita) nematodes: identification by fatty acid analysis and frequency of biological control activity. Plant Soil 139:75-84.

Kõljalg, U., Nilsson, R. H., Abarenkov, K. et al., 2013. Towards a unified paradigm for sequence-based identification of fungi. Molec. Ecol. 22:5271-5277.

Meyer, S. L. F., and Roberts, D. P. 2002. Combinations of biocontrol agents for management of plant-parasitic nematode and soilborne plant-pathogenic fungi. J. Nematol. 34:1-8.

Morgan-Jones, G., and Rodriguez-Kabana, R. 1986. Fungi associated with cysts of potato cyst nematodes in Peru. Nematropica 16:21-31.

Munif, A., Hallmann, J., and Sikora, R. A. 2013. The influence of endophytic bacteria on Meloidogyne incognita infection and tomato plant growth. J. ISSAAS 19:68-74.

Muyzer, G., de Waal, E. C., and Uitterlinden, A. G. 1993. Profiling of complex microbial populations by denaturing gradient gel electrophoresis analysis of polymerase chain reaction-amplified genes encoding for 16S rRNA. Appl. Environ. Microbiol. 59:695-700.

Muyzer, G., and Smalla, K. 1998. Application of denaturing gradient gel electrophoresis (DGGE) and temperature gradient gel electrophoresis (TGGE) in microbial ecology. Antonie van Leeuwenhoek, 73: 127-141. 
Ngala, B. M., Haydock, P. P. J., Woods S., and Back, M. A. 2015. Biofumigation with Brassica juncea, Raphanus sativus and Eruca sativa for the management of field populations of the potato cyst nematode Globodera pallida. Pest Manag. Sci. 71:759-769.

Nour, S. M., Lawrence, J. R., Zhu, H., Swerhone, G. D. W., Welsh, M., Welacky, T. M., and Topp, E. 2003. Bacteria associated with cysts of the soybean cyst nematode (Heterodera glycines). Appl. Environ. Microbiol. 69:607-615.

Quast, C., Pruesse, E., Yilmaz, P., Gerken, J., Schweer, T., Yarza, P., Peplies, J., and Glöckner, F.O. 2013. The SILVA ribosomal RNA gene database project: improved data processing and web-based tools. Nucl. Acids Res. 41:D590-D596.

Racke, J., and Sikora, R. A. 1992. Isolation, formulation and antagonistic activity toward the potato cyst nematode Globodera pallida. Soil Biol. Biochem. 24:521-526.

Renker, C., Alphei, J., and Buscot, F. 2003. Soil nematodes associated with the mammal pathogenic fungal genus Malassezia (Basidiomycota: Ustilaginomycetes) in Central European forests. Biol. Fertil. Soils 37:70-72.

Roessner, J. 1987. Pilze als Antagonisten von Globodera rostochiensis. Nematologica 33:106118.

Schloss, P. D., Westcott, S. L., Ryabin, T., Hall, J. R., Hartmann, M., Hollister, E. B., Lesniewski, R. A., Oakley, B. B., Parks, D. H., Robinson, C. J., Sahl, J. W., Stres, B., Thallinger, G. G., Van Horn, D. J., and Weber, C. F. 2009. Introducing mothur: open-source, platform-independent, community-supported software for describing and comparing microbial communities. Appl. Environ. Microbiol. 75:7537-7541.

Scholte, K. 2000. Screening of non-tuber bearing Solanaceae for resistance and induction of juvenile hatch of potato cyst nematodes and their potential for trap cropping. Ann. Appl. Biol. 136:239-246.

Schouten, H. J., and Beniers, J. E. 1997. Durability of resistance to Globodera pallida I. Changes in pathogenicity, virulence, and aggressiveness during reproduction on partially resistant potato cultivars. Phytopathology 87:862-867.

Scurrah, M. I., Niere, B., and Bridge, J. 2005. Nematode parasites of Solanum and sweet potatoes. Pages 193-220 in: Luc, M., Sikora, R. A., Bridge, J. eds. Plant parasitic nematodes in subtropical and tropical agriculture. CAB International, Wallingford, UK. 
Shang, S. T., Chiu, S. K., Chan, M. C., Wang, N. C., Yang, Y. S., Lin, J. C., Chang, F. Y. 2012. Invasive Brevundimonas vesicularis bacteremia: Two case reports and review of the literature. J. Microbiol. Immun. Infect. 45:468-472.

Sikora, R., Hiemer, M., Schuster, R. P. 1990. Reflections on the complexity of fungal infection of nematode eggs and the importance of facultative perthophytic fungal pathogens in biological control of Globodera pallida. Meded. Facu. Landbouwwetensch. Rijksuni. Gent 55:699-712.

Steiner, A. A. 1968. Soilless culture. Proceedings of the 6th Colloquium of the International Potash Institute. International Potash Institute, Bern, Switzerland, pp. 324-341.

Stirling, G. R. 1991. Biological control of plant-parasitic nematodes: progress problems and prospects. CAB International, Wallingford, UK. 282 pp.

Storey, R. M. J. 1983. The initial neutral lipid reserves of juveniles of Globodera spp. Nematologica 29:144-150.

Tan, L., and Grewal, P. S. 2001. Pathogenicity of Moraxella osloensis, a bacterium associated with the nematode Phasmarhabditis hermaphrodita, to the slug Deroceras reticulatum. Appl. Environ. Microbiol. 67:5010-5016.

Tennant, D. 1975. A test of a modified line intersection method of estimating root length. J. Ecol. 63:995-1001.

Tian, B., Yang, J., and Zhang, K. Q. 2007. Bacteria used in the biological control of plantparasitic nematodes: populations, mechanisms of action, and future prospects. FEMS Microbiol. Ecol. 61: 197-213.

Tribe, H. T. 1977. Pathology of cyst-nematodes. Biol. Rev. 52:477-507.

United States Department of Agriculture, Animal and Plant Health Inspection Service. Golden Nematode http:/www.aphis.usda.gov/planthealth/gn $\quad$ Pale Nematode http://www.aphis.usda.gov/planthealth/pcn (accessed 08.07.2015).

Van Elsas, J. D., Speksnijder, A. J., and van Overbeek, L. S. 2008. A procedure for the metagenomics exploration of disease-suppressive soils. J. Microbiol. Meth. 75:515-522.

Wang, Y., and Qian, P. Y. 2009. Conservative Fragments in Bacterial 16S rRNA Genes and Primer Design for 16S Ribosomal DNA Amplicons in Metagenomic Studies. PLoS ONE 4, e7401. 
Weinert, N., Meincke, R., Gottwald, C., Heuer, H., Gomes, N. C., Schloter, M., Berg, G., and Smalla, K. 2009. Rhizosphere communities of genetically modified zeaxanthin accumulating potato plants and their parent cultivar differ less than those of different potato cultivars. Appl. Environ. Microbiol. 75:3859-3865.

Westphal, A. 2005. Detection and description of soils with specific nematode suppressiveness. J. Nematol. 37:121-130.

Westphal, A., and Becker, J. O. 1999. Biological suppression and natural population decline of Heterodera schachtii in a California field. Phytopathology 89:434-440.

Westphal, A., and Becker, J. O. 2001. Components of soil suppressiveness against Heterodera schachtii. Soil Biol. Biochem. 33:9-16.

Westphal, A., and Xing, L. J. 2011. Soil suppressiveness against the disease complex of the soybean cyst nematode and sudden death syndrome of soybean. Phytopathology 101:878886.

White, T. J., Bruns, T., Lee, S., and Taylor, J. W. 1990. Amplification and direct sequencing of fungal ribosomal RNA genes for phylogenetics. Pages 315-322 in: Innis, M. A., Gelfand, D. H., Sninsky, J. J., White, T. J. eds. PCR Protocols: A Guide to Methods and Applications. Academic Press, Inc., New York, US.

Woods, S. R., Haydock, P. P. J., and Edmunds, C. 1999. Mode of action of fosthiazate used for the control of the potato cyst nematode Globodera pallida. Ann. Appl. Biol. 135:409-415.

Yin, B., Valinsky, L., Gao, X., Becker, J. O., and Borneman, J. 2003a. Bacterial rRNA Genes Associated with Soil Suppressiveness against the Plant-Parasitic Nematode Heterodera schachtii. Appl. Environ. Microbiol. 69:1573-1580.

Yin, B., Valinsky, L., Gao, X., Becker, J. O., and Borneman, J. 2003b. Identification of fungal rDNA associated with soil suppressiveness against Heterodera schachtii using oligonucleotide fingerprinting. Phytopathology 93:1006-1013.

Yu, Q., and Coosemans, J. 1998. Fungi associated with cysts of Globodera rostochiensis, G. pallida, and Heterodera schachtii; and egg masses and females of Meloidogyne hapla in Belgium. Phytoprotection 79:63-69. 
Table 2.1 Means \pm SE of percentage of diseased eggs, number of eggs per cyst and eggs with fungal growth from the content of Globodera pallida females and cysts raised in root observation chambers in potato monoculture soil infested with one of two G. pallida populations.

\begin{tabular}{|c|c|c|c|c|c|c|}
\hline & \multirow[b]{2}{*}{ Experiment } & \multicolumn{2}{|c|}{ Delmsen $^{3}$} & \multicolumn{2}{|c|}{ Chavornay $^{3}$} & \multirow{2}{*}{$\begin{array}{c}\text { Control } \\
\text { Non-heated }\end{array}$} \\
\hline & & Non-heated & Heat-treated & Non-heated & Heat-treated & \\
\hline \multirow[t]{2}{*}{ Diseased eggs $(\%)^{1}$} & 1 & $40.6 \pm 16.3$ & $12.5 \pm 0.6$ & $15.3 \pm 3.8$ & $18.7 \pm 7.1$ & - \\
\hline & 2 & $8.9 \pm 1.4$ & - & $15.9 \pm 2.9$ & - & $16.4 \pm 1.9$ \\
\hline \multirow[t]{2}{*}{ Eggs per cyst (total) ${ }^{1}$} & 1 & $81.5 \pm 26.4$ & $157.5 \pm 20.4$ & $143.6 \pm 10.9$ & $136.1 \pm 27.9$ & - \\
\hline & 2 & $190.8 \pm 28.0$ & - & $124.6 \pm 21.2$ & - & $103.0 \pm 9.7$ \\
\hline \multirow[t]{2}{*}{ Eggs with fungal growth $(\%)^{2}$} & 1 & $0.9 \pm 0.4$ & $0.6 \pm 0.4$ & $3.3 \pm 1.6$ & $1.0 \pm 0.6$ & - \\
\hline & 2 & $2.8 \pm 0.8$ & - & $0.8 \pm 0.6$ & - & $1.5 \pm 0.5$ \\
\hline
\end{tabular}

\footnotetext{
${ }^{1}$ Microscopic observation immediately after preparation of egg suspensions.

${ }^{2}$ Microscopic observation after incubation for three days on water agar.

${ }^{3}$ Delmsen and Chavornay are G. pallida populations; control soil had no previous history of potato cultivation.
} 
Table 2.2 Operational taxonomic units (OTU) of the most the dominant bacteria within females of Globodera pallida populations raised in non-heated potato monoculture of Chavornay and Delmsen soil based on the V3V4 region amplicon pyrosequencing.

\begin{tabular}{ll}
\hline \multicolumn{1}{c}{ OTUs } & \multicolumn{1}{c}{ Identity values [\%] } \\
\hline Actinophytocola oryzae & $99.7 ; 99.5-99.7^{\mathrm{a}, \mathrm{b}}$ \\
Aquabacterium parvum & $98.9^{\mathrm{a}}$ \\
Bosea vestrisii & $100^{\mathrm{b}}$ \\
Bradyrhizobium sp./Pseudomonas & $100^{\mathrm{a}}$ \\
Brevundimonas vesicularis & $100^{\mathrm{a}}$ \\
Burkholderia caledonica & $99.6^{\mathrm{b}}$ \\
Burkholderia kuriensis & $99.1^{\mathrm{a}}$ \\
Candidate division TM7 & $97.9,98.2^{\mathrm{b}, \mathrm{c}}$ \\
Dermacoccus profundi & $99.4,99.7^{\mathrm{a}}$ \\
Devosia chinhatensis & $99.0^{\mathrm{b}, \mathrm{c}}$ \\
Devosia ginsengisoli & $99.3^{\mathrm{a}}$ \\
Moraxella osloensis & $99.6^{\mathrm{a}}$ \\
Pantoea aglomerans & $99.6-99.7^{\mathrm{a}}$ \\
Pelomonas aquatica / Pelomonas puraquae & $100^{\mathrm{a}}$ \\
Pelomonas puraquae & $99.8^{\mathrm{a}}$ \\
Ralstonia picketii & $100 ; 99.4-100^{\mathrm{a}, \mathrm{b}}$ \\
Ralstonia solanacearum & $96.7-98.5^{\mathrm{a}}$ \\
Ralstonia syzygii & $98.2-98.5 ; 97.8-98.5^{\mathrm{a}, \mathrm{b}}$ \\
Rhizobium giardinii & $100^{\mathrm{b}}$ \\
Rhodobacter blasticus & $97.7^{\mathrm{b}}$ \\
Sphingopyxis panaciterrae & $100^{\mathrm{a}, \mathrm{b}}$ \\
Streptomyces vinaceus & $100^{\mathrm{b}, \mathrm{c}}$ \\
Uncultured Chitinophagaceae & $100^{\mathrm{b}, \mathrm{c}}$ \\
Uncultured Nakamurella & $99.1^{\mathrm{b}}$ \\
Uncultured Rhizobiales & $99.3^{\mathrm{b}}$ \\
Uncultured Thiotrichaceae & $98.3^{\mathrm{a}}$ \\
Zoogloea ramigera & $100^{\mathrm{b}}$ \\
\hline
\end{tabular}

\footnotetext{
${ }^{a}$ affiliations to sequences present in at least 3 replicates within a population.

${ }^{b}$ affiliations to sequences $\geq 100$ times detected in at least one replicate within a population.

${ }^{\mathrm{c}}$ affiliations to sequences $\geq 400$ times detected in at least one replicate within a population.
} 
Table 2.3 Operational taxonomic units (OTU) of the most dominant fungi within females of Globodera pallida raised in non-heated potato monoculture of Chavornay and Delmsen soil based on ITS2 region amplicon pyrosequencing.

\begin{tabular}{|c|c|}
\hline OTUs & Identity values [\%] \\
\hline Davidiella tassiana & $97.8-100^{b}$ \\
\hline Hirsutella rhossiliensis & $96.3-100^{\mathrm{b}, \mathrm{d}}$ \\
\hline Malassezia globosa & $99.0^{\mathrm{a}, \mathrm{b}, \mathrm{c}}$ \\
\hline Malassezia restricta & $95.1-100^{\mathrm{a}, \mathrm{b}, \mathrm{d}}$ \\
\hline Malassezia sympodiales & $95.5-99.7^{\mathrm{b}, \mathrm{c}}$ \\
\hline Microdochium bolleyi & $97.4-100^{b}$ \\
\hline Monographella cucumerina & $95.3-100^{b}$ \\
\hline Penicillium commune & $95.5-98.4^{\mathrm{a}}$ \\
\hline Penicillium expansum & $95.5-98.4^{\mathrm{a}, \mathrm{b}}$ \\
\hline Uncultured ectomycorrhizal fungus & $95.8-100^{\mathrm{a}, \mathrm{b}, \mathrm{d}}$ \\
\hline
\end{tabular}

${ }^{a}$ affiliations to sequences present in at least 3 replicates within a population

${ }^{\mathrm{b}}$ affiliations to sequences $\geq 100$ times detected in at least one replicate within a population

${ }^{c}$ affiliations to sequences $\geq 400$ times detected in at least one replicate within a population

d affiliations to sequences $\geq 800$ times detected in at least one replicate within a population 


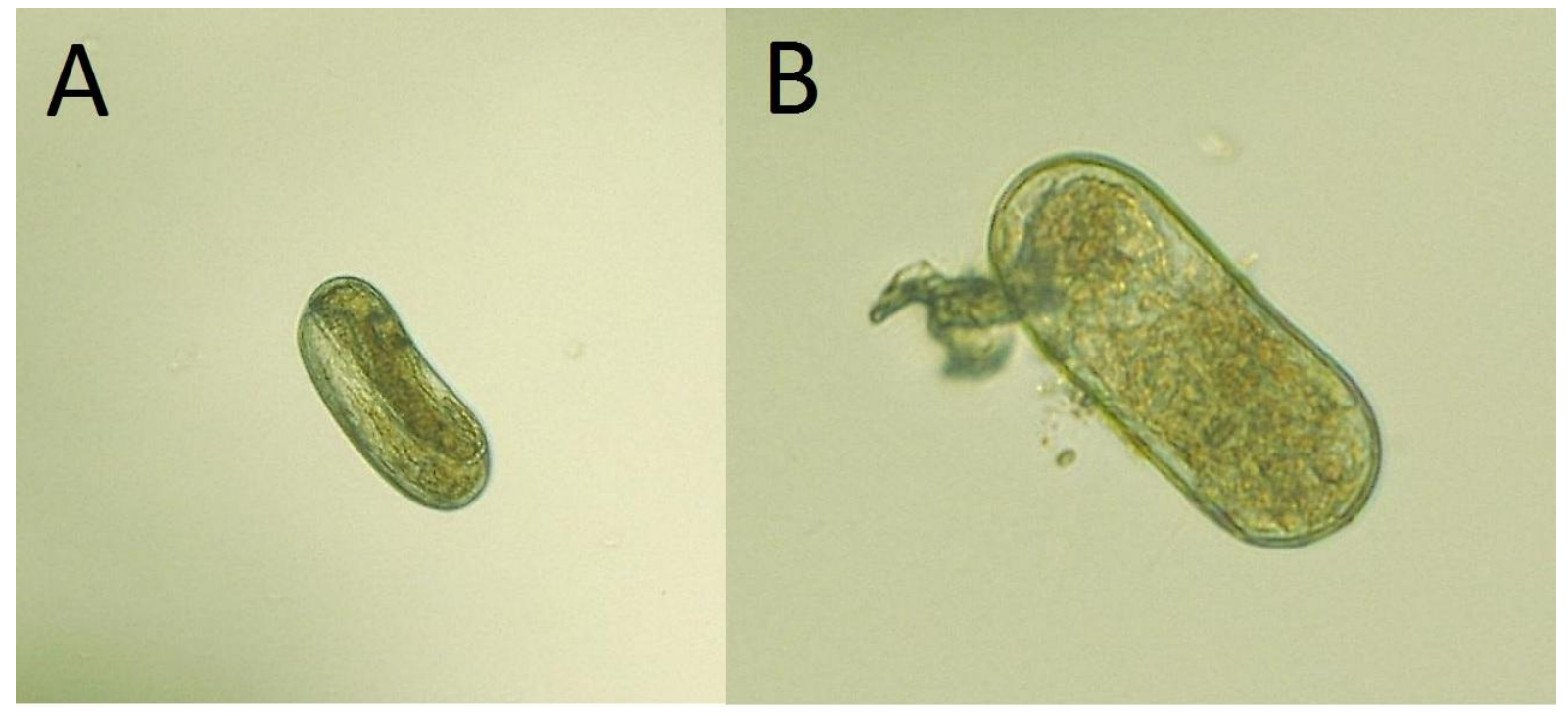

Fig. 2.1 Egg of Globodera pallida (A) healthy and (B) compromised, rated as diseased. 


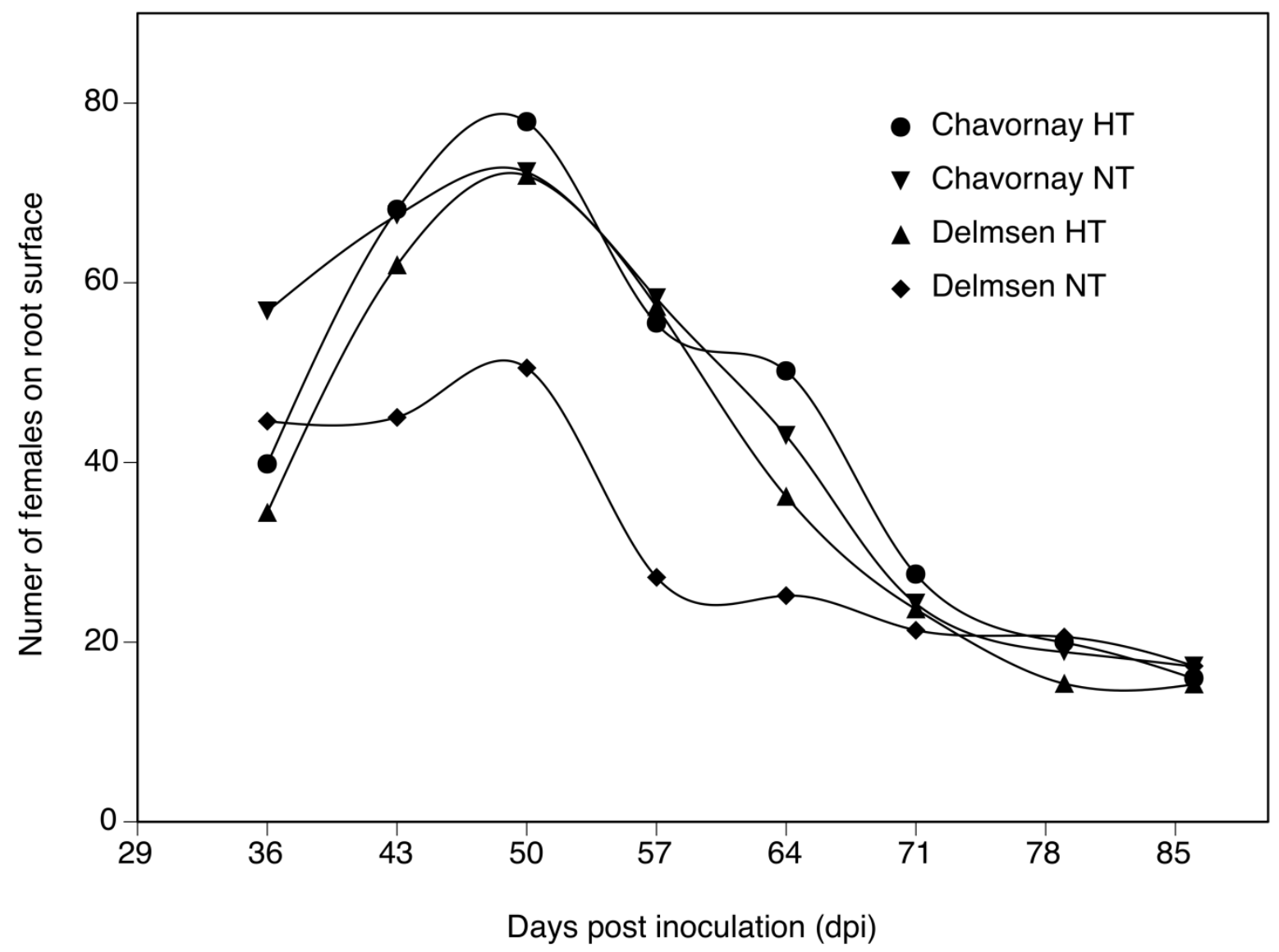

Fig. 2.2 Number of females visible on potato roots 'Selma' during monitoring in root observation chambers from 36 dpi to 90 dpi of heated and non-treated portions of soil from Chavornay or Delmsen microplots during the first experiment. 
A

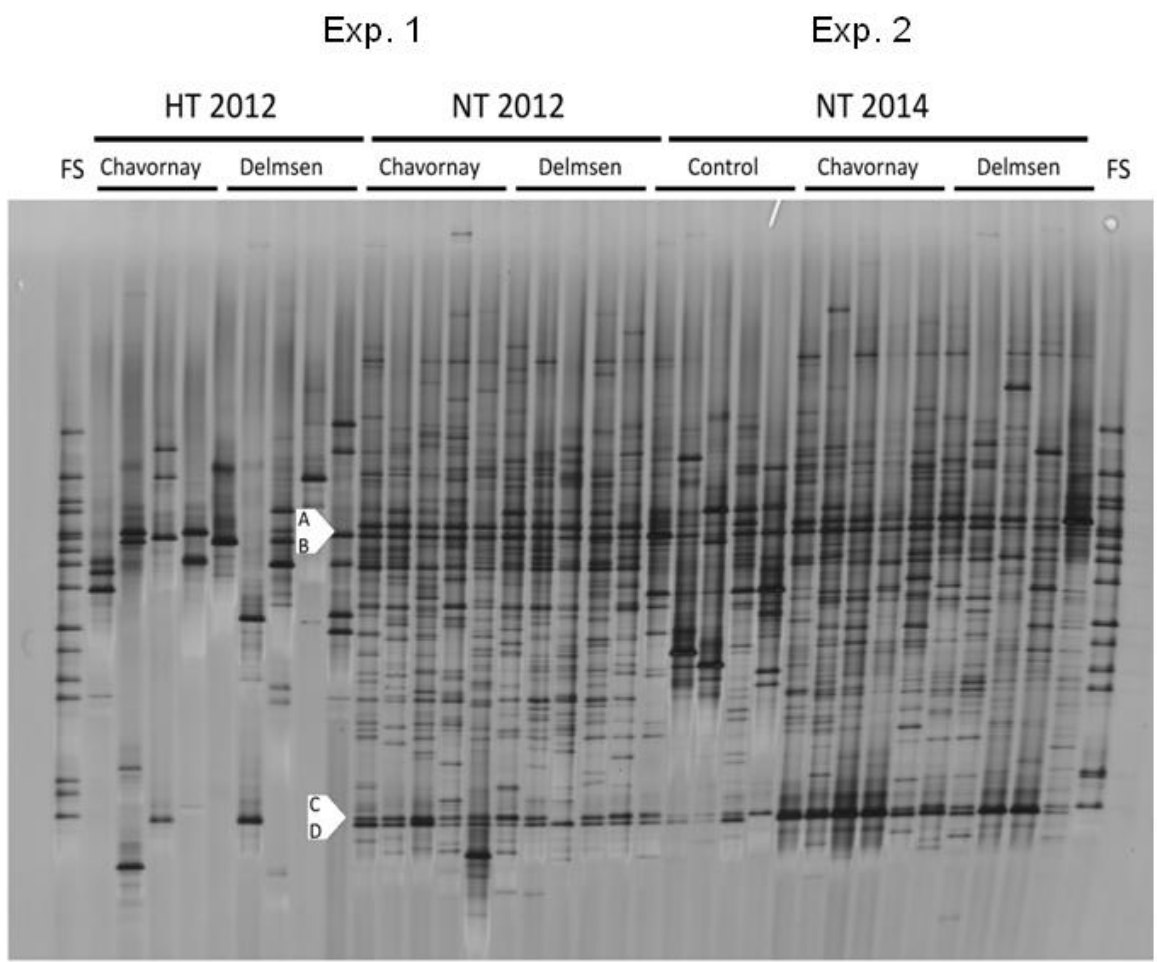

B

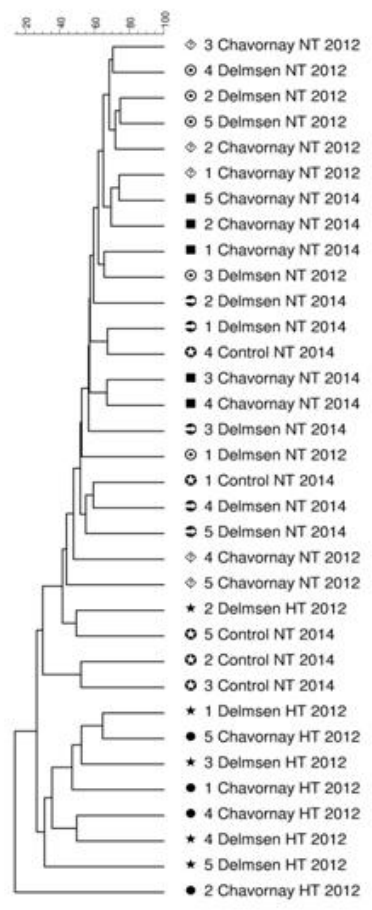

Fig. 2.3 Bacterial (16S rRNA gene) DGGE fingerprints for G. pallida females collected from heat-treated (HT) and non-heated soil (NT) at 64 dpi in 2012 and at 91 dpi in 2014 (A) and corresponding UPGMA cluster (B). Groups of five/four lines are replicates. (BS: bacterial standard). In the dendrograms, replicates are labelled 1 to 5. The scale shows similarity values. 
A

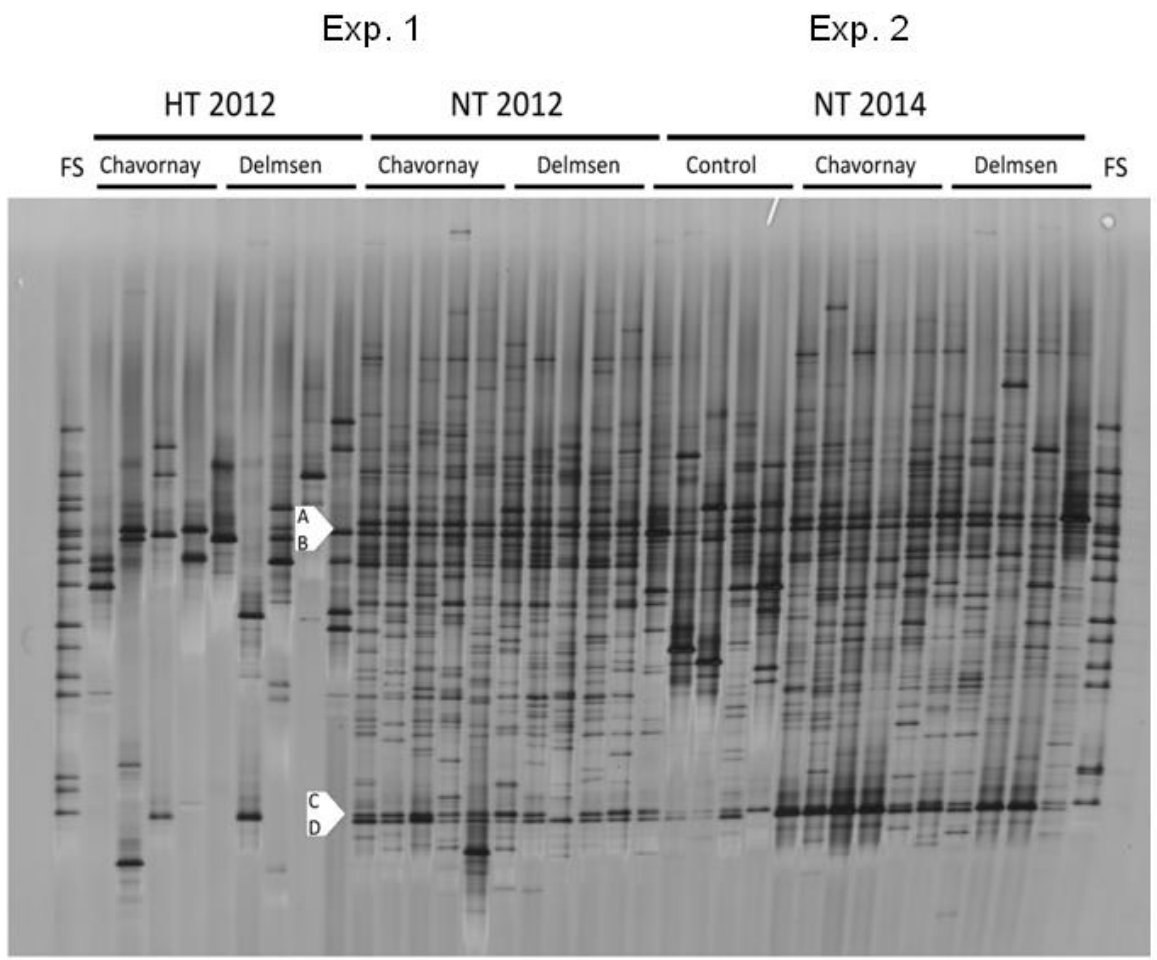

B

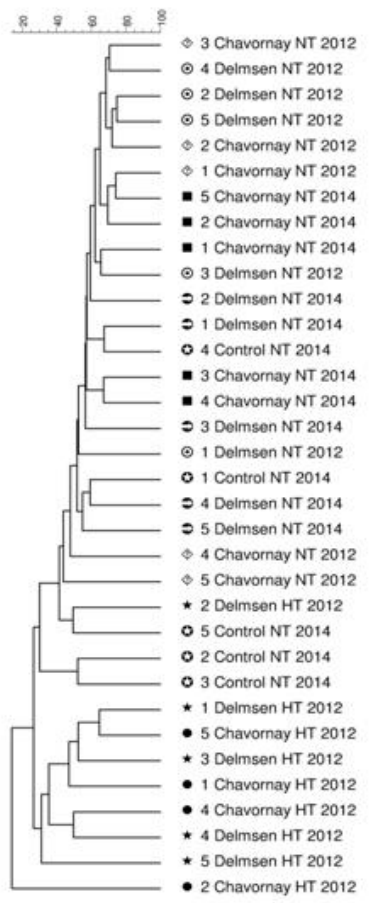

Fig. 2.4 Fungal (ITS) DGGE fingerprints for G. pallida females collected from heat-treated (HT) and non-heated soil (NT) at 64 dpi in 2012 and at 91 dpi in 2014 (A) and respective UPGMA cluster (B). Groups of five/four lines are replicates. (FS: fungal standard). Band A, B, C and D are regarded as dominant bands with identical electrophoretic mobility. In the dendrograms, replicates are labelled 1 to 5 . The scale shows similarity values. 
A

Exp. 1

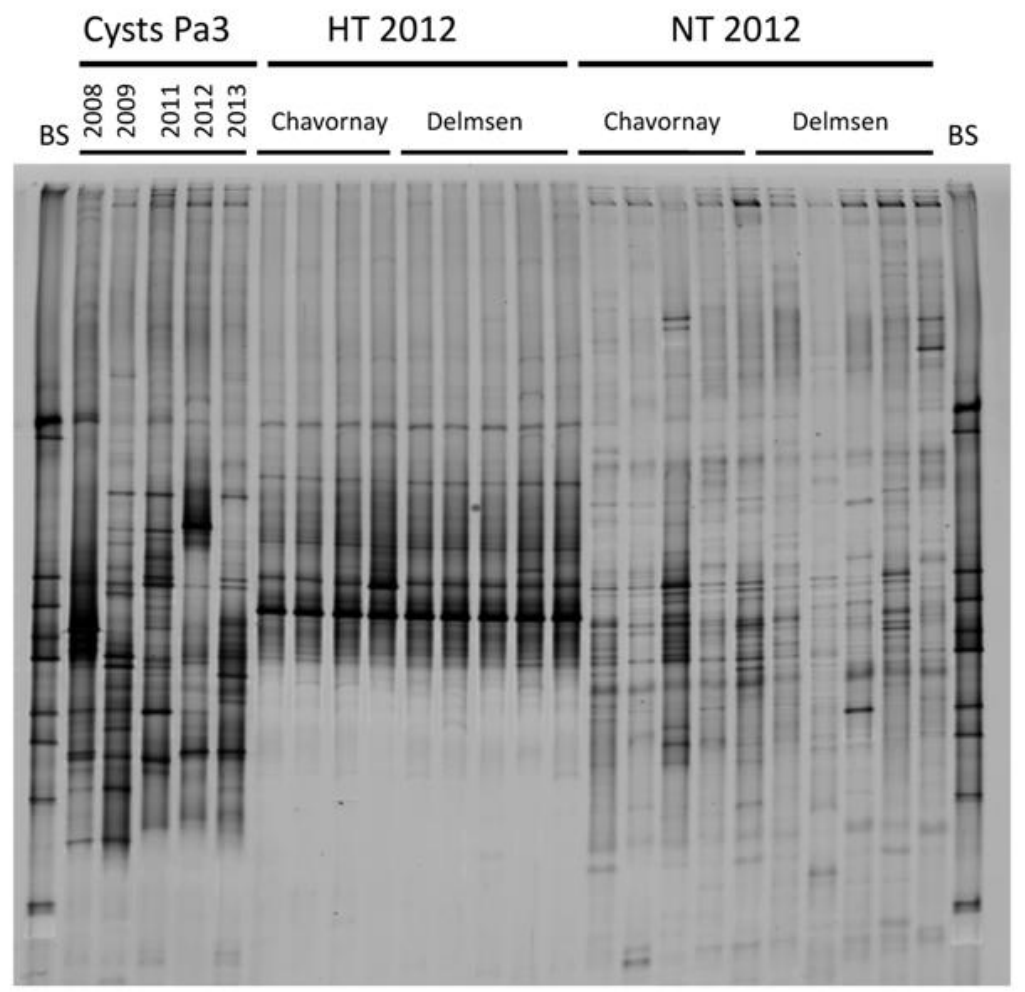

B

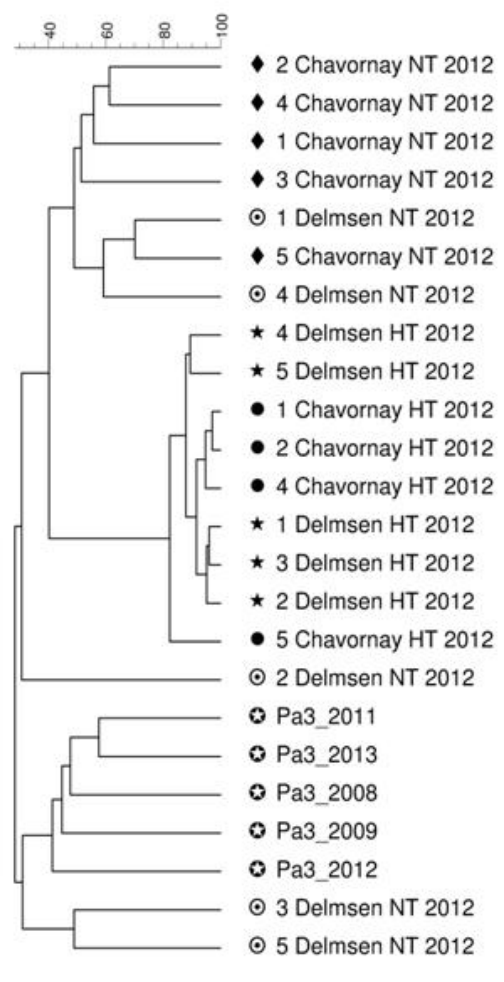

Fig. 2.5 Bacterial (16S rRNA gene) DGGE fingerprints for inoculation cysts (Cysts Pa3) and $G$. pallida females in heat-treated (HT) and non-heated soil (NT) in 2012 (A) and corresponding UPGMA cluster (B). Groups of five/four lines are replicates. (BS: bacterial standard). Inoculation cysts from five years are considered replicates. In the dendrograms, replicates are labelled 1 to 5 . The scale shows similarity values. 
A

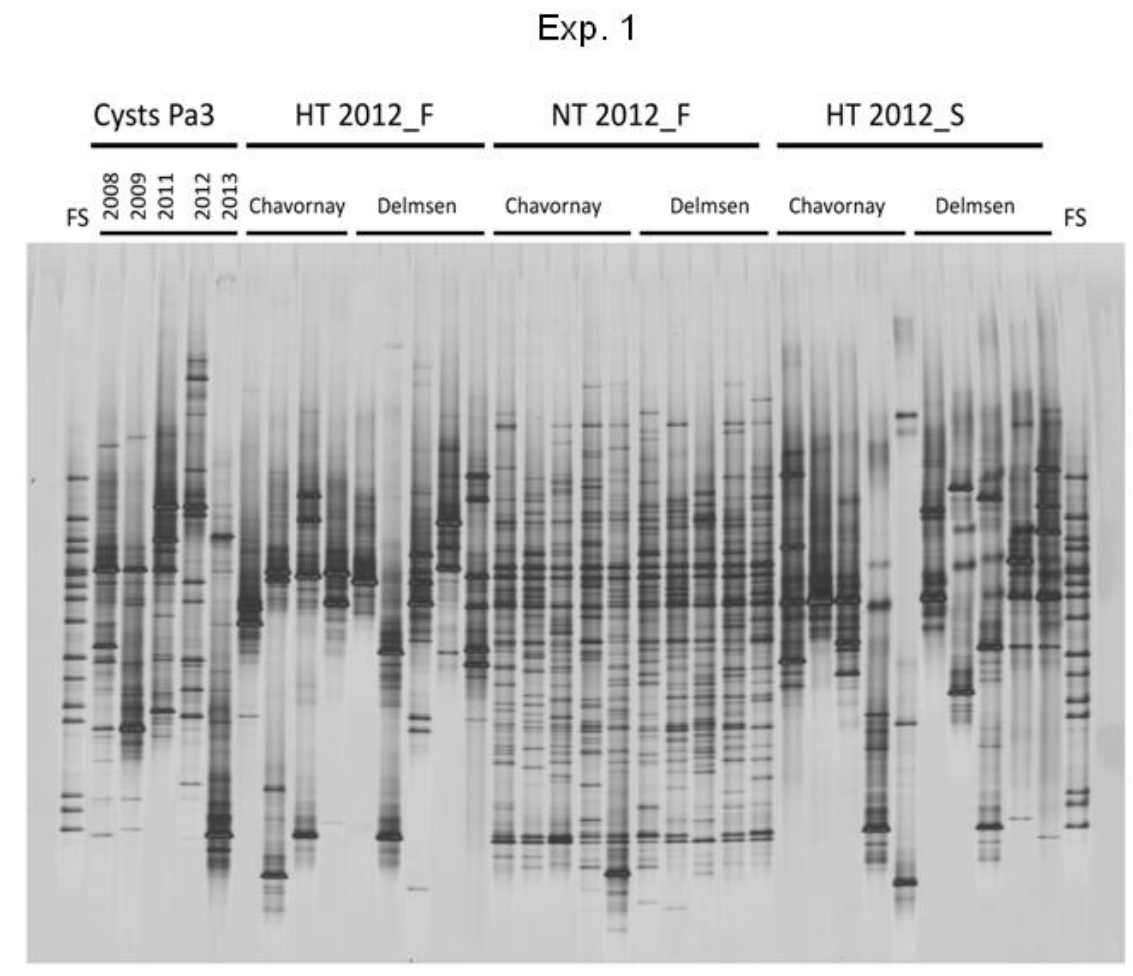

B

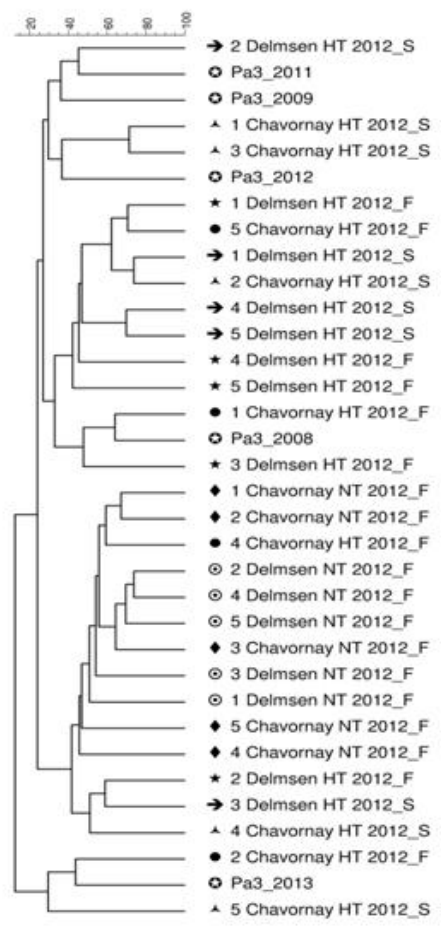

Fig. 2.6 Fungal (ITS) DGGE fingerprints for inoculation cysts (Cysts Pa3), for G. pallida females from heat-treated (HT_F) and from non-heated soil (NT_F), and for heat-treated soil (HT_S) in 2012 (A) and respective UPGMA cluster (B). Groups of five/four lines are replicates. (FS: fungal standard). Inoculation cysts from five years are considered replicates. In the dendrograms, replicates are labelled 1 to 5 . The scale shows similarity values. 


\title{
Chapter 3:
}

\section{Impact of cropping sequences and production strategies on soil suppressiveness against cereal cyst nematodes}

\author{
Caroline Eberlein $^{1,2}$, Holger Heuer ${ }^{3}$, Andreas Westphal ${ }^{1 *}$
}

${ }^{1}$ Julius Kühn-Institut, Institute for Plant Protection in Field Crops and Grassland, Messeweg

11/12, 38104 Braunschweig, Germany

${ }^{2}$ Department of Crop Sciences, University of Göttingen, Grisebachstrasse 6, 37077 Göttingen, Germany

${ }^{3}$ Julius Kühn-Institut, Institute for Epidemiology and Pathogen Diagnostics, Messeweg 11/12, 38104 Braunschweig, Germany

*Current address: Department of Nematology, University of California Riverside, Kearney Agricultural Research and Extension Center, 9240 S. Riverbend Ave., Parlier, CA 93648, U.S.

This chapter is a reprint of similar material already published in Applied Soil Ecology. Eberlein, C., H. Heuer, and A. Westphal. 2016. Impact of cropping sequences and production strategies on soil suppressiveness against cereal cyst nematodes. Applied Soil Ecology 107: 381393.

Online access: http://doi.org/10.1016/j.apsoil.2016.07.012 


\section{Abstract}

Cereal cyst nematodes (CCN) cause severe crop damage in many cereal-producing areas. Effects of cropping sequence and production system on soil suppressiveness against $\mathrm{CCN}$ were investigated. In a first approach, it was tested if a soil transfer of long-term oat monoculture soil (MOMS) facilitated the development of soil suppressiveness under monoculture of susceptible hosts. At Münster, Germany, microplots with no nematode infestation, Heterodera avenae or Heterodera filipjevi were amended with non-treated or heat-treated portions of $5 \%$ (volume of the upper $15 \mathrm{~cm}$ of soil) of MOMS and nematode population dynamics were monitored. Plots were planted either to cyst nematode susceptible cereal or to the non-host sugar beet in the first year, and then to susceptible cereals for three years. In a repetition of the experiment at Braunschweig, Germany, populations of $H$. avenae were monitored for two years. In these experiments, no acute increase of suppressiveness after soil amendment was observed. At Münster in $H$. avenae, final numbers of cysts and number of eggs did not increase in plots after initial oat. In plots with sugar-beet in the first year, cysts and egg populations did not increase, only cysts of $H$. filipjevi initially increased to then decline. In oat and in sugar beet plots at Münster, percentage of diseased eggs of $H$. avenae and $H$. filipjevi significantly increased between 2.4- and 6.5-fold under the third cropping season. Similar results were obtained at Braunschweig. In a second approach in environmental growth chamber experiments, the suppressive potential against $H$. avenae of MOMS sandy loam soil and two loam soils from intensive cereal cropping systems (OSCR: organic production, CSCR: conventional farming) was compared. Microbial communities of these soils and $H$. avenae females were characterized by PCR-DGGE. In the environmental growth chamber experiment, non-heated MOMS soil had fewer than $1 / 3$ of females compared with heated soil equivalents in contrast to $1 / 2$ in OSCR and CSCR both in such comparison. All three soils had higher suppressiveness than soil from infrequent cereal cropping (BNCC). The fingerprinting with PCR-DGGE illustrated high diversity in the different soil origins but did not allow to determine potential contributors in the suppressiveness. Findings of the studies suggested the presence of $\mathrm{CCN}$-suppressive factors under monoculture, and demonstrated a stronger influence of the cropping rather than the farming system on populations of $\mathrm{CCN}$ and on soil microbial communities that may lead to soil suppressiveness. 
Keywords: cereal cyst nematode; microbial communities; root observation chambers; soil suppressiveness; soil transfer

\section{Introduction}

Soil-borne pathogens and pests persist in complex soil environments constituted by abiotic and biotic parameters. Among the biotic parameters, various microbial activities reduce pests and pathogens, and their functions in suppressive soils are greatly enhanced compared to conducive soils (Baker and Cook, 1974). While great efforts are being made in understanding the processes in specifically suppressive soils (Borneman and Becker, 2007; Weller et al., 2002), strategies for establishing soil suppressiveness to exploit beneficial natural control are lacking. A current hypothesis is that monoculture of susceptible hosts of the target pathogen can lead to the development of suppressive soil (Kerry, 1987). This surmises that copious reproduction of the primary parasite leads to increases of hyperparasites that eventually reduce the primary parasite to low levels, and thus leads to a suppressive soil (Kerry, 1987). Implementing this concept into production practice recommendations is challenging, because the first years of such monoculture typically are associated with severe yield penalties. In contrast, if a suppressive agent is known, establishing such microorganisms in a new environment is difficult, and inundative biocontrol strategies often are not reproducibly successful (Stirling, 2014). This creates limitations in enabling the establishment and activity of candidate organisms to new soils (Sayre and Walter, 1991).

Cereal cyst nematodes $(\mathrm{CCN})$ are distributed worldwide and are responsible for important yield losses (Nicol et al., 2003). In Central Europe, CCN are major concerns in the production of cereals (Rivoal and Cook, 1993). Recent studies in the Pacific Northwest of the US have shown damaging effects in more wide-spread regions than in the previously known occurrences in the Mediterraneans (Smiley, 2009). In temperate climate zones, Heterodera avenae is the most widely distributed and damaging species (Nicol and Rivoal, 2008). In a dated CCN survey of agricultural soils in Germany, this species was considered more common than any other Heterodera or Globodera species, and constituted 93\% of all CCN species sampled from agricultural soils (Sturhan, 1982). Recognition of Heterodera filipjevi as the true identity of several strains of CCN including the "Gotland strain" (Subbotin et al., 2003) has resulted in 
increased recognition of the damage potential of $\mathrm{CCN}$. This species was frequently distributed in primarily continental climates (Nicol and Rivoal, 2008), and identified as a constraint to cereal production (Öztürk et al., 2000; Nicol et al., 2003; Hajihasani et al., 2010). In a survey of five regions of Germany, H. filipjevi occurred in 20-30\% of CCN-infested fields (Große, 2006).

In Central Europe, $\mathrm{CCN}$ damage is primarily observed in spring cereals. Based on a required winter cold incubation period for overcoming nematode dormancy and initiating infectivity, nematode populations become active during rising soil temperatures in the spring (Rivoal, 1986) when spring cereals germinate and emerge. The exposure of the most sensitive young cereal seedlings to nematode infections results in root deformations and reductions in root functions. For example, excessive root proliferations at the infection sites result in typical knotlike symptoms (Smiley, 2106). CCN are a serious problem in Scandinavia where cropping of spring cereals is more common (Holgado et al., 2004) than in Central Europe. CCN has been partially ignored owed to the exciting finding in the UK that $\mathrm{CCN}$ are naturally suppressed by antagonistic fungi in an average summer with copious precipitation (Kerry et al., 1980). In many parts of Germany, problems with CCN may go unnoticed even when conditions are conducive for the nematode's activity.

Studies have addressed the occurrence and microbial communities of nematode suppressive soils (Kerry et al., 1982; Yin et al., 2003; Borneman and Becker, 2007), but it is still poorly understood how a soil becomes suppressive, and furthermore how agronomic practices with the exception of monoculture of susceptible hosts support the development of suppressive soil (Ohnesorge et al., 1974; Westphal and Becker, 2001; Noel and Wax, 2003). Contributors to soil suppressiveness have been identified but many suppressive soils are probably more complex than being solely based on parasitism of the nematode by one species. Specific soil suppressiveness is transferable with small portions of soil (Westphal, 2005). Experimentally, this was repeatedly used to demonstrate specific suppressiveness when untreated suppressive soil was added to fumigated or otherwise microbially perturbed soil (Kluepfel et al., 1993; Westphal and Becker, 2000). Higher soil amendment amounts were necessary for successful transfer of suppressiveness if the receiving conducive soil was left untreated (Stirling and Kerry, 1983; Westphal and Becker, 2000). General soil suppressiveness is eliminated by biocidal treatments.

It was shown for different suppressive soil systems that susceptible host plants were necessary for the development and maintenance of soil suppressiveness (Gair et al., 1969; Kerry 
et al., 1982; Kerry and Anderson, 1984; Westphal and Becker, 1999; Chen, 2007; Westphal and Xing, 2011). A repeated cultivation of the resistant hosts oilseed radish or sugar beet did not eliminate suppressiveness against $H$. schachtii whereas a double crop of the non-host wheat reduced suppressiveness (Westphal and Becker, 2001). This provided some evidence that resistant plants can maintain soil suppressiveness while a non-host may be detrimental.

Hypothetically, cropping a susceptible host combined with a soil transfer may support the establishment of soil suppressiveness more than such transfer coupled with cropping a non-host. It is not known how non-hosts would interfere with the establishment of soil suppressiveness. Soil transfer introduces the beneficial organisms perhaps along with supportive components of the already suppressive soil to the nematode-conducive soil environment but could also unintentionally introduce plant pathogens. The nematode antagonists may then increase on the primary parasite more effectively than in traditional inundation of single microbes. This hypothesis was tested in the current study where population density dynamics of $H$. avenae and $H$. filipjevi were compared when a soil transfer event was followed by a host crop or non-host plant and thereafter by a sequence of highly susceptible hosts. The soil used for this transfer project was further characterized and compared to soils of different cropping origins.

The specific objectives of the project were (A) to determine if soil of a long-term oat monoculture at Münster, Germany (MOMS) was specifically suppressive, (B) to examine if susceptible crops were crucial for the success of suppressiveness transfer, and (C) to compare the suppressive potential and microbial communities of oat monoculture soil to two soils from intensive cereal cropping systems from conventional (CSCR) or organic farming (OSCR) backgrounds.

\section{Materials and Methods}

\section{Microplot studies}

Microplots of $1 \mathrm{~m}^{2}$ surface area at JKI Münster, Germany contained sandy soil $(90.2 \%$ sand, $6.1 \%$ silt, $6.1 \%$ clay, $2.2 \%$ O.M., $\mathrm{pH} 6.1$ ) and either (I) non-infested, (II) naturally infested with $H$. avenae (1478 \pm 280 eggs per $100 \mathrm{~g}$ soil before planting in 2010) or (III) infested with $H$. filipjevi (240 \pm 61 eggs per $100 \mathrm{~g}$ soil before planting in 2010). In March 2010, these plots were amended with a sandy loam soil (72.6\% sand, $13.6 \%$ silt, $13.8 \%$ clay, 1.3\% O.M., pH 6.6) from 
an adjacent field that had been infested with $H$. avenae (averages between 48 and 62 cysts per $100 \mathrm{ml}$ soil one year after infestation), and had been in oat monoculture (MOMS) at this location since 1968 (Steudel and Rumpenhorst, 1978). On average of samples from sand and loam soil, this field had ca. 3,000 eggs per $100 \mathrm{ml}$ of soil in the early years between 1971 and 1976 and anecdotal evidence reports of plant damage associated with the nematode. In 2010, only 35 eggs per $100 \mathrm{~g}$ of soil were found in the soil used for the plot amendments. Other plant-parasitic nematodes were observed but considered of minor importance for plant growth. No cereal cyst nematode-induced plant damage was observed during 2010, 2011 and 2012 (Westphal, unpublished). Entire microplots served as main plots: (1) heat-treated amendment $\left(180{ }^{\circ} \mathrm{C}\right.$ for 2 hr), and (2) non-heated amendment. An amount of 7.5 L of such soil amendment (equivalent of 5\% of $0-15 \mathrm{~cm}$ of the soil depth) was spread on the soil surface and incorporated into the $0-15 \mathrm{~cm}$ soil layer. Main plots were subdivided into $0.5 \mathrm{~m} \times 1.0 \mathrm{~m}$ subplots for planting to oat, Avena sativa L. 'Nordstern' (susceptible to H. avenae, resistant to H. filipjevi) or oat 'Sang' (susceptible to both CCN species), or to the CCN non-host sugar beet, Beta vulgaris L. 'Beretta'. Respective subplots were planted to sugar beet Beretta and oat Nordstern ( H. avenae plots; $\mathrm{n}=3$ ), sugar beet Beretta and oat Sang (H. filipjevi plots, heat-treated amendment $\mathrm{n}=4$, non-heated amendment $\mathrm{n}$ = 3), and Nordstern and Sang (non-infested controls, heated amendment $n=4$, non-heated amendment $n=3$ ). After cropping of sugar beet and oat in 2010, entire microplots were monocultured with different susceptible cereals until July 2013. Crops were: 10/2010 to 07/2011: winter wheat, Triticum aestivum L. 'Dekan'; 04/2012 to 08/2012: spring barley, Hordeum vulgare L. 'Hanka'; 10/2012 to 07/2013: winter wheat 'Dekan'. Every year prior to sowing and during the growing season, plots were fertilized according to regional recommendations with varying combinations of a multi-nutrient fertilizer $(12 \% \mathrm{~N}, 5.2 \% \mathrm{P}, 10.4 \% \mathrm{~K})$, ammonium nitrate $(27 \% \mathrm{~N})$ and phosphate potassium fertilizer, so-called thomaskali $(3.5 \% \mathrm{P}, 12.5 \% \mathrm{~K})$ to deliver annual $\mathrm{N}$ rates ranging from 60 to $200 \mathrm{~kg} \mathrm{ha}^{-1}$, $\mathrm{P}$ rates ranging from 80 to $120 \mathrm{~kg} \mathrm{ha}^{-1}$ and $\mathrm{K}$ rates ranging from 120 and $200 \mathrm{~kg} \mathrm{ha}^{-1}$. Sugar beet was seeded in one row with three planting sites; cereal seeds were sown by hand into 4 rows per sub-plot at a rate of 225 viable seeds per subplot. In June 2011 (winter wheat), root samples were collected from an area of $0.16 \mathrm{~m}^{2}$ in each subplot. Root fresh weight was measured, and the percentage of $\mathrm{CCN}$-induced excessive root proliferation at the nematode infection site "root knotting" (Smiley, 2016) was assessed. The percentage of $\mathrm{CCN}$-induced knots on the root system was categorized into four classes: 0,1 to 15 , 
16 to 50 and $>50 \%$. The experiment was terminated in 2014 because of take-all disease caused by Gaeumannomyces graminis var. tritici.

A second microplot experiment was conducted at the JKI location at Braunschweig, Germany. Microplots of $1 \mathrm{~m}^{2}$ surface had been established in 2011 with steamed silt loam soil (15.7\% sand, $70.7 \%$ silt, $13.6 \%$ clay, 1.5\% O.M., $\mathrm{pH} 7.3$ ), and cropped to spring wheat, Triticum aestivum 'Troll', in 2012. In April 2013, these plots were infested with $H$. avenae raised previously in pot culture on oat Nordstern in steam-pasteurized field soil. A soil amount of 3.2 kg containing approximately 1.5 million eggs (500 eggs/100g) was incorporated into the first 30$\mathrm{cm}$ soil depth. For non-infested control plots, only steamed field soil was incorporated, and no plant-parasitic nematode was expected. After infestation, microplots were amended with MOMS collected in January 2013 from JKI Münster either non-heated or heat-treated $\left(180{ }^{\circ} \mathrm{C}\right.$ for $\left.3 \mathrm{hr}\right)$. Microplot soil from the $0-15 \mathrm{~cm}$ layer was mixed with $7.5 \mathrm{~L}$ (equivalent of $5 \%$ of $0-15 \mathrm{~cm}$ of the soil depth) of one of the soil portions. The experiment was arranged as a split-plot design with four replicates. The experiment of a 3-factor factorial design consisted of the mainplots (a) noninfested or infested with $H$. avenae, (b) heat-treated MOMS or non-heated added, and (c) the subplots of $0.5 \mathrm{~m} \times 1.0 \mathrm{~m}$ planted to sugar beet 'Beretta' or to oat 'Nordstern'in the first year. From 09/2013 to 07/2014, plots were planted to winter wheat 'Dekan'. Both years prior to sowing, and during the growing season, plots were fertilized with varying combinations of mulitnutrient fertilizer $(12 \% \mathrm{~N}, 5.2 \% \mathrm{P}, 14.1 \% \mathrm{~K})$, ammonium nitrate $(27 \% \mathrm{~N})$ and thomaskali $(3.5 \%$ $\mathrm{P}, 12.5 \% \mathrm{~K}$ ) fertilizers to deliver annual $\mathrm{N}$ rates ranging from 60 to $120 \mathrm{~kg} \mathrm{ha}^{-1}$, $\mathrm{P}$ rates of $35 \mathrm{~kg}$ $\mathrm{ha}^{-1}$ and $\mathrm{K}$ rates of $133 \mathrm{~kg} \mathrm{ha}^{-1}$.

For both microplot experiments, plants were maintained following standard regional cultivation recommendations including watering as needed, and fungicide and insecticide applications. Plant growth parameters were monitored during the growing seasons but not further reported. Plants were harvested manually at crop maturity. Grain was gathered by threshing in a stationary machine (Baumann Saatzuchtbedarf, Waldenburg, Germany), cleaned in a Röber's Mini-Petkus machine (Röber Saatreiniger o.H.G., Minden, Germany) and weighed. Grain moisture content was determined with the Granomat moisture meter (Pfeuffer GmbH, Kitzingen, Germany). Grain yield results were adjusted to $14 \%$ moisture content. Fresh weight of sugar beet tops and washed taproots were determined but not further discussed in this report. 
To determine initial and final population densities of $H$. avenae and $H$. filipjevi, soil samples of twelve 2 -cm diameter cores were collected from the upper $30 \mathrm{~cm}$ with an Oakfield soil sampling tube from each of the sub-plots prior to sowing and after harvest. Subsamples of $400 \mathrm{~g}$ of fresh soil were used for extracting cysts by density centrifugation with $\mathrm{MgSO}_{4}(\mathrm{Müller}$, 1980). Cysts were counted under a binocular before being crushed in a custom-made tissue grinder to release the eggs and juveniles (J2; Müller, 1980). These nematode stages were suspended and diluted in different volumes of water, according to the number of cysts counted per sample (max. $1000 \mathrm{ml}$ used). Eggs and J2 were counted in duplicate under an inverted transmitted light microscope (63 x magnification), using $2 \times \mathrm{ml}$ aliquot, each containing between 50 and 200 specimens that were classified into healthy (normally developed, intact J2 inside) or diseased (abnormal development or obviously colonized by microbes). Population densities of cysts and eggs were reported per $100 \mathrm{~g}$ of soil.

\section{Environmental growth chamber experiment}

In January 2013, two climate chamber experiments were initiated in a randomized complete block design with four replicates each. In both experiments, freshly collected MOMS was tested for suppressive potential against $H$. avenae. A loamy sand soil from a field with limited frequency of cereal cropping originating from Braunschweig (77.4\% sand, 16.6\% silt, $6.1 \%$ clay, 1.7\% O.M., pH 6.5) was included as control (BNCC). In the second experiment, two loam soils from intensive cereal cropping fields from Schleswig-Holstein near Westerau, Germany were tested. One loam soil (43.7\% sand, $32.8 \%$ silt, $23.5 \%$ clay, $1.9 \%$ O.M., pH 6.8) had been managed organically with a rotation of red clover, winter wheat, spring barley, field peas, winter rape and triticale since 2009 (OSCR). The other loam soil (40.2\% sand, 36.6\% silt, 23.2\% clay, $2.2 \%$ O.M., $\mathrm{pH}$ 6.5) had been managed conventionally with constant rotation cycles of winter wheat, winter barley and winter rape since 2009 (CSCR). Each soil was divided into two portions; one was left untreated and the other one was steam heat-treated $\left(134{ }^{\circ} \mathrm{C}, 10 \mathrm{~min}\right)$ to test if reducing biotic components in the test soils impacted the female development (Westphal, 2005). Soil portions were placed in rectangular root observation chambers with a $18 \times 13 \mathrm{~cm}$ transparent side and $6 \mathrm{~cm}$ depth. The chambers were tilted in a 45-degree angle towards the transparent side, so roots grew preferentially against this side to allow for observation of the roots and developing females. At initiation, root chambers were adjusted to soil moisture content 
of $15 \%$. Spring barley 'Hanka' (susceptible to $H$. avenae) was planted at six germinated seeds per chamber. Seeds were surface-disinfested in 5\% of a commercial bleach solution $(2.8 \%$ $\mathrm{NaOCl}$, DanKlorix, Colgate-Palmolive $\mathrm{GmbH}$, Schmelz, Germany) for 2 min and throroughly rinsed with water before incubation for germination on moist filter paper for two days. One week after sowing, root observation chambers were inoculated with 10,000 J2 of $H$. avenae each. A nematode suspension of $14 \mathrm{ml}$ per root chamber was pipetted into three inoculation holes per chamber. Before sowing, soil samples of $2 \mathrm{ml}$ were taken from each chamber and stored at $20{ }^{\circ} \mathrm{C}$ for microbial community analysis.

The experiments were maintained under artificial light with a day and night cycle of 16/8 $\mathrm{hr}$ at temperatures of $15 / 10^{\circ} \mathrm{C}$ during the first three weeks after sowing, $17 / 12^{\circ} \mathrm{C}$ for week 4 and 5, 19/14 ${ }^{\circ} \mathrm{C}$ for week 6 and $7,21 / 16^{\circ} \mathrm{C}$ for week 8 and 9 , and $23 / 17{ }^{\circ} \mathrm{C}$ until the experiments were terminated. The root observation chambers were watered daily with tap water and fertilized with $5 \mathrm{ml}$ nutrient solution $(5.3 \% \mathrm{~N}, 3.9 \%$ P, $19.7 \%$ K; Steiner, 1968) once a week. Starting 53 days post inoculation (dpi), females visible on the root surface were counted weekly. At 67 dpi, six individual females were carefully hand-picked from the roots of each chamber in a nondestructive way with the help of forceps, washed with sterile water and stored at $-20{ }^{\circ} \mathrm{C}$ for microbial community analysis. At $95 \mathrm{dpi}$, the visible root length per chamber was determined using the line intersection method (Tennant, 1975).

DGGE analysis of the amplified bacterial and fungal amplicons from soil, females and cysts.

To evaluate the transfer of potential antagonistic microbes from the oat monoculture soil (MOMS) into the receiving microplot soils at Braunschweig, and their establishment after cropping of a nematode susceptible host, microbial communities of MOMS soil and the transfer microplots were compared by denaturing gradient gel electrophoresis (DGGE; Muyzer et al., 1993).

Because the cropping system is thought to affect the soil microbial communities and thereby the soil suppressiveness, microbial communities of MOMS soil, soils from intensive (CSCR, OSCR) and infrequent cropping of cereal (BNCC), and from females raised in these soils, were compared by DGGE.

To test the potential acquisition of microbes from the MOMS soil by females from the receiving microplots at Braunschweig and by females raised in the root chambers filled with this 
soil, microbial communities of females from the root chambers or cysts from microplots were compared by DGGE.

DNA extracted from (A) soil collected at the microplots in Braunschweig after amendment with MOMS soil (before sowing) and after harvest in 2013, (B) Heterodera avenae cysts extracted from the microplots at Braunschweig at harvest in 2013 and 2014, and (C) soil sampled before sowing and females picked 67 dpi from the root observation chamber experiment, was used for analysis of 16S rRNA bacterial gene fragments and fungal internal transcribed spacers (ITS) by DGGE.

DNA extraction and PCR amplification of bacterial 16S rRNA gene and fungal ITS fragments from soil and $H$. avenae females and cysts followed by DGGE analysis

Total DNA from soil, from the egg content of 10 cysts per sub-plot, or from the egg content of six females per root observation chamber, respectively, was extracted with the FastDNA SPIN Kit for Soil by using the FastPrep-24 bead beating system (MP Biomedicals, Santa Ana, CA, USA) according to manufacturer's recommendations. In every step, extraction and amplification results for positive DNA were checked by electrophoresis ( $80 \mathrm{~V}, 45 \mathrm{~min}$ ) on a 0.8 - $1 \%$ - agarose gel followed by ethidium bromide staining, and viewing under UV light. DNA was stored at $-20{ }^{\circ} \mathrm{C}$ between the different steps if necessary.

The bacterial specific primers F984GC and R1378-1401 were used for amplification of 16S rRNA gene fragments (Heuer et al., 1997). PCR reactions were performed in $25 \mu$ reaction volumes, containing $5 \mu \mathrm{l}$ 5x GoTaq buffer, $2.5 \mu 12 \mathrm{mM}$ dNTPs, $3.75 \mu 125 \mathrm{mM} \mathrm{MgCl}_{2}, 2 \mu 150 \%$ (w/v) acetamide, $0.5 \mu \mathrm{l} 10 \mu \mathrm{M}$ of each primer, $0.125 \mu \mathrm{l} \mathrm{GoTaq}$ polymerase $5 \mathrm{U} / \mu \mathrm{l}$ (Promega, Madison, Wisconsin, USA), and $1 \mu \mathrm{l}$ template DNA. After 5 min of denaturation at $94{ }^{\circ} \mathrm{C}, 35$ thermal cycles including $1 \mathrm{~min}$ at $94{ }^{\circ} \mathrm{C}, 1 \mathrm{~min}$ at $53{ }^{\circ} \mathrm{C}$ and 2 min at $72{ }^{\circ} \mathrm{C}$ were performed, followed by a final extension at $72{ }^{\circ} \mathrm{C}$ for $10 \mathrm{~min}$.

The fungal internal transcribed spacer (ITS) fragments were amplified using a nested PCR with primer pairs ITS1F/ITS4 and ITS1FGC/ITS2 according to the PCR conditions described by Weinert et al. (2009), but including $0.1 \mathrm{~g} / \mathrm{l} \mathrm{BSA}$ in the first PCR. For both reactions, 0.625 U True-Start Taq DNA polymerase (Thermo Scientific, Schwerte, Germany) per $25 \mu \mathrm{l}$ reaction was used. An aliquot of $2 \mu \mathrm{l}$ of the first stage PCR products was used as template for the subsequent PCR that was run for 30 cycles. 
PCR products were separated by DGGE based on the protocol of Weinert et al. (2009). Polyacrylamide gels with denaturing gradients of $46.5-65 \%$ and $23-58 \%$ (100\% denaturant was defined as $7 \mathrm{M}$ urea and 40\% de-ionized formamide) were used for 16S rRNA and ITS fragments of bacteria and fungi, respectively, for electrophoresis on a IngenyphorU system (Ingeny, Goes, The Netherlands). The volume of PCR products loaded on the gel was adjusted according to the amplicon concentration as assessed by agarose gel electrophoresis ( 3 to $10 \mu \mathrm{l}$ ). The electrophoresis was run in 1x tris-acetate-EDTA buffer for $17 \mathrm{~h}$ at $58{ }^{\circ} \mathrm{C}$ and $140 \mathrm{~V}$ in the case of PCR-amplified 16S rRNA gene fragments, and for $18 \mathrm{~h}$ at $60{ }^{\circ} \mathrm{C}$ and $100 \mathrm{~V}$ for ITS fragments. The gels were silver stained (Heuer et al., 2001), dried at room temperature and scanned with a digital flat bed scanner.

\section{Statistical analysis}

Analysis of variance was carried out using a factorial split-plot model to analyze microplot data from Münster (control $\mathrm{n}=3$ or $4, H$. avenae $\mathrm{n}=3$, H. filipjevi $\mathrm{n}=3$ or 4 ) and Braunschweig $(\mathrm{n}=4)$, respectively. At Münster, the main factor was assigned to random plots of nematode infestation (non-infested, H.avenae and $H$. filipjevi), the factor to soil amendment (heat-treated, non-heated), and the sub factor to the cultivar (sugar beet 'Beretta', oat 'Nordstern', oat 'Sang'), that were arranged in split-plot design. In Braunschweig, main factores were: (i) nematode (non-infested, H.avenae), and (ii) amendment (heat-treated, non-heated), and the subfactor was: cultivar (sugar beet 'Beretta', oat 'Nordstern'). Analyses were performed for each cereal crop separately using the MIXED procedure of SAS (version 9.4, SAS Institute, Cary, NC, USA). To compare nematode populations among cereal crops, each crop was analyzed as strip factor within the factorial split-plot model. Count data was $\log _{10}$-transformed, whereas percentages were arcsine-transformed. Specific comparisons were tested with Least Square Means (LSM) estimates, and their p-values adjusted with the Edwards and Berry's simulation method. Cereal yields were compared within years, and as relative yield to the year's average yield (relative yield $=100 \cdot \mathrm{x} /$ average yield ${ }_{\text {year }}$ ) to enable comparisons over the different cereal crop species. In the root observation chamber experiments, counts of females were analyzed as repeated measurements using the GLIMMIX procedure. In addition within each observation time, the relative numbers of females within soil source were computed for the heated soil portions as relative numbers of the average of those in the non-heated soil $\left(f(x)=100 \bullet\left(f_{e m a l e s}\right.\right.$ heated $/$ average 


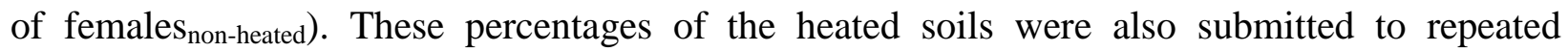
measure analysis in the GLIMMIX procedure. Statistical significance was set at $P \leq 0.05$. Results obtained from MIXED are presented as means \pm se. Results obtained from GLIMMIX are presented as back-transformed lsmeans \pm 1smse. Cluster analysis of bacterial and fungal community profiles was conducted with the software package GelCompar II 6.5 (Applied Maths, Gent, Belgium) to evaluate the percentage of similarity shared among samples. Lanes were normalized and similarities for each pair of lanes within a gel were determined using the Pearson correlation. A cluster analysis was performed by the un-weighted pair group method using arithmetic averages (UPGMA).

\section{Results}

\section{Microplot studies}

To test the specific suppressiveness of an oat monoculture soil (objective A), and to examine if susceptible crops were crucial for the success of suppressiveness transfer (objective B), CCN population densities and yield parameters were evaluated under cropping of susceptible hosts, after a first cropping cycle of a susceptible and a non-host crop, at two different locations.

\section{Nematode population densities}

After amendment with non-heated MOMS soil, no reductions of $H$. avenae or $H$. filipjevi cysts and eggs final population densities compared to amendment with the equivalent heated soil were found at Münster or at Braunschweig. Thus numbers averaged across the amendment treatments were presented.

At Münster. When comparing final population densities between the different cereals cropped from 2010 to 2013, the number of $H$. avenae cysts in oat 'Nordstern' sub-plots decreased by $60 \%$ from winter wheat (2011) to winter wheat (2013; Fig. 3.1A). In sugar beet sub-plots, no significant changes along this time axis were found. In the number of eggs, no significant changes were observed (Fig. 3.1C). Percentage of diseased eggs increased 6.1- and 2.4-fold from oat (2010) to spring barley (2012) in oat and sugar beet sub-plots, respectively, and 6.0- and 6.1-fold from winter wheat (2011) to spring barley in oat and sugar beet sub-plots, respectively (Fig. 3.1E). For H. filipjevi where oat had been cropped, cysts increased 2.2-fold 
from oat (2010) to spring barley (2012; Fig. 3.1B). Where sugar beet had been grown, cysts increased 2.2-fold from oat (2010) to winter wheat (2011), but then decreased by $70 \%$ to winter wheat (2013; Fig. 3.1B). The numbers of total eggs increased 7.3-fold from oat (2010) to spring barley (2012) in oat sub-plots, whereas no significant change occurred in sugar beet sub-plots $(P$ $=1.0$; Fig. 3.1D). Percentage of diseased eggs increased 6.5-fold from oat to spring barley (2012) in oat and sugar beet sub-plots, and 4.3- and 5.6-fold from oat to winter wheat (2013) in oat and sugar beet sub-plots, respectively (Fig. 3.1F).

Non-infested control plots had nematode numbers close to the detection level until the last year of the study.

At Braunschweig. When comparing $H$. avenae final populations between oat (2013) and winter wheat (2014), number of cysts in oat sub-plots did not change significantly $(P=0.3180$; Fig. 3.2A), but increased 3.7-fold $(P<0.01)$ where sugar beet had been cropped (Fig. 3.2A). Numbers of total eggs did not change significantly in oat sub-plots ( $P=0.8692$; Fig. 3.2B), but increased 29.1-fold under wheat in sugar beet sub-plots. Percentage of diseased eggs remained similar in oat sub-plots $(P=0.9128$; Fig. 3.2C), but decreased in sugar beet sub-plots $(P=$ 0.0237; Fig. 3.2C). Non-infested control plots had nematode numbers at the detection level during this two-year study.

\section{Plant growth and yield}

After amendment with untreated MOMS soil, with only one exception, no changes in plant growth or cereal yield compared to amendment with the equivalent heated soil were detected at Münster or at Braunschweig. When comparing the effects of the cropping sequences, effects on various yield components were summarized in the grain yield.

At Münster. Relative cereal yields across the different rotation treatments ranged from 85 to $108 \%$ of the the annual averages but none of the comparisons were significantly different (Table 3.1). In the oat crop of 2010, oat Nordstern yielded similarly in $H$. avenae and control plots, but Sang yielded greater in H. filipjevi than the corresponding control sub-plots, producing $140 \mathrm{~g}$ more grain (Table 3.1).

In winter wheat (2010-2011) in H. avenae oat sub-plots, grain yield compared to control plots was not significantly different (Table 3.1). After oat Nordstern but not after sugar beet, the percentage of wheat roots with 1 to $15 \%$ knotting was higher in plots with the heat-treated $(29 \pm$ 
2) than with the non-heated amendment $(13 \pm 5 ; P=0.0478)$. Heterodera filipjevi plots with oat Sang had similar yields as the respective controls (Table 3.1).

In spring barley (2012) and winter wheat (2012-2013), no significant differences were observed, except that in spring barley, grain yield was larger following oat than in sugar beet sub-plots for $H$. filipjevi $(P=0.0559$; Table 3.1).

At Braunschweig. In 2013, treatments had limited detectable impacts on yield parameters. Grain yield of oat Nordstern was significantly reduced in H. avenae $(642 \pm 42)$ compared with non-infested control plots ( $905 \pm 19$; data not shown).

In winter wheat (2013-2014), treatments had limited effects on yields. Only grain yield was greater in $H$. avenae plots amended with non-heated oat monoculture soil $(988 \pm 12)$ than in plots with the heat-treated amendment $(881 \pm 42$; data not shown $)$.

\section{Female population development of Heterodera avenae in root observation chambers}

To compare the suppressive potential of oat monoculture soil (MOMS) and two soils from intensive cereal cropping systems (OSCR, CSCR) and the non-cereal cropped control (BNCC; objective C), H. avenae female populations developed in these soils were monitored and compared.

In the first root observation chamber experiment with MOMS and BNCC, numbers of females averaged for the observation period were significantly higher in the heated $(26 \pm 5)$ than in the non-heated soil $(5 \pm 1)$ for MOMS soil (data not shown). For the control BNCC soil, no significant differences were observed between the treatments ( $P=0.3376$; data not shown). In the heat-treated soils, season average numbers of females were similar in both soils $(P=0.5489$; data not shown), but in the non-heated portions, significantly more females were found in BNCC (17 \pm 4$)$ than in MOMS ( $5 \pm 1$; data not shown). In the heat-treated MOMS soil, females increased 2.5-fold from $53 \mathrm{dpi}$ to $61 \mathrm{dpi}$ and then remained similar until the last monitoring (95 dpi, data not shown).

The second root observation chamber experiment included the two soils from intensive cropping of cereal (OSCR and CSCR) and MOMS and BNCC. On average of the monitoring time, significantly more females were counted in heat-treated than in non-heated soil of MOMS (heat-treated: $29 \pm 9$, non-heated: $8 \pm 3$; Fig. 3.3A) and CSCR (heat-treated: $17 \pm 6$, non-heated: $6 \pm 2 ; P=0.0311$; Fig. 3.3B). In this comparison, differences between heated and non-heated 
portions of OSCR (heated: $18 \pm 6$, non-heated: $8 \pm 3$; $P=0.0789$; Fig. 3.3B) were only numerical. In BNCC these numbers were similar as well (heated: $38 \pm 12$, non-heated: $20 \pm 7 ; P$ $=0.1733$; Fig. 3.3A). In the non-heated soils, season-average numbers of females in BNCC (20 \pm 7) were significantly higher than in MOMS $(8 \pm 3)$, and the soils from intensive cereal cropping (OSCR: $8 \pm 3$; CSCR: $6 \pm 2$ ) whereas OSCR and CSCR were similar. Averaged across treatment, maximum numbers were observed at 61 dpi $(30 \pm 8)$ in BNCC, but no significant overall variation was observed from the first ( $53 \mathrm{dpi}$ ) to the last monitoring (95 dpi; Fig. 3.3A). In MOMS, OSCR and CSCR, female numbers increased up to 2.5-fold between 53 dpi and 67 dpi to then remain similar until the last monitoring occasion (95 dpi; Fig. 3.3A,B). On average of all monitoring times, the relative female numbers were about 3.5 times higher in the heated portions of MOMS than in the non-heated portion (data not shown). In the other soils, numbers only about doubled in the heated compared to the non-heated portions (data not shown). This rate difference was significant between MOMS and the other soil origins.

DGGE analysis of the amplified bacterial and fungal amplicons from soil, females and cysts.

Bacterial fingerprints of soil collected from MOMS and Braunschweig microplots after the soil transfer prior to sowing in 2013 had few intense bands representing bacterial populations with increased abundance, and high numbers of faint bands, indicating less dominant ribotypes (Fig. 3.4A). Within MOMS soil, different patterns and clusters distinguished the heat-treated from the non-heated portion, the latter presenting more bands (Fig. 3.4). Patterns of microplot soil were clearly distinct from heat-treated MOMS soil, but shared a common dominant band (band A) and a similarity of 77\% with non-heated MOMS (Fig. 3.4). Within the microplot soils, neither a separation between control and $H$. avenae-infested plots, nor between amendments was observed (Fig. 3.4). In fungal communities, a large number of dominant bands was observed in MOMS and microplot soils, with a highly intense band with identical electrophoretic mobility (band A) present in all samples, irrespective of the amendment (Fig. 3.5A). MOMS formed a separate cluster with a similarity of $86 \%$ among replicates (Fig. 3.5B). Due to the absence of clear and characteristic patterns within microplot soils, no differences could be found between control and $H$. avenae-infested plots or between amendments, and no comparison between MOMS and non-heated microplot soils could be established (Fig. 3.5). 
In DGGE fingerprints of bacterial communities of soil collected from Braunschweig microplots after harvest in 2013, a highly uniform profile characterized mostly by faint bands(data not shown)and a high similarity among the majority of the samples in the cluster analysis (Fig. 3.6A) indicated the absence of a nematode, amendment or cultivar effect. Fungal DGGE displayed a complex pattern with a larger number of dominant bands distributed with a high variability among replicates (data not shown), thus not allowing a clear detection of amendment or cultivar specific ribotypes (after oat or after sugar beet) and the formation of separated clusters for the control and $H$. avenae plots, the two amendments, and the two crops (oat vs sugar beet; Fig. 3.6B).

Despite to the presence of some dominant bands shared by most samples in fungal fingerprints from cysts extracted at harvest in 2013 and 2014 from the Braunschweig microplots amended with MOMS soil, and from females raised in chambers filled with the non-heated portion of this soil, (data not shown), a high variability of a large number of dominant bands among replicates did not allow the identification of specific ribotypes common to females raised in non-heated MOMS soil and cysts from microplots amended with the non-heated portion of this soil (Fig. 3.6C). Fungal DGGE of females showed several highly dominant bands, but a high degree of variability among replicates did not allow comparison and formation of separate clusters distinguishing treatments and soils within a treatment (Fig. 3.6D).

Clearly different DGGE patterns and clusters of bacterial communities of soil collected after filling the root observation chambers, distinguished the heat-treated from the non-heated soils (Fig. 3.7A, B). The non-heated soil was dominated by a high number of faint bands, but the heat-treated soil profile showed an extremely reduced number of bands, with a highly dominant band present in all samples (band A; Fig. 3.7A). Although each of the four non-heated soils formed a separate cluster, similarities of ca. 90\% and 95\% were shared among heat-treated and non-heated soils, respectively (Fig. 3.7B). As in the bacterial DGGE, two different fungal profiles distinguished heat-treated from non-heated soils in two separate clusters (Fig. 3.7C). The heat-treated soils were characterized by the presence of highly dominant bands, but with different electrophoretic mobility among replicates, which was reflected in the absence of separate clusters for each soil (Fig. 3.7C), so that a comparison between heat-treated soils could not be made. Non-heated soils revealed a larger number of dominant bands (data not shown), and clustered separately from each other (Fig. 3.7C). Soils from MOMS and intensive cereal 
cropping (OSCR and CSCR) shared a 57\% similarity and clustered apart from the control soil (BNCC), to which they only shared 36\% similarity (Fig. 3.7C). The two soils from intensive cereal cropping (OSCR and CSCR) showed a higher similarity with each other than with the other soils (Fig. 3.7C).

Fingerprints from bacterial communities present in the female egg content were grouped into two different clusters, one including the females from the heat-treated and the other the females from the non-heated soils (Fig. 3.8B). However, this distinction was probably due to the fact that the non-heated soil was mostly characterized by weak bands, in contrast to the heattreated soil, where more dominant bands were observed, including three bands of high intensity (B, C, D) present in all soils (Fig. 3.8A). No evidence for an influence of the soil was found within females from heat-treated soils. Due to the high number of weak bands and a high variability among replicates in the profile from females from non-heated soil, a comparison between soils was not possible. A dominant band with identical electrophoretic mobility (band A) was common to all samples in both treatments, but the increased intensity within females from non-heated soils, indicated the presence of an enriched ribotype in this treatment (Fig. 3.8A).

\section{Discussion}

In microplot studies, soil amendment with non-heated oat monoculture (MOMS) soil to nematode-conducive soils coupled with monoculture of susceptible hosts did not lead to a decline of nematode population densities. The requirement of transferability for specific suppressiveness was not fulfilled. Irrespective of soil amendment and after extended monoculture, a significant increase in percentages of diseased eggs of $H$. avenae and $H$. filipjevi was found. The hypothesis of specific suppressiveness of the oat monoculture soil was not supported (objective A). In contrast, this monoculture soil (MOMS) was highly suppressive to populations of $H$. avenae females compared to a soil of limited frequency of cereal cropping in environmental growth chamber experiments. Suppressiveness was inherent to MOMS soil, at the very least a general suppressiveness could be attested. In fact in the growth chamber experiment, heating of the soil increased reproduction of inoculated nematodes 3.5-fold in MOMS soil compared to only doubling in the other soils. In the presented study, cropping of the susceptible host oat or the non-host sugar beet in the first year did not alter the population dynamics of the 
nematode (objective B). The absence of common dominant bacterial and fungal ribotypes specific to the MOMS soil and plots with the non-heated portion of this amendment, before and after cropping of susceptible oat, suggested that antagonists failed to establish. There are several examples of suppressive soils that could establish successfully after transfer into microbially perturbed soils (Mankau, 1975; Kluepfel et al., 1993; Westphal and Becker, 2000). There are only a few reports on transfer of suppressiveness into untreated soils. In these, higher amounts of amendments were needed for the successful establishment of antagonists (Stirling and Kerry, 1983; Westphal and Becker, 2000). It is likely that a lack of soil receptivity due to microbiostasis (Ho and Ko, 1982) or competition exhibited by the resident microflora, prevented the successful establishment of potential antagonists. Monfort et al. (2006) found that all nematophagous fungi were inhibited when growing in non-sterilized soil, irrespective of the percentage of nonsterilized soil used. Since microbial competition has been considered an impediment in attempts to establish biocontrol organisms (Baker and Cook, 1974; Jaffee et al., 1996), perturbation of the microbiota in the receptive soil through autoclaving or biocidal treatments, have been considered crucial for the successful transfer of suppressiveness (Westphal, 2005). Highly abundant bacterial and fungal ribotypes common to microplots that received either the heat-treated or the non-heated amendment indicated the presence of dominant populations originally present in microplot soil. Since communities are generally dominated by few species having the largest total biomass (Odum, 1954; Mariotte, 2014), these resident populations might have displaced less dominant antagonists present in the amendment. However, microorganisms responsible for disease suppressiveness do not necessarily have to be highly abundant. For example Lysobacter spp., that was suggested to play a key role in disease suppressiveness towards Rhizoctonia, only represented $0.03 \%$ of the bacterial population, and thus was not visualized by DGGE (Postma et al., 2008).

Irrespective of the soil amendment, the percentage of diseased eggs increased significantly during monocropping of susceptible cereal hosts, and yield was not constrained compared to the non nematode-infested control, suggesting the development of some nematodesuppressive effect. From these observations, it can be inferred that cultivation of susceptible crops was beneficial for antagonists originally present in the microplots, and thereby crucial for the establishment of soil suppressiveness (objective B). Kerry et al. (1982) found that fungal parasites on females and eggs were responsible for the decline of $H$. avenae under cereal 
monocultures. However, at the Münster location with much longer cropping history, an increase in diseased eggs was also observed in sugar-beet plots, where almost no increase in populations of $\mathrm{CCN}$ was observed, suggesting that cropping of susceptible hosts after growing a non-host for one cropping period also leads to the development of soil suppressiveness.

Results obtained from the environmental growth chamber experiment revealed a suppressive potential of oat monoculture (MOMS) and intensive cereal cropping soils (OSCR and CSCR) against $H$. avenae (objective C). Lower numbers of females in non-heated compared to heat-treated soils in the oat monoculture and intensive cereal cropping soil (conventional farming) indicated a suppressive effect of biological nature (Westphal, 2005). In DGGE fingerprints of non-heated soils, a strong increased of bacterial and fungal ribotypes was observed compared to heat-treated soils. Whether this increased number of ribotypes corresponded to microorganisms responsible for reducing the number of females remains to be investigated.

Within non-heated soils, the level of female populations was reduced in the oat monoculture (MOMS) soil and the two soils from intensive cropping of cereal (CSCR, OSCR) compared to the soil from a limited frequency of cereal cropping (BNCC). However, before attributing this suppressive effect to a biotic factor, the different textures of these soils should be taken into account, since it is known that population levels of a nematode are affected by abiotic factors of soil texture and pore size that influence nematode mobility (Rode, 1962; Wallace, 1968; Prot and Van Gundy, 1981). The presence of pores more suitable for nematode movement in sandy soils may explain the higher densities of nematodes generally observed in light sandy soils than in heavy clay soils (Southey, 1956; Rode 1962; Fidler and Bevan, 1963; Wallace, 1968). Prot and Van Gundy (1981) found that in natural soils the percentage of Meloidogyne incognita second-stage juveniles capable of migrating $20 \mathrm{~cm}$ and penetrating the roots decreased when the percentage of clay and silt increased. On the other hand, by absorbing root exudates or bacterial secondary metabolites, clay particles can form a concentration gradient that aid nematodes to locate the roots (Prot and Van Gundy, 1981). In the current study, numbers in nonheated soils were similar among the different soil sources except for the BNCC soil, but the heated portions of the oat monoculture allowed much more reproduction of the nematode. This was illustrated by relating the numbers in the heated soil to those in non-heated portions of the same soil. This indicated a probably much more conducive edaphon of this soil than the finer 
textured soils of different origin. It also suggests the existence of varying degrees of suppressiveness against Heterodera avenae, namely very strong in oat monoculture soil versus detectable in soils from other sources.

In addition to a similar suppression in the level of female populations in non-heated soils from the oat monoculture and from intensive cropping of cereal, a similarity between these soils was also observed in fungal communities, where they clustered together and apart from the control soil (objective C). This suggested that the frequent presence of the host is necessary for the development of suppressiveness, but that the latter is not exclusive for a monoculture of the host. According to Cook and Baker (1983) the pathogen and a susceptible host have to be present for suppressiveness to develop. However, there are some examples of suppressiveness when cropping resistant host plants (Sneh et al, 1987; Westphal and Becker, 2001) and under crop rotations that alternated with non-hosts (Xing and Westphal, 2006). It appears that in those studies a one-season break crop did not reduce nematode suppressivness. Since plant species and genotype play an important role in shaping soil and rhizosphere microbial communities (Smalla et al., 2001; Mazzola, 2004; Berg and Smalla, 2009), rotations with favorable non-host crops may not only maintain the suppressiveness developed during cropping of susceptible hosts, but also induce it by altering the soil microbial communities, stimulating specific microbes that can suppress the pathogen (Mazzola, 2004). Several studies have pointed out the importance of agronomic practices such as permanent grassland versus arable land under rotation, biological amendments, and different cropping systems in influencing the microbial communities, and thereby the degree of soil suppressiveness (Van Elsas et al., 2002; Larkin, 2008; Larkin et al., 2006, 2010).

In non-heated portions of the different soils, those from organic farming (OSCR) and conventional farming (CSCR) had similar ability to suppress the female populations of $H$. avenae, and soil bacterial and fungal communities were very similar. Although we cannot make extrapolations from the data from a limited number of fields sampled, the data suggested effects of management practices, e.g. cropping system rather than farming system (conventional versus organic), on the pathogen populations and the soil microbial communities alike. Doran et al. (1987) found that the type of crops grown in a rotation was the major factor regulating soil microbial populations and activities under conventional and organic managed systems. After evaluating the variability of fungal abundance in soils under organic and conventional farming, 
Elmholt and Labouriau (2005) concluded that management likely accounted for much of the observed fungal variability, irrespective of the farming system. However, under identical crop rotations, Hartmann et al. (2006) and Esperschütz et al. (2007) showed a clear influence of the farming system on the structural diversity of soil microbial communities. Studies comparing microbial communities from organic and conventional farming soils and their effect in soil suppressiveness have also yielded inconsistent results (Workneh et al., 1993; Workneh and Van Bruggen, 1994; Knudsen et al., 1999; reviewed by Timper, 2011).

Most fungal DGGE fingerprints, especially those associated with females were characterized by a high degree of variability among replicates, impeding in many cases specific comparisons. Several other studies also reported a high internal variability in fungal fingerprints (Klamer et al. 2002; Girvan et al. 2004; Costa et al. 2006). This may have been the result of a more heterogeneous distribution of fungi compared to bacteria as previously suggested (Costa et al., 2006). A high degree of internal variability was also found in DGGE fingerprints of microbial communities associated with Globodera pallida females (Eberlein et al., 2016). It is most likely that only a few microbes had the chance to penetrate into the female's body and establish successfully in this specific niche. A low abundance of specific bacterial and fungal ribotypes prevented them to be PCR-amplified, meaning that no stable and reproducible populations were associated with the females developed in these soils.

Bacterial DGGE fingerprints dominated by faint bands indicating a high evenness of many equally abundant populations were also observed by Smalla et al. (2001) for bulk soils in contrast to rhizosphere profiles that displayed a lower number of faint bands but several strong bands, indicating bacterial populations with increased abundance in the vicinity of the roots.

\section{Conclusion}

In these studies, monoculture of host plants resulted in increases of percentages of diseased eggs in $H$. avenae and $H$. filipjevi. Establisment of specific soil suppressiveness by mono-cropping of nematode hosts was not supported by the concomitant amendment with oat monoculture soil. A differential of one year of non-host cropping did not alter the emergence of diseased eggs that points to the presence of suppressive factors. While the oat monoculture soil had the highest level of suppressiveness the similarity of soils from intensive cereal cropping on the ability to suppress a female population of $H$. avenae was mirrored in microbial communities. 
This finding illustrated the foremost importance of cropping system on CCN populations and on soil microbial communities. Careful combination of crop rotation with soil suppressiveness benefits offer sustained management strategies of this nematode.

\section{Acknowledgments}

The authors thank Conicyt for financial support of the first author. The technical assistance of J. Banyari, T. Blöthe-Hartmann, I. Dörries, H. Grosse-Lengerich, F. Lange and A. Windt is greatly appreciated. The authors thank J. Moos and H.M. Paulsen (Thünen-Institute of Organic Farming, Westerau) for provision of soil samples. The provision of seed lots and support by several cereal breeders is appreciated. The experimental part of this study was conducted during the employment of A. Westphal with the Julius Kühn-Institut, writing and manuscript handling was conducted from his permanent address at the University of California.

\section{References}

Baker, K.F., Cook, R.J., 1974. Biological control of plant pathogens. American Phytopathological Society, St. Paul, Minnesota.

Berg, G., Smalla, K., 2009. Plant species and soil type cooperatively shape the structure and function of microbial communities in the rhizosphere. FEMS Microbiol. Ecol. 68, 1-13.

Borneman, J., Becker, J.O., 2007. Identifying Microorganisms Involved in Specific Pathogen Suppression in Soil. Annu. Rev. Phytopathol. 45, 153-172.

Chen, S.Y., 2007. Suppression of Heterodera glycines in soils from fields with long-term soybean monoculture. Biocontrol. Sci. Technol. 17, 125-134.

Costa, R., Götz, M., Mrotzek, N., Lottmann, J., Berg, G., Smalla, K., 2006. Effects of site and plant species on rhizosphere community structure as revealed by molecular analysis of microbial guilds. FEMS Microbiol. Ecol. 56, 236-249.

Cook, R.J., Baker, K.F., 1983. The Nature and Practice of Biological Control of Plant Pathogens. American Phytopathological Society, St. Paul, Minnesota. 
Doran, J.W., Fraser, D.G., Culik, M.N., Liebhard, W.C., 1987. Influence of alternative and conventional agricultural management on soil microbial processes and nitrogen availability. Am. J. Alt. Agric. 2, 99-106.

Eberlein, C., Heuer, H., Vidal, S., Westphal, A. 2016. Microbial communities in Globodera pallida females raised in potato monoculture soil. Phytopathology 106, 581-590.

Elmholt, S., Labouriau, R., 2005. Fungi in Danish soils under organic and conventional farming. Agric. Ecosyst. Environ. 107, 65-73.

Esperschütz, J., Gattinger, A., Mäder, P., Schloter, M., Fließbach, A., 2007. Response of soil microbial biomass and community structures to conventional and organic farming systems under identical crop rotations. FEMS Microbiol. Ecol. 61, 26-37.

Fidler, J.H., Bevan, W.J., 1963. Some soil factors influencing the density of cereal root eelworm (Heterodera avenae Woll.) populations and their damage to the oat crop. Nematologica 9, 412-420.

Gair, R., Mathias P.L., Harvey P.N., 1969. Studies of cereal nematode populations and cereal yields under continuous or intensive culture. Ann. Appl. Biol. 63, 503-512.

Girvan, M.S., Bullimore, J., Ball, A.S., Pretty, J.N., Osborn, A.M., 2004. Responses of active bacterial and fungal communities in soils under winter wheat to different fertilizer and pesticide regimens. Appl. Environ. Microbiol. 70, 2692-2701.

Grosse, E., 2006. Investigations on cereal cyst nematodes in Germany. Mitt. Biol. Bundesanst. Land- Forstwirtsch 404, 67-74.

Hajihasani, A., Maafi, Z. T., Nicol, J. M., Rezaee, S., 2010. Effect of the cereal cyst nematode, Heterodera filipjevi, on wheat in microplot trials. Nematology 12, 357-363.

Hartmann, M., Fliessbach, A., Oberholzer, H.R., Widmer, F., 2006. Ranking the magnitude of crop and farming system effects on soil microbial biomass and genetic structure of bacterial communities. FEMS Microbiol. Ecol. 57, 378-388.

Heuer, H., Krsek, M., Baker, P., Smalla, K., Wellington, E.M., 1997. Analysis of actinomycete communities by specific amplification of genes encoding16SrRNA and gel-electrophoretic separation in denaturing gradients. Appl. Environ. Microbiol. 63, 3233-3241.

Heuer, H., Wieland, G., Schoenfeld, J., Schoenwaelder, A., Gomes, N.C.M., Smalla, K., 2001. Bacterial community profiling using DGGE or TGGE analysis, in: Rouchelle, P. (Ed.) 
Environmental Molecular Microbiology: Protocols and Applications. Horizon Scientific Press, Wymondham, UK, pp. 177-190.

Ho, W.C., Ko, W.H., 1982. Characteristics of soil microbiostasis. Soil Biol. Biochem. 14, 589593.

Holgado, R., Rowe, J., Andersson, S., Magnusson, C., 2004. Electrophoresis and biotest studies on some populations of cereal cyst nematode, Heterodera spp. (Tylenchida: Heteroderidae). Nematology 6, 857-865.

Jaffee, B.A., Muldoon, A.E., Westerdahl, B.B., 1996. Failure of a mycelial formulation of the nematophagous fungus Hirsutella rhossillensis to suppress the nematode Heterodera schachtii. Biol. Control 6, 340-346.

Kerry, B.R., 1987. Biological control, in: Brown, H.R., Kerry, B.R. (Eds.) Principles and Practices of Nematode Control in Crops. Academic Press, Sydney, Australia. pp 233-263.

Kerry, B.R., Anderson, S., 1984. Nematophthora gynophila och Verticillium chlamydosporium, swampparasites på cystnematoder, vanliga I svenska jordar med förkomst av stråsädescynstnematoder. Vaxtskyddsnotiser 47, 79-80.

Kerry, B.R., Crump, D.H., Mullen, L.A., 1980. Parasitic fungi, soil moisture and multiplication of the cereal cyst nematode Heterodera avenae. Nematologica 26, 57-68.

Kerry, B.R., Crump D.H., Mullen L.A., 1982. Studies of the cereal cyst-nematode, Heterodera avenae under continuous cereals, 1975-1978. II. Fungal parasitism of nematode females and eggs. Ann. Appl. Biol. 100, 489-99.

Klamer, M., Roberts, M.S., Levine, L.H., Drake, B.G., Garland, J.L., 2002. Influence of elevated $\mathrm{CO}_{2}$ on the fungal community in a coastal scrub oak forest soil investigated with terminalrestriction fragment length polymorphism analysis. Appl. Environ. Microbiol. 68, 43704376.

Kluepfel, D.A., McInnis, T.M., Zehr, E.I., 1993. Involvement of root-colonizing bacteria in peach orchard soils suppressive of the nematode Criconemella xenoplax. Phytopathology 83, 1240-1245.

Knudsen, I.M., Debosz, K., Hockenhull, J., Jensen, D.F., Elmholt, S., 1999. Suppressiveness of organically and conventionally managed soils towards brown foot rot of barley. Appl. Soil Ecol. 12, 61-72. 
Larkin, R.P., 2008. Relative effects of biological amendments and crop rotations on soil microbial communities and soilborne diseases of potato. Soil Biol. Biochem. 40, 1341-1351.

Larkin, R.P., Honeycutt, C.W., 2006. Effects of different 3-year cropping systems on soil microbial communities and Rhizoctonia diseases of potato. Phytopathology 96, 68-79.

Larkin, R.P., Griffin, T.S., Honeycutt, C.W., 2010. Rotation and cover crop effects on soilborne potato diseases, tuber yield, and soil microbial communities. Plant Dis. 94, 1491-1502.

Mankau, R., 1975. Bacillus penetrans n. comb. causing a virulent disease of plant-parasitic nematodes. J. Invertebr. Pathol. 26, 333-339.

Mariotte, P., 2014. Do subordinate species punch above their weight? Evidence from above-and below-ground. New Phytol. 203, 16-21.

Mazzola, M., 2004. Assessment and management of soil microbial community structure for disease suppression. Annu. Rev. Phytopathol. 42, 35-59.

Montfort, E., Lopez-Llorca, L.V., Jansson, H.B., Salinas, J., 2006. In vitro receptivity assays to egg-parasitic nematophagous fungi. Mycol. Prog. 5, 18-23.

Müller, J., 1980. Ein verbessertes Extraktionsverfahren für Heterodera schachtii. [An improved method for the extraction of Heterodera schachtii.] Nachrichtenbl. Deutsch. Pflanzenschutzd. 32, 21-24.

Muyzer, G., de Waal, E.C., Uitterlinden, A.G., 1993. Profiling of complex microbial populations by denaturing gradient gel electrophoresis analysis of polymerase chain reaction-amplified genes encoding for 16S rRNA. Appl. Environ. Microbiol. 59, 695-700.

Nicol, J., Rivoal, R., Taylor, S., Zaharieva, M., 2003. Global importance of cyst (Heterodera spp.) and lesion nematodes (Pratylenchus spp.) on cereals: distribution, yield loss, use of host resistance and integration of molecular tools. Nematol. Monogr. Perspect. 2, 1-19.

Nicol, J.M., Rivoal, R., 2008. Global knowledge and its application for the integrated control and management of nematodes on wheat, in: Ciancio, A. and Mukerji, K.G. (Eds.), Integrated Management and Biocontrol of Vegetable and Grain Crops Nematodes. Springer Netherlands, pp. 251-294.

Noel, G.R., Wax, L.M., 2003. Population dynamics of Heterodera glycines in conventional tillage and no-tillage soybean/corn cropping systems. J. Nematol. 35, 104-109.

Odum, E.P., 1954. Fundamentals of Ecology. Saunders, Philadelphia, U.S. 
Ohnesorge, B., Freidel, J., Oesterlin, U., 1974. Investigations on the distribution pattern of Heterodera avenae and its changes in a field under continuous cereal cultivation. $\mathrm{Z}$. Pflanzenkrankh. Pflanzenschutz 81, 356-363.

Öztürk, G., Yıldırım, A.F., Kepenekci, I., Ekiz, H., 2000. [Investigation on the effect of Heterodera filipjevi Madzhidov on cereal yields which is one of the important cyst nematodes in cereal planted areas in Konya province], in: H. Ekiz (Ed.), Orta Anadolu'da hububat tarımının sorunları ve çözüm yolları Sempozyumu, Konya, Turkey, 8-11 Haziran 1999. Ministry of Agriculture and Rural Affairs, Bahri Dağdaş International Winter Cereals Research Center, pp. 477-482.

Postma, J., Schilder, M.T., Bloem, J., van Leeuwen-Haagsma, W.K., 2008. Soil suppressiveness and functional diversity of the soil microflora in organic farming systems. Soil Biol. Biochem. 40, 2394-2406.

Prot, J.C., Van Gundy, S.D., 1981. Effect of soil texture and the clay component on migration of Meloidogyne incognita second-stage juveniles. J. Nematol. 13, 213-217.

Rivoal, R., 1986. Biology of Heterodera avenae Wollenweber in France. IV. Comparative study of the hatching cycles of two ecotypes after their transfer to different climatic conditions. Rev. Nématol. 9, 405-410.

Rivoal, R., Cook, R., 1993. Nematode pests of cereals, in: Evans, K., Trudgill, D.L., Webster, J.M. (Eds.), Plant Parasitic Nematodes in Temperate Agriculture. CAB International, Wallingford, UK, pp. 259-303.

Rode, H. 1962. Untersuchungen über das Wandervermögen von Larven des Kartoffelnematoden (Heterodera rostochiensis Woll.) in Modellversuchen mit verschiedenen Bodenarten. Nematologica 7, 74-82.

Sayre, R.M. and Walter, D.E. 1991. Factors affecting the efficacy of natural enemies of nematodes. Annu. Rev. Phytopathol. 29, 149-166.

Smalla, K., Wieland G., Buchner A., Zock A., Parzy J., Kaiser S., Roskot, N., Heuer, H., Berg, G., 2001. Bulk and rhizosphere soil bacterial communities studied by denaturing gradient gel electrophoresis: plant-dependent enrichment and seasonal shifts revealed. Appl. Environ. Microbiol. 67, 4742-4751. 
Smiley, R.W., 2009. Occurrence, distribution and control of Heterodera avenae and H. filipjevi in the western USA. Cereal cyst nematodes: Status, research and outlook. CIMMYT, Ankara, Turkey, pp. 35-40.

Smiley, R.W., 2016. Cereal cyst nematodes: Biology and management in Pacific Northwest wheat, barley, and oat crops. Pacific Northwest Extension publication PNW 620, Oregon state University, University of Idaho, Washington State University. Online: https://catalog.extension.oregonstate.edu/sites/catalog.extension.oregonstate.edu/files/projec t/pdf/pnw620_2.pdf accessed: May 15, 2016.

Sneh, B., Pozniak, D., Salomon, D., 1987. Soil suppressiveness to Fusarium wilt of melon, induced by repeated croppings of resistant varieties of melons. Phytopathology 120, 347354.

Southey, J.F., 1956. National survey work for root eelworm. [Heterodera major (O.Schmidt) Franklin]. Nematologica 1, 64-71.

Subbotin, S.A., Sturhan, D., Rumpenhorst, H.J., Moens, M., 2003. Molecular and morphological characterization of the Heterodera avenae species complex (Tylenchida: Heteroderidae). Nematology 5, 515-528.

Steiner, A.A., 1968. Soilless culture. Proceedings of the 6th Colloquium of the International Potash Institute. International Potash Institute, Bern, Switzerland, pp. 324-341.

Steudel, W., Rumpenhorst, H.J., 1978. Untersuchungen zur Populationsdynamik des Haferzystenälchens (Heterodera avenae Woll.) und zum Ertrag von anfälligem und resistentem Hafer in einer Hafer-Dauerkultur. Z. Acker Pflanzenb. 146, 90-108.

Stirling, G.R. 2014. Biological Control of Plant-parasitic Nematodes: Soil Ecosystem Management in Susatainable Agriculture. $2^{\text {nd }}$ edition, $C A B$ International, Wallingford, Oxfordshire OX19 8DE, UK, 510 pp.

Stirling, G.R., Kerry, B.R., 1983. Antagonists of the cereal cyst nematode Heterodera avenae Woll. in Australian soils. Anim. Prod. Sci. 23, 318-324.

Sturhan, D., 1982. Distribution of Cereal and Grass Cyst Nematodes in the Federal Republic of Germany. EPPO Bulletin. 12, 321-324.

Tennant, D., 1975. A test of a modified line intersection method of estimating root length. J. Ecol. 63, 995-1001. 
Timper, P., 2011. Utilization of biological control for managing plant-parasitic nematodes, in: Davies, K., Spiegel, Y. (Eds.). Biological Control of Plant-Parasitic Nematodes. Springer Netherlands, pp. 259-289.

van Elsas, J.D., Garbeva, P., Salles, J., 2002. Effects of agronomical measures on the microbial diversity of soils as related to the suppression of soil-borne plant pathogens. Biodegradation $13,29-40$.

Wallace, H.R., 1968. The dynamics of nematode movement. Annu. Rev. Phytopathol. 6, 91-114.

Weinert, N., Meincke, R., Gottwald, C., Heuer, H., Gomes, N. C., Schloter, M., Berg, G., Smalla, K., 2009. Rhizosphere communities of genetically modified zeaxanthin accumulating potato plants and their parent cultivar differ less than those of different potato cultivars. Appl. Environ. Microbiol. 75, 3859-3865.

Weller, D.M., Raaijmakers, J.M., Gardener, B.B., Thomashow, L.S., 2002. Microbial populations responsible for specific soil suppressiveness to plant pathogens. Annu. Rev. Phytopathol. 40, 309-348.

Westphal, A., 2005. Detection and description of soils with specific nematode suppressiveness. J. Nematol. 37, 121-130.

Westphal, A., Becker, J.O., 1999. Biological suppression and natural population decline of Heterodera schachtii in a California field. Phytopathology 89, 434-440.

Westphal, A., Becker, J.O., 2000. Transfer of biological soil suppressiveness against Heterodera schachtii. Phytopathology 90, 401-406.

Westphal, A., Becker, J.O., 2001. Soil suppressiveness to Heterodera schachtii under different cropping sequences. Nematology 3, 551-558.

Westphal, A., Xing, L.J., 2011. Soil suppressiveness against the disease complex of the soybean cyst nematode and sudden death syndrome of soybean. Phytopathology 101, 878-886.

Workneh, F., van Bruggen, A.H.C., 1994. Microbial density, composition, and diversity in organically and conventionally managed rhizosphere soil in relation to suppression of corky root of tomatoes. Appl. Soil Ecol. 1, 219-230.

Workneh, F., van Bruggen, A.H.C., Drinkwater, L.E., Shennan, C., 1993. Variables associated with corky root and Phytophthora root rot of tomatoes in organic and conventional farms. Phytopathology 83, 581-589. 
Xing, L.J., Westphal, A., 2006. Transferring soil suppresiveness against Heterodera glycines under field conditions. J. Nematol. 38: 302 [abstract]

Yin, B., Valinsky, L., Gao, X., Becker, J. O., Borneman, J., 2003. Identification of fungal rDNA associated with soil suppressiveness against Heterodera schachtii using oligonucleotide fingerprinting. Phytopathology 93, 1006-1013. 


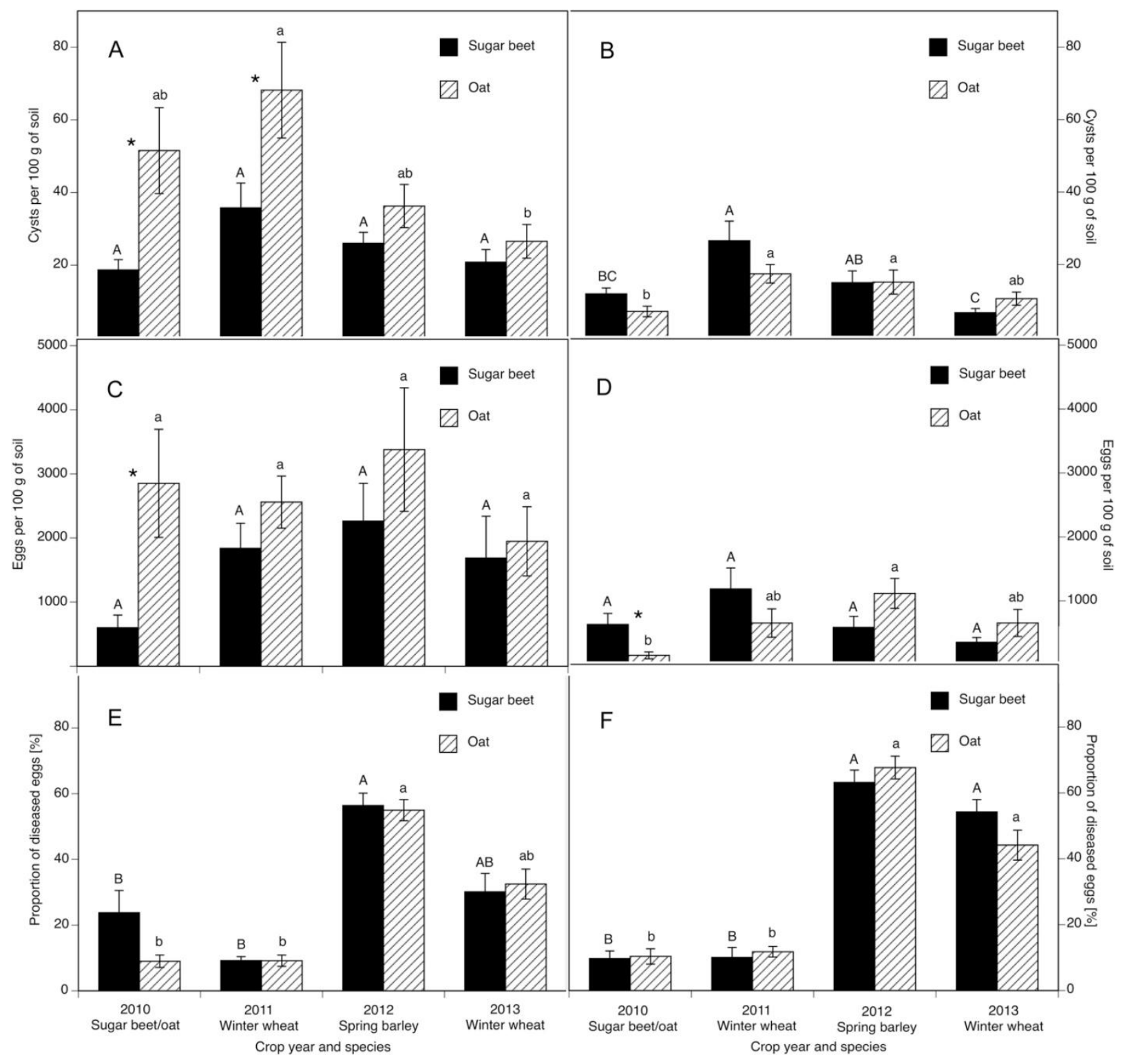

Fig. 3.1 Population densities of Heterodera avenae and $H$. filipjevi at harvest on different crop species following differential crops of sugar beet or oat in 2010 at Münster from 2010 to 2013: number of cysts: (A) H. avenae, (B) H. filipjevi; number of total eggs (C) H. avenae, (D) $H$. filipjevi; proportion of diseased eggs of total number of eggs (E) H. avenae, (F) H. filipjevi. Original means $\pm \mathrm{SE}$ are presented. Bars indexed with the same letter were not signifcantly different at $P=0.05$ : large cap: sugar beet plots, small cap: oat plots. Bars indexed with a $*$ were significant different when comparing the plots within the monitoring time. 


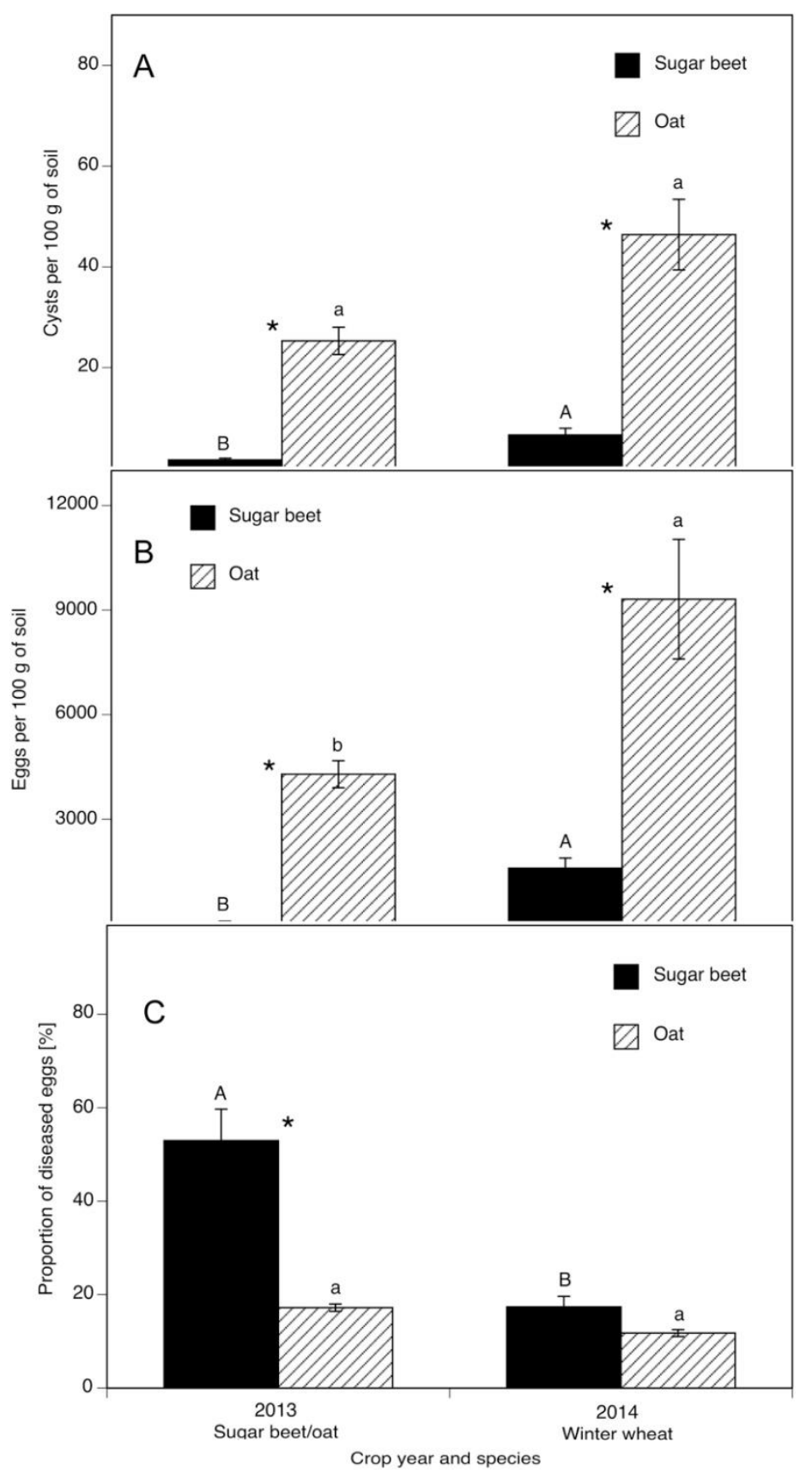

Fig. 3.2 Population densities of Heterodera avenae on oat/sugar beet and winter wheat crops in H. avenae-infested soil at harvest in 2013 to 2014 at Braunschweig: (A) number of cysts, (B) number eggs, and (C) percentage of diseased eggs of total number of eggs. Original means $\pm \mathrm{SE}$ are presented. Bars indexed with the same letter were not signifcantly different at $P=0.05$ : large cap: sugar beet plots, small cap: oat plots. Bars indexed with a * were significant different when comparing the plots within the monitoring time. 


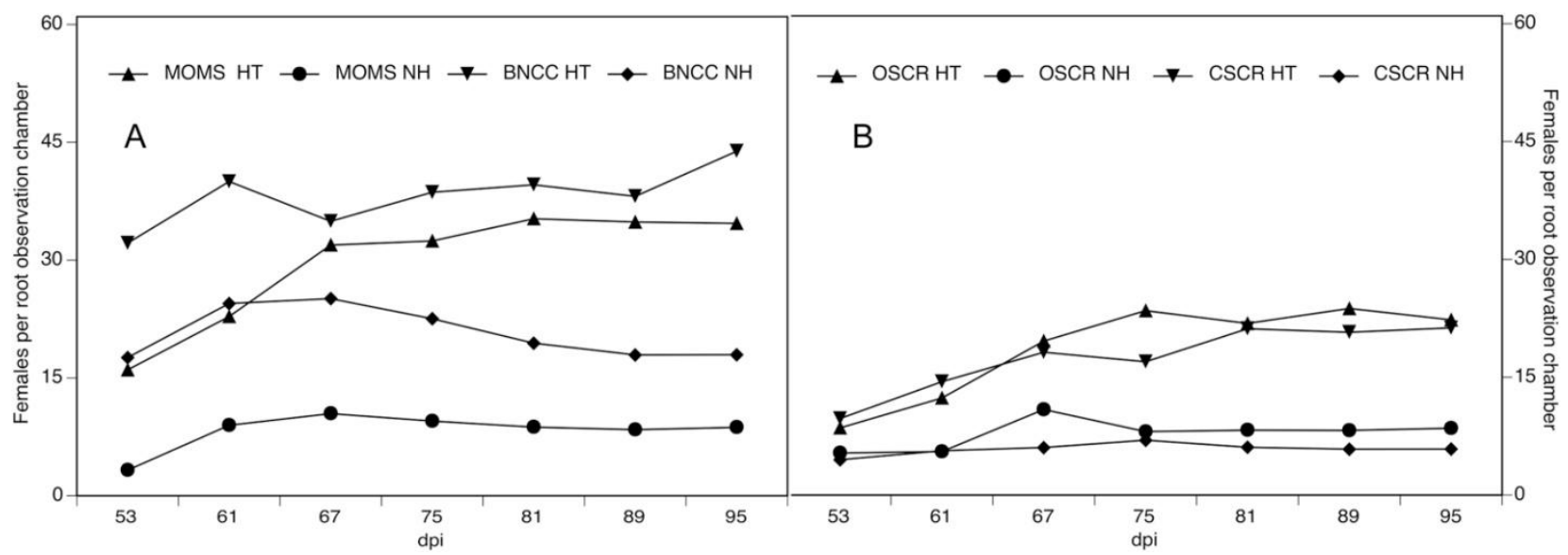

Fig. 3.3 Females of Heterodera avenae on root systems of spring barley 'Hanka' in root observation chambers with soil from (A) oat monoculture MOMS: non-heated: MOMS NH and heat-treated: MOMS HT; and crop rotation BNCC: or non-heated: BNCC NH and heat-treated BNCC HT; (B) soils from organic farming OSCR: heat-treated: OSCR HT or non-heated: OSCR $\mathrm{NH}$, and conventional farming CSCR: heat-treated: CSCR HT or non-heated CSCR NH from 53 to 95 days post inoculation (dpi). Back-transformed lsmeans are presented. 


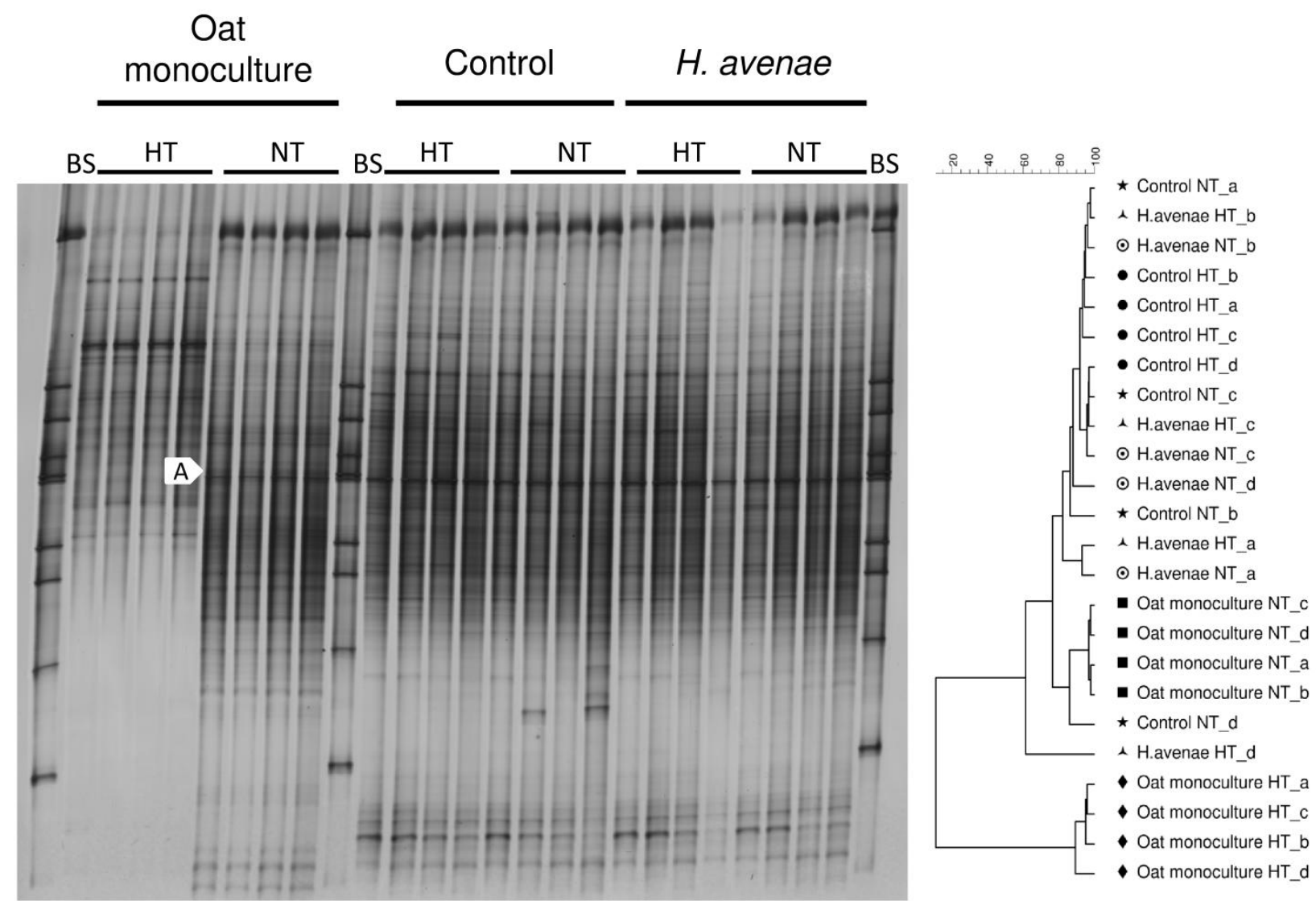

Fig. 3.4 Bacterial (16S rRNA gene) DGGE fingerprint (A) and corresponding UPGMA cluster (B) for heat-treated (HT) and non-heated (NT) soil from oat monoculture, and non-infested control and Heterodera avenae microplots at Braunschweig after soil transfer and before sowing in 2013. Groups of four lines are replicates. (BS: bacterial standard). Band A is regarded as a dominant band with identical electrophoretic mobility. In the dendrograms, replicates are labelled a to $\mathrm{d}$. The scale shows similarity values. 


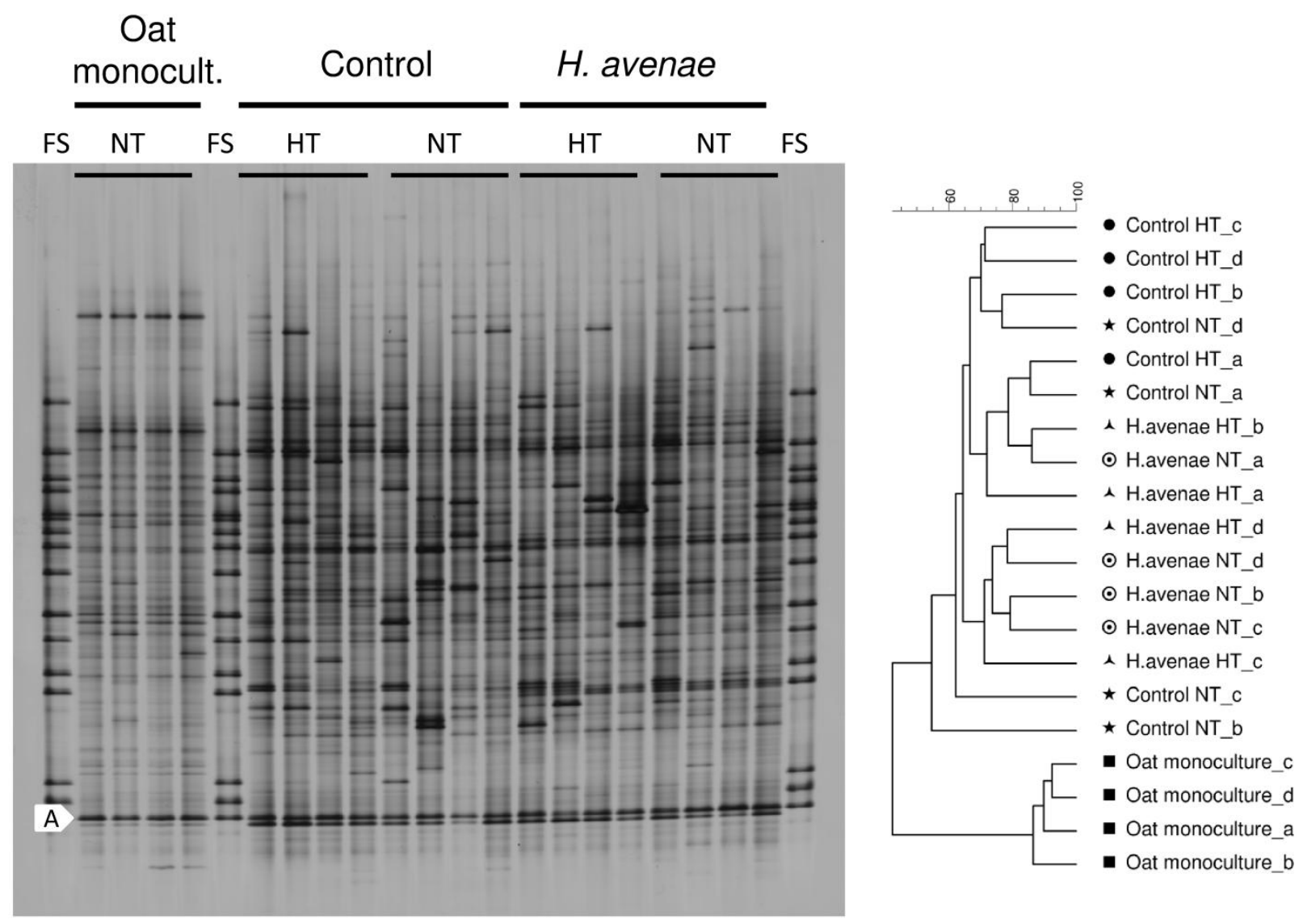

Fig. 3.5 Fungal (ITS) DGGE fingerprints (A) and respective UPGMA cluster (B) for non-heated (NT) soil from oat monoculture and non-infested control and Heterodera avenae microplots at Braunschweig after amendment with heat-treated (HT) and non-heated (NT) oat monoculture soil and before sowing in 2013. Groups of four lines are replicates. (FS: fungal standard). Band A is regarded as a dominant band with identical electrophoretic mobility. In the dendrograms, replicates are labelled a to $\mathrm{d}$. The scale shows similarity values. 
A

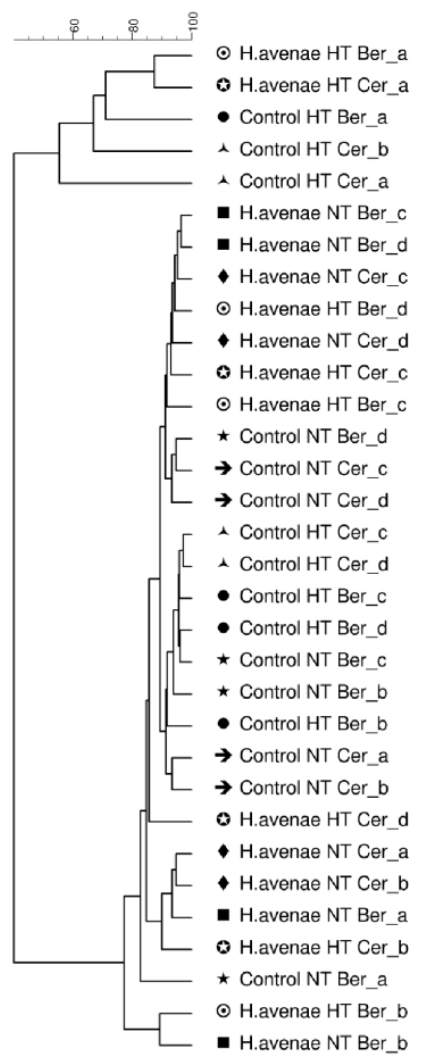

B

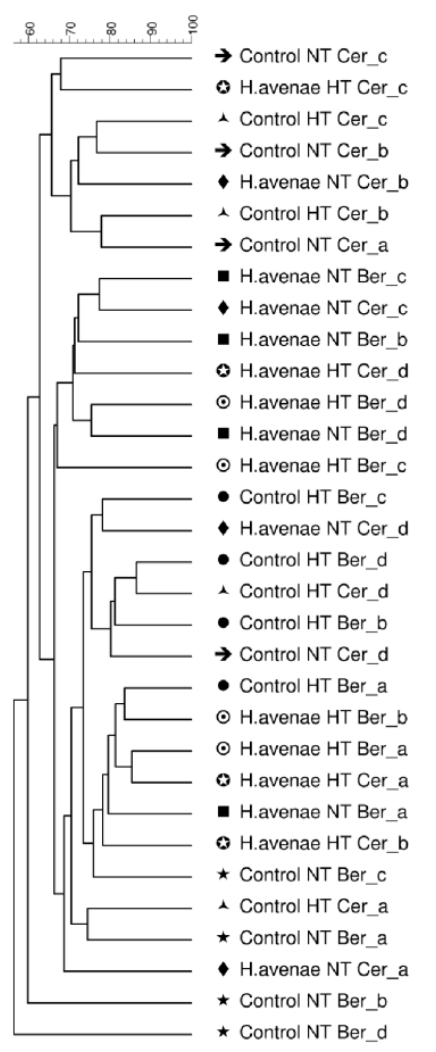

C

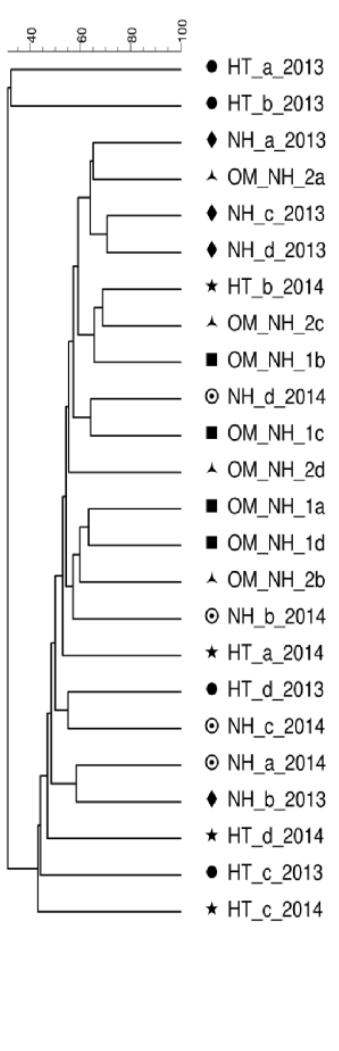

D

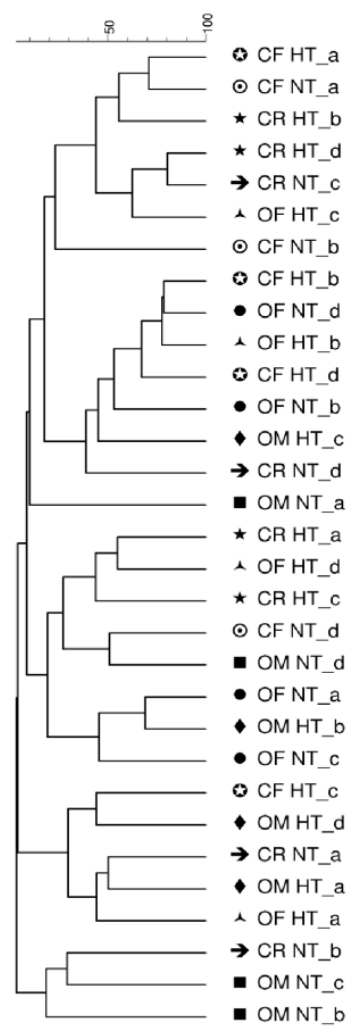

Fig. 3.6 UPGMA dendrograms from (A) bacterial (16S rRNA gene) and (B) fungal (ITS) DGGE fingerprints for soil collected after harvest in 2013 from sub-plots where sugar beet Beretta (Ber) or Oat (Cer) were cropped in plots that received the heat-treated (HT) and non-heated (NT) amendment at Braunschweig, (C) fungal (ITS) DGGE for cysts collected at harvest in 2013 and 2014 from microplots that received the heat-treated (HT) and non-heated (NH) amendment at Braunschweig, and for Heterodera avenae females raised on non-heated $(\mathrm{NH})$ oat monoculture soil (OM) and collected at $67 \mathrm{dpi}$ in experiment 1 and 2, and (D) fungal (ITS) DGGE for $H$. avenae females raised in heat-treated (HT) and non-heated (NT) oat monoculture (OM), control/crop rotation $(\mathrm{CR})$ and intensive cereal cropping; organic farming $(\mathrm{OF})$ and conventional farming (CF) soils and collected at $67 \mathrm{dpi}$ in experiment 2. Replicates are labelled a to d. The scale shows similarity values. 
B

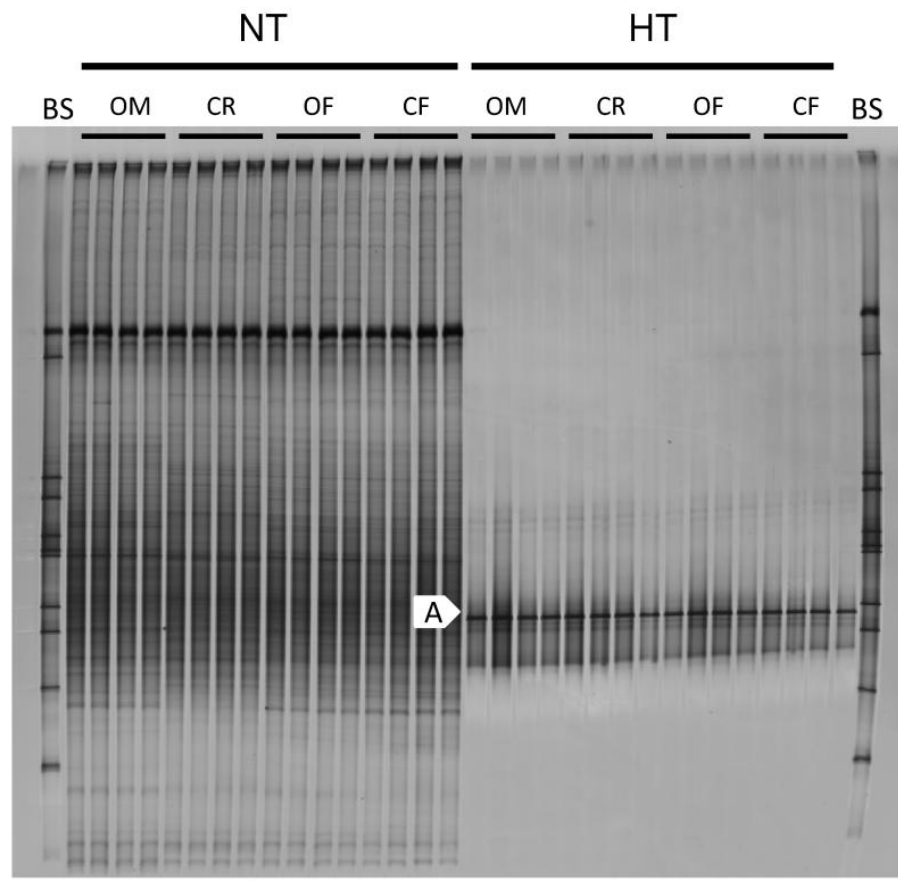

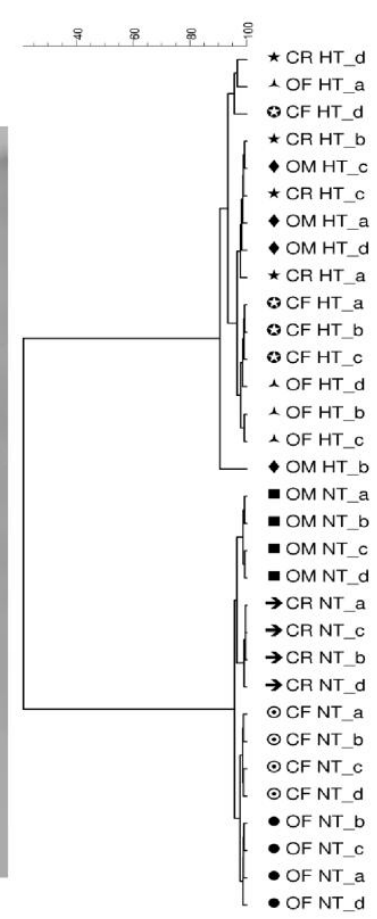

C

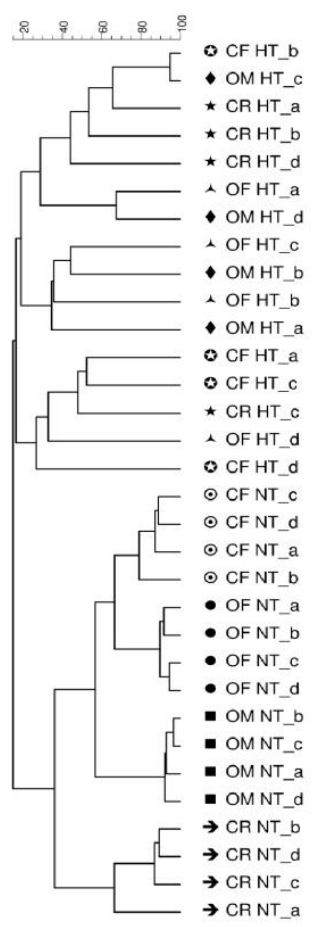

Fig. 3.7 Bacterial (16S rRNA gene) DGGE fingerprint (A), corresponding bacterial UPGMA cluster (B), and UPGMA cluster from fungal (ITS) DGGE fingerprint (C) for heat-treated (HT) and non-heated (NT) oat monoculture (OM), control/crop rotation (CR) and intensive cereal cropping; organic farming (OF) and conventional farming (CF) soils before sowing in experiment 2. Groups of four lines are replicates. (BS: bacterial standard). Band A is regarded as a dominant band with identical electrophoretic mobility. In the dendrograms, replicates are labelled a to $\mathrm{d}$. The scale shows similarity values. 
A

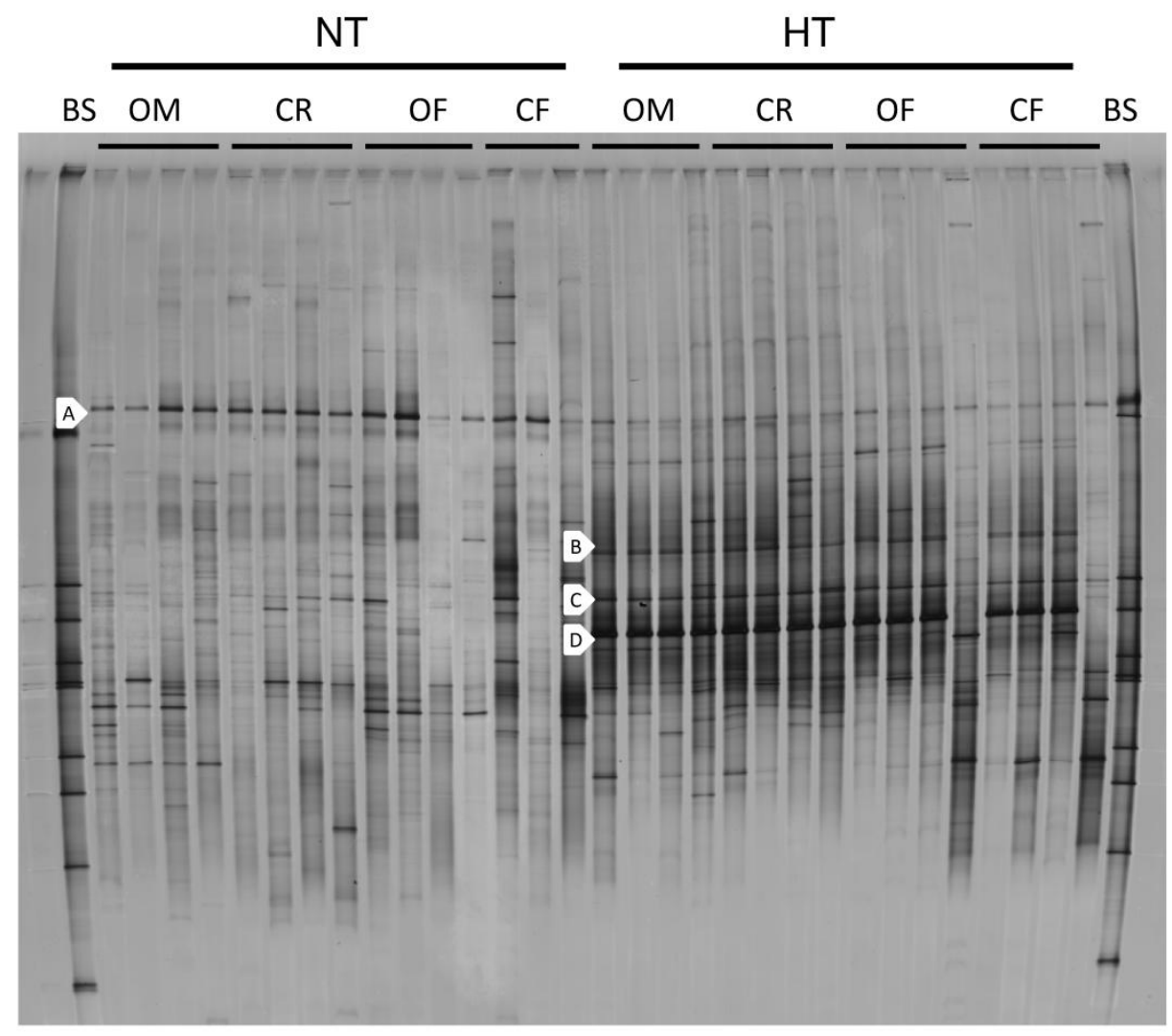

B

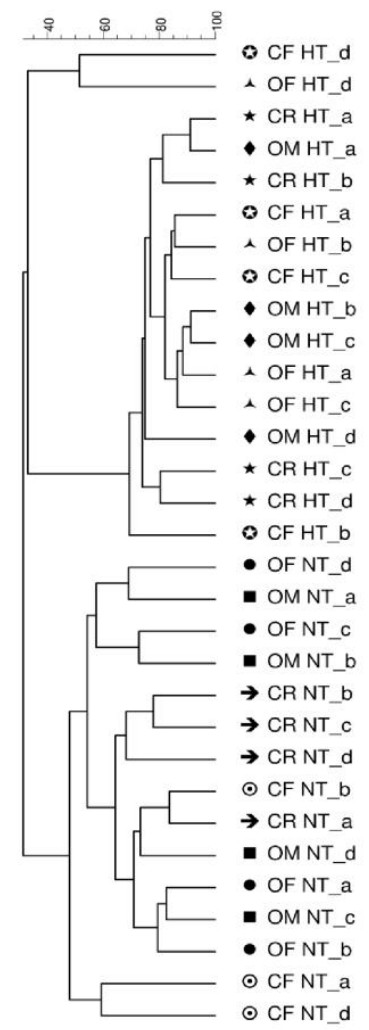

Fig. 3.8 Bacterial (16S rRNA gene) DGGE fingerprint (A) and corresponding UPGMA cluster (B) for Heterodera avenae females raised in heat-treated (HT) and non-heated (NT) oat monoculture $(\mathrm{OM})$, control/crop rotation $(\mathrm{CR})$ and intensive cereal cropping; organic farming (OF) and conventional farming (CF) soils and collected at 67 dpi in experiment 2. Groups of four/three lines are replicates. (BS: bacterial standard). Band A, B, C and D are regarded as dominant bands with identical electrophoretic mobility.In the dendrograms, replicates are labelled a to $d$. The scale shows similarity values. 
Table 3.1 Cereal yields in a transfer study averaged for amendment with non-heated or heated portions of oat monoculture soil in a cereal monoculture with initial oat 'Nordstern' or 'Sang' compared to a sequence with sugar beet 'Beretta' at Münster 2010-2013.

\begin{tabular}{|c|c|c|c|c|c|c|}
\hline \multirow{3}{*}{ Nematode } & \multirow{3}{*}{ Cultivar } & \multicolumn{4}{|c|}{ Grain yield $\left(\mathrm{g} \mathrm{m}^{-2}\right)$} & \multirow{3}{*}{$\frac{\text { Relative yield }(\%)^{\mathrm{b}}}{2010-2013}$} \\
\hline & & Oat & W. wheat & S. barley & W. wheat & \\
\hline & & 2010 & 2011 & 2012 & 2013 & \\
\hline \multirow[t]{2}{*}{ Control } & Nordstern & $393 \pm 20$ & $279 \pm 42$ & $230 \pm 21$ & $260 \pm 40$ & $101 \pm 5$ \\
\hline & Sang & $318 \pm 12$ & $301 \pm 36$ & $188 \pm 23$ & $318 \pm 58$ & $99 \pm 8$ \\
\hline \multirow[t]{2}{*}{ H. avenae } & Beretta & - & $377 \pm 62$ & $245 \pm 49$ & $164 \pm 40$ & $101 \pm 17$ \\
\hline & Nordstern & $374 \pm 27$ & $189 \pm 34$ & $226 \pm 45$ & $202 \pm 39$ & $85 \pm 9$ \\
\hline \multirow[t]{2}{*}{ H. filipjevi } & Beretta & - & $364 \pm 36$ & $218 \pm 33$ & $255 \pm 40$ & $108 \pm 9$ \\
\hline & Sang & $459 \pm 17$ & $238 \pm 48$ & $305 \pm 32$ & $227 \pm 59$ & $106 \pm 11$ \\
\hline
\end{tabular}

$P$-value

Nordstern: Control vs. H. avenae

Sang: Control vs. H. filipjevi

$\begin{array}{ccccc}\text { n.s. } & \text { n.s. } & \text { n.s. } & \text { n.s. } & \text { n.s. } \\ <0.01 & \text { n.s. } & \text { n.s. } & \text { n.s. } & \text { n.s. } \\ \text { n/a } & \text { n.s. } & \text { n.s. } & \text { n.s. } & \text { n.s. } \\ \text { n/a } & <0.01 & \text { n.s. } & \text { n.s. } & \text { n.s. } \\ \text { n/a } & <0.01 & 0.06 & \text { n.s } & \text { n.s. }\end{array}$

Beretta: H. avenae vs. H. filipjevi

H. avenae: Beretta vs. Nordstern

H. filipjevi: Beretta vs. Sang

n.s.

${ }^{\mathrm{a}}$ Mean \pm standard error of averaged treatments for non-heated and heated soil amendments for oat, winter wheat (W. wheat), and spring barley (S. barley) are presented.

${ }^{\mathrm{b}}$ For each year and for every plot the relative yield (relative yield $=100 \cdot \mathrm{x} /$ average yield $_{\text {year }}$ ), and the statistical analysis repeated as with the original values.

'Specific comparisons were tested with LSM Estimates, and their p-values adjusted with the Edwards and Berry's simulation method; n.s.: indicate non-significant differences at $P \leq 0.05 ; \mathrm{n} / \mathrm{a}$ : comparison could not be made. 


\title{
Chapter 4:
}

\section{Biological suppression of populations of the plant-parasitic nematode Heterodera schachtii adapted to different host genotypes of sugar beet.}

\author{
Caroline Eberlein $^{1,2}$, Holger Heuer ${ }^{3}$, Andreas Westphal ${ }^{1 *}$
}

${ }^{1}$ Julius Kühn-Institut, Federal Reasearch Centre for Cultivated Plants, Institute for Plant

Protection in Field Crops and Grassland, Messeweg 11/12, 38104 Braunschweig, Germany

${ }^{2}$ Department of Crop Sciences, University of Göttingen, Grisebachstrasse 6, 37077 Göttingen, Germany

${ }^{3}$ Julius Kühn-Institut, Institute for Epidemiology and Pathogen Diagnostics, Messeweg 11/12, 38104 Braunschweig, Germany

*Current address: Department of Nematology, University of California Riverside, Kearney Agricultural Research and Extension Center, 9240 S. Riverbend Ave., Parlier, CA 93648, U.S. 


\begin{abstract}
Productivity of sugar beet and brassica vegetable crops is constrained by Heterodera schachtii worldwide. In sugar beet cropping areas of Central Europe and North America, $H$. schachtii is managed by crop rotation, and cultivation of resistant brassica cover crops. The recently release of nematode-tolerant sugar beet cultivars suffer less damage than susceptible cultivars at high initial population densities of $H$. schachtii. Many of the cultivars allow for less nematode reproduction than susceptible cultivars. Hypothetically, monoculture of susceptible hosts is a typical way to facilitate the evolution of suppressive soil. Objectives of this study were to determine if susceptible host plants are mandatory for soil suppressiveness to develop, and if Pasteuria nishizawae or Dactylella oviparasitica amendments establish consistently under monoculture of different sugar beet genotypes (susceptible, resistant, tolerant). In four-year microplot studies with $H$. schachtii Schach0 or Schach1, one susceptible, one Schach0-resistant and one tolerant sugar beet genotype were cultivated in monoculture. In 2010, plots were either amended with $P$. nishizawae or D. oviparasitica, the last being introduced into natural soil for Schach0, and into previously biocide-treated soil for Schach1. In 2011, only some Schach0infested plots received a second amendment with $D$. oviparasitica. Nematode population densities, as well as growth and yield parameters were determined annually. Effects of $D$. oviparasitica and $P$. nishizawae on populations of $H$. schachtii were limited but the eggs of both pathotypes became diseased resulting in $90 \%$ diseased eggs represented of the total eggs by the third cropping cycle, under the susceptible, resistant and tolerant cultivar. In all years, the tolerant genotype produced the highest and most stable white sugar yields. Results of this study suggest the presence of controlling factors in this sugar beet monoculture that may be responsible for the dramatic increase of diseased eggs, irrespective of the cultivar being cropped.
\end{abstract}




\section{Introduction}

The soil environment is the place of tri-trophic interactions of the plant, its parasites/pathogens and potential beneficial organisms/hyperparasites that interfere with activities of the second trophic level. In many cases, these interactions can have an encompassing positive outcome in that detrimental organisms are suppressed in their activities allowing flourishing growth of host plants despite the presence of the parasites. In extreme cases of degraded soils, this balance is offset, and severe activities of detrimental organisms with resulting disease expression occur (Sikora, 1992; Stirling, 2014). Some suppression of parasitic activity by biological balancing is expected in most soils (Stirling, 1991; Mazzola, 2004; Janvier et al., 2007). The discovery of soils where this antagonistic potential or soil suppressiveness is noticeably high has fueled interest in biological control mechanisms in the soil environment. Several studies have reported such soils and methods of their detection and description have long been proposed (Weller at al., 2002; Westphal, 2005; Borneman and Becker, 2007).

The currently accepted hypothesis is that monoculture of a susceptible host is mandatory for generating such pathogen-suppressive soils. This train of thought was based on results from early studies on take-all decline soils that established under wheat monoculture (Cook, 1981), and also from investigations of cereal cyst nematode suppressive soils in the UK (Gair et al., 1969). The recommendation of using a susceptible host seemed supported by the lack of increase of population densities of the antagonists under a resistant cereal crop (Kerry \& Andersson, 1983). Monoculture of a susceptible host has repeatedly been viable to generate suppressive soil, presumably when beneficial organisms for induction of this phenomenon were present at the beginning of such strategy (Gair et al., 1969; Baker and Cook, 1974; Westphal and Becker, 1999; Chen, 2007). It appeared that at least one of the target pathogens needed to be present at onset of such trials to result in suppressive soil (Westphal and Xing, 2011).

The practical value of generating suppressive soil by monoculture of susceptible hosts was quickly negated because of the expected yield losses in such strategy that made this approach non-viable for commercial producers (Kerry, 1990). The role of resistant cultivars as impacting this balance within this tri-trophic network in suppressive soil has been studied (Westphal and Becker, 2001). In that study, resistant cultivars of Beta vulgaris or Raphanus sativus were able to preserve suppressiveness against the sugar beet cyst nematode while a 
double crop of the non-host Triticum aestivum reduced soil suppressiveness against $H$. schachtii (Westphal and Becker, 2001). It was speculated that some activity of the nematode under the host crop was necessary for maintenance of this beneficial soil function.

In sugar beet production, more recently cultivars tolerant to $H$. schachtii damage have been released, and quickly have become the preferred sugar beet genotypes in high-production areas. These cultivars can withstand higher population densities of $H$. schachtii than standard susceptible (and sensitive) cultivars. Tolerant cultivars do permit some reproduction higher than resistant cultivars, but less than susceptible ones (Westphal 2013; Kaemmerer et al., 2014; KWS, 2015). Such genotypes offer the novel potential to overcome the yield decline in the "establishing phase" of soil suppressiveness.

It was our hypothesis that these tolerant genotypes would not suffer as severe yield losses in the initiating time of the suppressiveness as susceptible lines would but that they would still permit for significant increases of suppressive principals in the soil. This was challenging the current concept of mandatory susceptible crop monoculture. As representative model organisms for an obligate parasite Pasteuria nishizawae was included in these trials. Dactylella oviparasitica represented highly effective but non-obligate fungal antagonists. The specific objectives of this study with $H$. schachtii pathotypes Schach0 and Schach1 were to determine: (A) if the obligate bacterial hyperparasite Pasteuria nishizawae or the facultative fungus Dactylella oviparasitica reduce nematode population densities and protect yield of susceptible, resistant and tolerant cultivars; and (B) if microbial soil amendments establish consistently under monoculture of different sugar beet genotypes (susceptible, resistant, tolerant).

\section{Materials and Methods}

A multi-year study was conducted in microplots of $1 \mathrm{~m}^{2}$ surface area containing sandy soil (88.2\% sand, $7.4 \%$ silt, $4.4 \%$ clay, $2.4 \%$ O.M., pH 6.9) and originally infested with $H$. schachtii pathotype Schach0 (16 microplots; wild type with no virulence on any resistance

sources) or Schach1 (16 microplots; virulent on sugar beet genotypes that carry the Hs $1^{\text {pro-1 }}$ gene for resistance to $H$. schachtii; Müller, 1998). For each pathotype a different experiment was conducted. Each experiment was arranged as a split-plot design with the entire microplot being the mainplots further divided into threee subplot with a total of four replicates. In April 2010, 
mainplots infested with Schach0 received the following treatments: (i) untreated control (ii) Pasteuria nishizawae amendment, (iii) Dactylella oviparasitica amendment, and (iv) an experimental seed treatment. Mainplots infested with Schach1 received the following treatments: (i) untreated control, (ii) $P$. nishizawae amendment, (iii) Dazomet $+D$. oviparasitica amendment, and (iv) Dazomet - D. oviparasitica amendment. The Dazomet at $500 \mathrm{~kg} / \mathrm{ha}$ (Tetrahydro-3,5-dimethyl-1,3,5-thiadiazine-2-thione; Basamid, BASF, Ludwigshafen, Germany) was administered to perturb soil microbial communities three weeks before adding $D$. oviparasitica. Within each main plot, the three parallel subplots for one three-plant row each were established in split-plot design. For microbial amendments, a soil core of 19-cm diameter and $10-\mathrm{cm}$ depth was removed from each planting site within a subplot and the total $8.5 \mathrm{~L}$ were transferred into a 20-L bucket. The soil was mixed and amended with either $150 \mathrm{ml} D$. oviparasitica suspension (the equivalent of three 9-cm culture plates; $9 \times 10^{5} \mathrm{CFUs} / \mathrm{subplot}$ for Schach0 and $13 \times 10^{5} \mathrm{CFUs} /$ subplot for Schach1), or $3.04 \mathrm{~g}$ P. nishizawae spores (4.25e ${ }^{9}$. D. oviparasitica suspension was produced according to the method followed by Olatinwo et al. (2006a). P. nishizawae inoculum was commercially provided. The respective soil mixes were then evenly distributed and replaced into the three planting sites per subplot. Two days after the amendments, $0.3 \mathrm{~m} \times 1.0 \mathrm{~m}$ subplots were planted to randomly assigned Beta vulgaris $\mathrm{L}$. 'Beretta' (susceptible to H. schachtii), 'Sanetta' (resistant to Schach0), or 'Pauletta' (tolerant to H. schachtii). At each of the three planting sites per subplot, six seeds of the respective cultivar were hand seeded. For control plots without microbial amendments, the same soil mixing procedures were followed. In 2011, in Schach0-infested plots, plots amended with $D$. oviparasitica received a second amendment, whereas plots that were planted to treated sugar beet seeds in 2010 were amended with D. oviparasitica $\left(3.6 \times 10^{7} \mathrm{CFUs}\right.$ per subplot). Both experiments, Schach0 and Schach1, were cropped in monoculture of sugar beet with the same sugarbeet genotypes in each subplot until harvest 2013.

A second microplot experiment was conducted at the JKI location at Braunschweig, Germany. In April 2013, microplots of $1 \mathrm{~m}^{2}$ surface containing sandy loam soil $(72.9 \%$ sand, $20.5 \%$ silt, $6.6 \%$ clay, $1 \%$ O.M., $\mathrm{pH} 7.3$ ) were infested with $H$. schachtii Schach1 raised on winter rape NK Fair in loess soil. A soil amount of $3.2 \mathrm{~kg}$ containing $>1.5$ million eggs (500 eggs/100 g) was divided into two portions; one portion was incorporated and mixed with spade and fork into the $15-30 \mathrm{~cm}$ depth soil layer, and the other one was incorporated and mixed into 
the $0-15 \mathrm{~cm}$ depth layer. For non-infested control plots, only loess soil was incorporated this way. The experiment was arranged as a split-plot design with four replicates. The entire microplot served as main plot, receiving the following treatments: (i) untreated infested control (ii) P. nishizawae amendment, (iii) D. oviparasitica amendment, (iv) non infested control, and (v) fosthiazate $(10 \% \mathrm{w} / \mathrm{w} ; O$-ethyl-S-(1-methylpropyl) (2-oxo-3-thiazolidinyl) phosphonothioate; Nemathorin 10G, Syngenta, Maintal, Germany) at a rate of 0.213 g/subplot. Similar as in Münster randomly assigned $0.3 \mathrm{~m} \times 1.0 \mathrm{~m}$ subplots were planted to Beta vulgaris L. 'Beretta', 'Sanetta' or 'Pauletta'. D. oviparasitica suspensions at $1.3 \times 10^{8} \mathrm{CFUs}$ per subplot were produced and incorporated using the same procedures as described for Münster.

Since transferability of suppressiveness is an indication of specific soil suppressiveness (Westphal, 2005), and to further evaluate the suppressive potential of $P$. nishizawae when transferred as a soil amendment into untreated soil, a soil transfer experiment was also conducted at the JKI location at Braunschweig. In April 2014, a soil amount of $2.5 \mathrm{~L}$ per subplot was collected from Schach1 microplots at Münster amended with P. nishizawae to a depth of 0-30 $\mathrm{cm}$. As a negative control, soil from untreated microplots was collected as well. These soils were incorporated and mixed with a spade and fork to a depth of $0-15 \mathrm{~cm}$ into each of three $0.3 \mathrm{~m} \times$ $1.0 \mathrm{~m}$ subplots of $1 \mathrm{~m}^{2}$ surface microplots. The experiment was arranged as a split-plot design with four replicates. The entire microplot served as main plot, receiving the following treatments: (i) untreated control soil amendment and (ii) P. nishizawae soil amendment. The 0.3 $\mathrm{m} \times 1.0 \mathrm{~m}$ subplots consisted of the three sugar beet cultivars 'Beretta', 'Sanetta' and 'Pauletta'.

In all experiments, approximately three weeks after sowing at the cotyledon stage with initial true leaves (Biologische Bundesanstalt, Bundessortenamt und Chemische Industrie, BBCH 10; Meier et al., 1993), one seedling per planting site was removed, so that from each replication, three seedlings per cultivar in each treatment were recovered for staining. Two seedlings were maintained per planting site in the plots, the rest was discarded. After staining the roots with acid fuchsin (Byrd et al., 1983), root penetration by second-stage juveniles (J2) was determined. The root lengths of the seedlings were measured with a ruler and penetration was reported as $\mathrm{J} 2$ per centimeter of root. Every year prior to sowing and during the growing season, plots were fertilized with varying combinations of NPK $(12 \% \mathrm{~N}, 5.2 \% \mathrm{P}, 6.6 \% \mathrm{~K})$, ammoniumnitrate $(27 \% \mathrm{~N})$ and thomaskali $(3.5 \% \mathrm{P}, 12.5 \% \mathrm{~K})$ fertilizers to deliver $\mathrm{N}$ rates ranging from 40 to $120 \mathrm{~kg} \mathrm{ha}^{-1}$, $\mathrm{P}$ rates of $120 \mathrm{~kg} \mathrm{ha}^{-1}$ and $\mathrm{K}$ rates of $170 \mathrm{~kg} \mathrm{ha}^{-1}$. Plants were 
maintained following standard regional cultivation recommendations including watering as needed, and fungicide and insecticide applications to control fungal pathogens and insect pests. Plant growth was monitored and the perpendicular diameter of the plant canopy was measured 6to 9 weeks after sowing. At harvest, fresh weight of sugar beet tops and washed taproots were determined. Sugar content was determined by standard procedures (Buchholz et al. 1995) and reported as white sugar yield (WSY) per plant.To determine initial population densities of $H$. schachtii prior to sowing, soil samples of twelve 2-cm diameter cores were collected per subplot from the upper $30 \mathrm{~cm}$ with a soil corer.

To determine final population densities at harvest, four 2-cm diameter soil cores were taken from the root zone of each of the three plant sites of one subplot. Twelve soil cores per subplot were separated into 0- to 30- and 30- to 60-cm depth samples. Subsamples of $400 \mathrm{~g}$ of fresh soil were used for extracting cysts by density centrifugation with $\mathrm{MgSO}_{4}$ (Müller, 1980). Cysts were counted under a binocular before being crushed in a custom-made tissue grinder to release the eggs and juveniles. These nematode stages were suspended in water and counted in duplicate under an inverted transmitted light microscope (63 x magnification), using 2 x $1 \mathrm{ml}$ aliquot portions. During counting, eggs and juveniles were classified into healthy (normally developed, intact $\mathrm{J} 2$ inside) or diseased (abnormal development or obviously colonized by microbes).

\subsection{Statistical analysis}

Analysis of variance was carried out using a split-plot model in SAS (version 9.4, SAS Institute, Cary, NC, USA). Analyses were performed for each experiment separately. For nematode numbers, the depth factor was analyzed as a strip factor within the split-plot model. Count data was $\log _{10}$-transformed, whereas percentages were arcsine-transformed. For each year, pooling of error terms was done where possible to simplify models in Proc GLM. Mean separation was conducted in Proc MIXED. To compare nematode populations, growth and yield parameters between years, data was analyzed as repeated measurements using the GLIMMIX procedure. Specific comparisons were tested and their p-values adjusted with the Edwards and Berry's simulation method. Statistical significance was set at $P \leq 0.05$. Results obtained from Proc MIXED are presented as means \pm se. Results obtained from Proc GLIMMIX are presented as back-transformed lsmeans \pm lsmse. 


\section{Results}

\section{$\underline{\text { Root penetration at Münster }}$}

The penetration rate was mostly influenced by the cultivar.

Schach0. Averaged across treatment, root penetration rate was more numerous in Beretta than Sanetta and Pauletta each year (data not shown). In 2012, Sanetta had a reduced penetration rate in plots amended with $D$. oviparasitica in $2011(1.2 \pm 0.3)$ than in untreated control plots $(5.8 \pm$ 2.4; $P=0.0182$; Fig. 4.1A,D). An increase in penetration rate was observed from 2010 to 2013 in all treatments and cultivars (Fig. 4.1).

Schach1. Averaged across treatment, root penetration rate was higher in Beretta than Pauletta and similar to Sanetta in 2010 and 2011. In 2012 and 2013 no significant differences among cultivars were observed, except that in 2013 Beretta $(9.3 \pm 3.0)$ had a larger penetration rate than Sanetta $(2.5 \pm 1.0)$ in $P$. nishizawae plots $(P=0.0180$; Fig. 4.2B). Between 2010 and 2013 in untreated plots, penetration rate in Beretta increased 330\% from 2010 to $2011(P=0.0040)$ and then decreased $70 \%$ to $2013(P=0.0370$; Fig. 4.2A). In Sanetta it increased $690 \%$ from 2010 to 2013 ( $P<0.01)$, and in Pauletta it increased 370\% from 2010 to 2012 ( $P=0.0267$; Fig. 4.2A). In $P$. nishizawae plots, penetration rate increased $230 \%$ from 2010 to 2013 in Beretta $(P=0.0319)$, remained similar in Sanetta, and increased 310\% from 2010 to 2012 in Pauletta $(P=0.0319$; Fig. 4.2B). In D. oviparasitica plots and corresponding control, penetration rate increased between $826 \%$ and 2,440\% from 2010 to 2013 in all cultivars (Fig. 4.2C,D).

\section{$\underline{\text { Root penetration at Braunschweig }}$}

In 2013, root penetration did not differ among cultivars. In 2014 in untreated control, $P$. nishizawae, D. oviparasitica and Nemathorin plots it was more numerous in Beretta than Sanetta (data not shown). Between 2013 and 2014, penetration rate in untreated control remained similar in Beretta and Pauletta and decreased $70 \%$ in Sanetta $(P<0.01$; data not shown). In $P$. nishizawae and D. oviparasitica plots, it increased $200 \%$ and $480 \%$ in Beretta, respectively. In Sanetta it decreased 80\%, and in Pauletta remained similar (data not shown). In Nemathorin plots, penetration rate increased 1,140\% and 960\% in Beretta and Pauletta, respectively, and remained similar in Sanetta (data not shown).

In the soil transfer experiment in 2014 , no significant effect of treatment or cultivar was found in root penetration (data not shown). 


\section{$\underline{\text { Population densities at Münster }}$}

Overall, differences in the population densities were observed among susceptible (Beretta), resistant (Sanetta) and tolerant (Pauletta) cultivars. An effect of the amendments with D. oviparasitica or P. nishizawae on nematode population densities was seldom when compared to the corresponding control plots, and was only observed under the resistant cultivar. In both pathotypes, final population densities (determined at harvest) of cysts and total eggs were higher at the 0 - to 30- than at the 30- to 60-cm depth (data not shown).

Schach0. Averaged across depth and treatment, final population densities of cysts were higher under Beretta than Sanetta and Pauletta each year. In 2013 however, these were higher under Beretta than Sanetta but similar to Pauletta. Averaged across depth and treatment, final populations of total eggs were higher under Beretta than Sanetta each year. In 2010 and 2012, these were also higher under Beretta than Pauletta, and higher under Pauletta than Sanetta. In 2010, final populations of total eggs under Sanetta, were lower in D. oviparasitica than untreated control plots (data not shown). In 2013, also under Sanetta, final populations of total eggs were lower in D. oviparasitica (second inoculation in 2011) than in untreated control plots and plots that received the first $D$. oviparasitica inoculation in 2011 (data not shown). Also in $P$. nishizawae plots, final populations of total eggs under Sanetta were lower than in untreated control plots in 2013 (data not shown). In 2010, 10.2\% of the total eggs were diseased. In 2011, this percentage increased to $67.0 \%$, and to $94.3 \%$ in 2013 (data not shown). Final proportion of diseased eggs increased $850 \%$ from 2010 to 2013 ( $P<0.01$; data not shown).

At 0- to 30-cm depth. Between 2010 and 2013, final populations of cysts remained similar under Beretta, and slightly increased by $40 \%$ and 30\% from 2010 to 2013 under Sanetta and Pauletta, respectively (Fig. 4.3A). Final populations of total eggs decreased 50\% from 2010 to 2012 under Beretta and Pauletta (Fig. 4.3B). Under Sanetta, these decreased 60\% from 2010 to 2012 and then increased $120 \%$ to 2013 (Fig. 4.3B).

At 30- to 60-cm depth. Final populations of cysts decreased by 30\% and 40\% from 2011 to 2012, and then increased 20\% and 70\% to 2013 under Beretta and Sanetta, respectively (data not shown). Under Pauletta, these increased by 40\% from 2010 to 2013 ( $P=0.0010$; data not shown). Final populations of total eggs decreased between $70 \%$ and $80 \%$ from 2010 to 2012, and then increased between $120 \%$ and $220 \%$ to 2013 under the three cultivars (data not shown). 
Schach1. Averaged across depth, final populations of cysts in 2010 were higher under Beretta than Pauletta in all treatments with the exception of untreated control, and higher under Beretta than Sanetta in P. nishizawae plots only (data not shown). In 2011 and 2012, these were higher under Beretta than Sanetta and Pauletta (data not shown). In 2013, no effect of the cultivar was observed on final populations of cysts. Final populations of total eggs in 2010 were similar among cultivars in untreated control plots. In P. nishizawae plots, these were higher under Beretta than Sanetta and similar to Pauletta (data not shown). In D. oviparasitica plots, numbers were higher under Beretta than Sanetta and Pauletta (data not shown). In the D. oviparasitica corresponding control (dazomet-treated), they were higher under Beretta and Sanetta than Pauletta (data not shown). In 2010 under Sanetta, final populations of total eggs were smaller in D. oviparasitica $(7,984 \pm 2,324)$ than in the corresponding control $(20,683 \pm 5,861 ; P=0.0247)$. In 2011, final populations of total eggs were higher under Beretta than Sanetta and Pauletta, and higher under Sanetta than Pauletta (data not shown). In 2012, final populations of total eggs in the untreated control were higher under Sanetta than Pauletta and similar to Beretta (data not shown). In P. nishizawae plots, they were higher under Beretta than Sanetta and Pauletta (data not shown). In D. oviparasitica plots and the corresponding control, they were higher under Beretta and Sanetta than Pauletta (data not shown). In 2012 under Sanetta, final populations of total eggs were smaller in P. nishizawae plots than in any other treatment. In 2013, higher populations of total eggs were found under Beretta than Pauletta (data not shown). For the final percentage of diseased eggs, no cultivar effect was observed, except that in 2013 percentages were higher under Sanetta than Pauletta (data not shown). In 2010, 11.8\% of the total eggs were diseased. On average, this percentage increased to $49.5 \%$ in 2011, and to 91.6\% in 2013 (data not shown). Proportion of diseased eggs increased 740\% from 2010 to 2013 (P <0.01; data not shown).

At the 0- to 30-cm depth. Between 2010 and 2013, final populations of cysts remained similar in the untreated control and $P$. nishizawae plots under all cultivars (Fig. 4.4A,B). In $D$. oviparasitica plots, these remained similar under Beretta and increased 50\% and 40\% from 2010 to 2013 under Sanetta and Pauletta, respectively (Fig. 4.4C). As in D. oviparasitica plots, similar observations were made for the D. oviparasitica corresponding control, except that populations remained similar under Sanetta (Fig. 4.4D). 
Final population densities of total eggs in the untreated control remained similar under Beretta and Sanetta and decreased 60\% from 2010 to 2013 under Pauletta $(P<0.01$; Fig. 4.5A). In P. nishizawae plots, these remained similar under all cultivars (Fig. 4.5B). In D. oviparasitica plots these decreased 80\% from 2010 to 2013 under Beretta $(P<0.01)$, increased by $110 \%$ from 2010 to $2011(P=0.0272)$ and then decreased by $60 \%$ to 2013 under Sanetta $(P<0.01)$, and remained similar under Pauletta (Fig. 4.5C). In D. oviparasitica corresponding control, numbers decreased 90\% and 70\% from 2010 to 2013 under Beretta and Sanetta, respectively, and remained similar under Pauletta (Fig. 4.5D).

At the 30- to $60-\mathrm{cm}$ depth. Final populations of cysts in the untreated control decreased $40 \%$ from 2011 to 2012 under Beretta $(P<0.01)$, and remained similar under Sanetta and Pauletta (data not shown). In P. nishizawae plots, numbers decreased 30\% from 2010 to 2012 under Beretta and Sanetta, and remained similar under Pauletta (data not shown). In D. oviparasitica plots, these remained similar under Beretta and Sanetta, and increased 40\% from 2012 to 2013 under Pauletta $(P=0.0342$; data not shown). In the $D$. oviparasitica corresponding control, final populations of cysts remained similar under all cultivars (data not shown).

Final populations of total eggs in the untreated control decreased 60\% from 2010 to 2012 under Beretta, remained similar under Sanetta, and decreased 50\% from 2011 to 2012 under Pauletta (data not shown). In P. nishizawae plots, numbers remained similar under Beretta and Pauletta. Under Sanetta these decreased 60\% from 2010 to $2012(P<0.01)$, and then increased $170 \%$ to 2013 ( $P<0.01$; data not shown). In D. oviparasitica plots, final populations of total eggs decreased 50\% from 2010 to 2012 under Beretta, remained similar under Sanetta, and decreased 50\% from 2011 to 2012 under Pauletta (data not shown). In D. oviparasitica corresponding control, these decreased $80 \%$ and 60\% from 2010 to 2013 under Beretta and Sanetta, respectively. Under Pauletta, these decreased 50\% from 2011 to 2012 ( $P=0.0223$; data not shown).

\section{Population densities at Braunschweig}

In 2013, differences in nematode population densities were observed among susceptible (Beretta), resistant (Sanetta) and tolerant (Pauletta) cultivars, but the three soil treatments did not result in lower population densities than in the untreated control plots. In untreated and $P$. nishizawae plots, final population densities of cysts under Beretta were similar at both depths, 
and higher at the 0- to 30-cm depth than at the 30- to 60-cm depth under Sanetta and Pauletta. In D. oviparasitica and Nemathorin plots, they were similar at both depths under Beretta and Sanetta, and higher at the 0- to 30- than at the 30- to $60-\mathrm{cm}$ depth under Pauletta. Final populations of total eggs were similar at both depths under Beretta, and higher at 0- to 30-cm depth than at 30- to 60-cm depth under Sanetta and Pauletta. No differences were found in percentages of diseased eggs, except that these were higher at the 30- to 60-cm depth than at the 30- to 60-cm depth.

In 2014, final populations of cysts were similar at both depths in all treatments and cultivars. Averaged across depth in untreated control, final populations of cysts were higher under Beretta than Sanetta but similar to Pauletta. In P. nishizawae plots and Nemathorin plots, these were higher under Pauletta than Sanetta but similar to Beretta. In D. oviparasitica plots, these were similar among cultivars. Final populations of total eggs were similar among depth, cultivars and treatments, with the exception of comparisons including the non-infested control. Percentage values of diseased eggs were similar among cultivars in all treatments, except in the untreated control where they were higher under Beretta than Pauletta.

Between 2013 and 2014 proportions of diseased eggs remained similar.

At 0 - to 30-cm depth. In 2013 final populations of cysts in the untreated control and $D$. oviparasitica plots were higher under Beretta than Sanetta and similar to Pauletta. In D. oviparasitica, P. nishizawae, and Nemathorin plots, these were higher under Pauletta than Sanetta and similar to Beretta. Final populations of total eggs in the untreated control and $D$. oviparasitica plots were higher under Beretta than Sanetta. In P. nishizawae and Nemathorin plots these were similar among cultivars. Between 2013 and 2014, final populations of cysts increased under all cultivars and treatments. Final populations of total eggs remained similar under all cultivars in the untreated control, $P$. nishizawae and Nemathorin plots. In $D$. oviparasitica plots, these remained similar under Beretta and Pauletta, and increased $450 \%$ under Sanetta $(P=0.0423)$.

At the 30- to 60- cm depth. In 2013, final populations of cysts in untreated control and $D$. oviparasitica plots were higher under Beretta than Sanetta and Pauletta. In P. nishizawae these were higher under Beretta and Pauletta than Sanetta. In Nemathorin plots these were higher under Beretta than Sanetta and similar to Pauletta. Final populations of total eggs were higher under Beretta than Sanetta in all treatments with the exception of the non-infested control. 
Between 2013 and 2014, final populations of cysts increased under all cultivars and treatments, except in non-infested plots. Final populations of total eggs remained similar under Beretta and increased $640 \%$ and $430 \%$ under Sanetta in the untreated control and D. oviparasitica plots, respectively. Under Pauletta these increased 1,230\% and $650 \%$ in the untreated control and $D$. oviparasitica plots, respectively. In $P$. nishizawae plots final population of total eggs remained similar under Beretta and Pauletta and increased 1,460\% under Sanetta $(P<0.01)$. In Nemathorin plots, these remained similar under Beretta and Sanetta and increased 590\% under Pauletta $(P=$ $0.0217)$.

In the soil transfer experiment in 2014, final populations of cysts and total eggs were higher at the 0- to 30- than at the 30- to 60-cm depth. Averaged across depth and treatment, final populations of cysts were higher under Beretta than Sanetta and Pauletta, and higher under Sanetta than Pauletta. Averaged across depth, final population of total eggs in untreated control plots were higher under Beretta and Sanetta than Pauletta. In P. nishizawae plots, these were higher under Beretta than Sanetta and Pauletta. On average, percentage of diseased eggs was higher under Beretta and Sanetta than Pauletta.

\section{Growth and yield at Münster}

Overall, differences were observed among cultivars, but almost no yield increase was observed in plots amended with D. oviparasitica or $P$. nishizawae compared to corresponding control plots.

Schach0. Overall, canopy diameter, top and taproot fresh weights, and WSY (Fig. 4.6) were higher in Pauletta than Beretta and Sanetta. Canopy diameter and top weight decreased from 2010 to 2011, and then increased from 2011 to 2013 in all cultivars, except that in Sanetta top weight increased from 2010 to 2013 (data not shown). Taproot weight and WSY (Fig. 4.6) increased up to $90 \%$ from 2010 to 2013 in Beretta and Sanetta, but remained similar in Pauletta.

Schach1. Overall, canopy diameter, top and taproot fresh weight, and WSY (Fig. 4.7) were higher in Pauletta than Beretta and Sanetta. In 2011 however, higher top weight of Pauletta compared to Beretta and Sanetta was only observed in D. oviparasitica plots (data not shown). In the same year, Pauletta in D. oviparasitica plots had a higher top weight $(434.4 \pm 55.4)$ than in the corresponding control $(277.2 \pm 35.4 ; P=0.0523$; data not shown). 
Canopy diameter decreased from 2010 to 2011 and then increased to 2013 in all treatments and cultivars (data not shown). Top weight in untreated control increased $120 \%$ from 2010 to 2013 in Beretta $(P<0.01)$, remained similar in Sanetta, and decreased 40\% from 2010 to 2011 in Pauletta ( $P=0.0155$; data not shown). In $P$. nishizawae plots and in the D. oviparasitica corresponding control, top weight remained similar in all cultivars during the extent of the experiment (data not shown). In D. oviparasitica plots, it decreased 50\% from 2010 to 2011 and then increased 60\% from 2011 to 2013 in Beretta, whereas in Sanetta and Pauletta remained similar (data not shown). Taproot weight in the untreated control increased 130\% from 2010 to 2013 in Beretta, it increased 60\% from 2010 to 2012 in Sanetta, and remained similar in Pauletta (data not shown). In P. nishizawae plots, taproot weight remained similar in Beretta and Pauletta, and increased 60\% from 2010 to 2012 in Sanetta $(P=0.0353$; data not shown). In $D$. oviparasitica plots, it decreased 50\% from 2010 to 2011 and then increased 60\% from 2011 to 2013 in Beretta, whereas in Sanetta and Pauletta remained similar (data not shown). In the $D$. oviparasitica corresponding control, it remained similar in all cultivars during the extent of the experiment. WSY in untreated control increased 130\% from 2010 to 2013 in Beretta, 60\% from 2010 to 2012 in Sanetta, and remained similar in Pauletta (Fig. 4.7A). In P. nishizawae plots WSY increased 60\% from 2010 to 2013 in Beretta $(P=0.0531)$ and 60\% from 2010 to 2011 in Sanetta, whereas in Pauletta remained similar ( $P=0.0462$; Fig. 4.7B). In D. oviparasitica plots it decreased 50\% from 2010 to 2011 and then increased 60\% from 2011 to 2013 in Beretta. In Sanetta and Pauletta it remained similar (Fig. 4.7C). In the D. oviparasitica corresponding control it remained similar in all cultivars during the extent of the experiment (Fig. 4.7D).

\section{Growth and yield at Braunschweig}

Overall, differences were observed among cultivars, but no yield increase was observed in the three treatments compared to the untreated control plots.

In 2013, averaged across treatment, canopy diameter was highest in Pauletta, second highest in Beretta, and lowest in Sanetta. Top, taproot weight, and WSY in untreated control and Nemathorin plots were similar in all cultivars. In P. nishizawae plots, these were higher in Pauletta than Beretta and Sanetta. In D. oviparasitica plots, top and taproot weight were similar in all cultivars, and WSY was higher in Pauletta than Beretta and Sanetta. 
In 2014, canopy diameter in the untreated control, P. nishizawae and D. oviparasitica plots was larger in Sanetta and Pauletta than Beretta. In Nemathorin plots, it was larger in Sanetta than Beretta and similar to Pauletta. Top weight in the untreated control, P. nishizawae and Nemathorin plots was higher in Sanetta and Pauletta than Beretta. In D. oviparasitica plots, it was similar among cultivars. Taproot weight and WSY were higher in Sanetta and Pauletta than Beretta in all treatments with the exception of the non-infested plots. However, no WSY was obtained for Beretta in P. nishizawae plots.

In all treatments in the time course of the experiment, canopy remained similar in Beretta, and increased in Sanetta and Pauletta. Top weight in untreated control and Nemathorin plots remained similar in Beretta, and increased in Sanetta and Pauletta. In P. nishizawae plots top weight decreased $40 \%$ in Beretta $(P=0.0311)$, and increased $240 \%$ and $110 \%$ in Sanetta and Pauletta, respectively. In D. oviparasitica plots it increased $170 \%, 250 \%$, and $130 \%$ in Beretta, Sanetta and Pauletta, respectively. Taproot weight in the untreated control remained similar in Beretta and Pauletta, and increased $220 \%$ in Sanetta $(P<0.01)$. In $P$. nishizawae plots it decreased $50 \%$ in Beretta $(P<0.01)$, and increased $240 \%$ and $90 \%$ in Sanetta and Pauletta, respectively. In D. oviparasitica and Nemathorin plots it remained similar in Beretta, and increased between $100 \%$ and $250 \%$ in Sanetta and Pauletta. WSY in the untreated control increased 70\%, 200\%, and 60\% in Beretta, Sanetta and Pauletta, respectively. In D. oviparasitica and Nemathorin plots, WSY remained similar in Beretta, and increased between $80 \%$ and $280 \%$ in Sanetta and Pauletta.

In the soil transfer experiment in 2014, canopy diameter was larger in Pauletta than Beretta and Sanetta. In top weight, no significant effect of treatment or cultivar was found. Taproot weight and WSY were higher in Beretta and Pauletta than Sanetta.

\section{Discussion}

Our results showed that amendment with $D$. oviparasitica or $P$. nishizawae were not consistent in reducing $H$. schachtii population densities or increasing yield compared to the corresponding controls. Interestingly, an effect of these amendments on the population densities was only observed under the resistant cultivar. In California, D. oviparasitica was considered the major agent in suppressing root-knot nematodes in a peach orchard, and later was shown to be 
one of the most abundant fungi in H. schachtii cysts from the suppressive 9E soil (Stirling et al., 1979; Westphal and Becker, 2001; Yin et al., 2003). However, lack of soil receptivity can be expected when introducing non-native organisms to the soil. Through parasitism, competition for nutrients, and microbiostasis, soil microbiota can negatively impact the establishment of nematode-parasitic fungi (Cook and Baker, 1983; De Boer et al., 2003; Monfort et al., 2006). The incapacity showed by populations of rhizobacteria introduced on seed or into the soil, to persist in time after a successful establishment, and their eventual decrease, illustrates the great impact of biological buffering (Kluepfel 1993; Weller and Thomashow 1994). Low levels of $D$. oviparasitica in H. schachtii cysts from field suppressive soils were found by Yang et al. (2012), suggesting that other microorganisms competed with D. oviparasitica in the cysts and eventually replaced this fungus. Competition is not the only obstacle biological control organisms face when applied to soil. It has been inferred that collembolans and enchytraeid worms consumed pellets containing nematophagous fungi when they were introduced into non-sterile soil (Jaffee et al., 1996, 1997). Later, Jaffe (1999) indicated interference by organisms smaller than $20 \mu \mathrm{m}$ with the fungal inoculums.

A second amendment of D. oviparasitica in 2011was only able to reduce Schach0 total egg populations under the resistant cultivar when compared to the untreated control, after the last cropping cycle in 2013. Although a reduction in 2013 was also observed in comparison to the one single amendment in 2011, no significant difference between these two treatments was observed in previous years. In microplot and greenhouse experiments, a single application of $D$. oviparasitica strain 50 led to a stable $H$. schachtii suppressiveness over the entire experimental period (Olatinwo et al., 2006b). The success of D. oviparasitica in parasitizing nematodes and to survive and compete with other microorganisms has been related to its ability to occupy the rhizoplane of host plants (Stirling, 1991; Olatinwo et al., 2006b). Since microbial population densities are 10 to 20 times greater in the rhizosphere than in the bulk soil (Weller and Thomashow 1994; Dandurand and Knudsen 2002), the inability of D. oviparasitica to establish successfully, can be explained by the exposure to the competitive soil environment.

Since various biocidal treatments, including heat, reduce soil buffering (Mankau, 1962), thus enhancing the chances for introduced microorganisms to establish successfully, $D$. oviparasitica was inoculated into soil pre-treated with dazomet in Schach1 plots. This treatment resulted in a reduction of final populations of total eggs under the resistant cultivar, compared to 
the corresponding control (basamid-treated plots without the fungus) after the first cropping cycle in 2010. This difference was not maintained in the subsequent cropping cycles, suggesting that the suppressiveness due to D. oviparasitica was not sustainable in this context. Application of $D$. oviparasitica strain 50 into fumigated soils in greenhouse trials has resulted in suppression of H. schachtii (Olatinwo et al., 2006a). In a follow-up experiment in field microplots, Olatinwo et al. (2006b) confirmed the suppressing ability of D. oviparasitica after inoculation into fumigated soil, although this effect was only measured during one cropping season. The different conditions and duration of the experiments, could explain the different results. Recolonization of the soil after soil fumigation by microorganisms that interfered with the persistence of $D$. oviparasitica, may also explain the unsustainable effect of this fungus in our microplots. Olatinwo et al. (2006a) found that adding D. oviparasitica strain 50 to the non-suppressive soil before $H$. schachtii infestation led to a significant reduction in cysts and egg populations that could develop compared with the simultaneous addition of the fungus and the nematode. Since in our experiments, amendment with D. oviparasitica was done in plots that were already infested with the nematode, it can be inferred, that the fungus did not have sufficient growth time before roots started to develop.

In plots that received the amendment of $P$. nishizawae, almost no suppression of $H$. schachtii was found when compared with untreated control plots. Spores of Pasteuria are endoparasitic, and thus do not grow outside of the nematode but still they are subjected to myriads of soil organisms. Chen and Dickson (1998) have suggested the possibility that microfauna feed on spores in field soil, especially if spore density is high. Talavera et al. (2002) suggested that amoebae and rotifers could have fed on spores of Pasteuria. Even though watering alone can have a positive distribution effects on spores of Pasteuria penetrans (Talavera et al., 2002), their downward dispersal with percolating water resulting from rainwater or irrigation can lead to a depletion of spores in the top 15 to $20 \mathrm{~cm}$ of soil if they are not continuously amplified in that soil layer (Cetintas and Dickson, 2005). Leaching of endospores is also greater in sandy than in clay soils. Under a drip system, $76 \%$ of endospores leached $10 \mathrm{~cm}$ after $24 \mathrm{~h}$ in sand. With increasing clay content fewer endospores leached, since spores can get trapped within clay aggregates (Dabire and Mateille, 2004). In our study, 4.4\% of clay content at Münster is below the percentages considered to be optimal for biological control with $P$. penetrans $(10 \%-30 \%)$. 
In contrast to the results obtained by Noel et al. (2010), who found that Pasteuria nishizawae was succesfully transferred to a soybean field and resulted in reduced populations of H. glycines and increased yield, transfer of soil infested with P. nishizawae into untreated soil at Braunschweig, did not have an effect in populations of $H$. schachtii or yield compared to the control. The study of Noel et al. (2010) also demonstrated that $P$. nishizawae can affect numbers of $H$. glycines associated with a resistant cultivar. Suppression of $H$. schachtii under the resistant cultivar was not observed during the cropping cycles that immediately followed the bacterial amendment but a reduced final egg population of Schach0 in P. nishizawae plots under the resistant cultivar was observed after the last cropping cycle. This agrees with experiments on root-knot nematodes, where several generations of the host nematode seemed necessary for measuring the suppressiveness (Gowen and Channer, 1988).

In spite of the unstable effect of $D$. oviparasitica and $P$. nishizawae amendments to reduce $H$. schachtii populations compared to control plots, final populations of total eggs at Münster mostly decreased or remained similar. Population decline of $H$. schachtii under a sugar beet monoculture were observed by Thielemann and Steudel (1973) in a field at Elsdorf, Germany, and by Heijbroek (1983) in the Netherlands. In the UK, Crump and Kerry (1987) found that there was little population increase of $H$. schachtii in the untreated soil during a three year-field trial. After four years of monitoring, the decline of Schach0 egg final populations under the susceptible cultivar (20\%) was similar to the decline observed by Thielemann and Steudel (10\%) and by Heijbroek (30\%). In Schach1 however, eggs final populations under the susceptible cultivar decreased by $70 \%$ after four years. On the other hand, diseased eggs presenting fungal hyphae or physiologically disordered content that represented around $10 \%$ in 2010, increased by 2013 to $94 \%$ and $92 \%$ in Schach0 and Schach1, respectively. This pronounced increase in diseased eggs in both pathotypes suggests the presence of controlling agents in this sugar beet monoculture. High numbers of diseased eggs were also observed by Bursnall and Tribe (1974) in H. schachtii, by Morgan-Jones et al. (1981) in H. glycines, and by Dackman (1990) and Eberlein et al. (2016) in potato cyst nematodes. Interestingly, the observed increase in diseased eggs was found among all cultivars of sugar beet, suggesting that not only susceptible genotypes are able to support the development of soil suppressiveness, but also resistant and tolerant genotypes. Westphal and Becker (2001) found that soil suppressiveness against $H$. schachtii was reduced after a double crop of the non-host Triticum aestivum but 
preserved after cropping of resistant cultivars of sugar beet or oil radish. Cotton, watermelon and melon resistant cultivars to their respective Fusarium wilt, some of them grown in monoculture, have been shown to induce soil suppressiveness against the causal agent of this disease (Katan et al. 1983; Hopkins et al., 1987; Sneh et al. 1987). Hopkins et al. (1987) also found that the suppressiveness that developed after monoculture of a resistant watermelon cultivar was

effective on all cultivars. It seems that resistant cultivars not only have the ability per se to reduce the population densities of a pathogen, but also indirectly by enhancing microbial antagonists that are able to survive under reduced populations of the pathogen, thus inducing the development of soil suppresiveness.

At Münster, penetration rate in Schach0 was higher in the susceptible than in the resistant and tolerant cultivars, whereas in Schach1, it was higher in the susceptible than in the tolerant cultivar the first two years, but thereafter similar among the cultivars. Similar penetration rates of H. schachtii in different sugar beet genotypes are frequently found (Westphal, unpublished). Differences are detected sometimes too, so overall it is not fully understood what mechanisms impact this biological phenomenon. In soybean for example, fewer J2 were present in roots of resistant than susceptible cultivars at 14 days after planting (Niblack et al., 1986).

As expected, the tolerant cultivar produced the highest yields in both pathotypes. Under high population densities but also under very low population densities, tolerant sugar beet cultivars are able to have a high yield, and almost identical compared to non tolerant cultivars (Heinrichs, 2013; Kaemmerer et al., 2014). In contrast, resistant cultivars have a lower yield potential than tolerant or susceptible cultivars, especially in the absence of or under low population densities of the respective nematode, where they can yield $15 \%$ less compared to susceptible cultivars (Bürcky, 2013; Schlinker, 2010, 2012).

\section{Conclusion}

An inconsistent effect of $D$. oviparasitica or P. nishizawae amendments on $H$. schachtii population densities or yield was found. A suppressive effect of the monoculture was evident by the rapid and dramatic increase in diseased eggs that constituted over $90 \%$ of the total eggs by the third cropping cycle in both pathotypes. Irrespective of the cultivar that was cropped, this pronounced increase in diseased eggs, suggests the compatibility of controlling factors with 
different sugar beet genotypes. The use of resistant and tolerant cultivars that can support the development of suppressiveness despite reduced populations of the pest nematode, could bypass the yield penalty of generating soil suppressiveness by monoculture of susceptible hosts.

\section{Aknowledgments}

The authors thank J.O. Becker for the provision of Dactylella oviparasitica and T. Hewlett for the provision of $P$. nishizawae. Both organisms were introduced from the US with the proper permits from the regional German Plant Protection authorities. The authors thank the teams at JKI Münster and JKI Braunschweig who made these studies possible. The authors thank the sugar beet processing laboratories at Jülich and at KWS, Kleinwanzleben, Germany. The first author was supported by Conicyt for the duration of these studies that were conducted during employment of the corresponding author with JKI. The mentorship by Dr. Stefan Vidal during the $\mathrm{Ph} . \mathrm{D}$. program of the first author is greatly appreciated.

\section{References}

Baker, K.F., and Cook, R.J. 1974. Biological control of plant pathogens. American Phytopathological Society, St. Paul, MN.

Borneman, J. and Becker, J. O. 2007. Identifying Microorganisms Involved in Specific Pathogen Suppression in Soil. Annu Rev Phytopathol 45:153-172.

Buchholz, K., Märländer, B., Puke, H., Glattkowski, H., Thielecke, K., 1995. Neubewertung des technischen Wertes von Zuckerrüben. Zuckerindustrie 120: 154-161.

Bursnall, L.A. \& Tribe, H.T. 1974. Fungal parasitism in cysts of Heterodera II. Egg parasites of H. schachtii. Trans Br Mycol Soc 62: 595-601.

Bürcky, K. 2013. Aktuelle Sortenergebnisse und Empfehlungen. Deut Zuckerrübenz 49: 14-19.

Byrd, D.W., Kirkpatrick, T., Jr., and Barker, K.R. 1983. An improved technique for clearing and staining plant tissues for detection of nematodes. J Nematol 15: 142-143.

Cetintas, R., Dickson, D.W. 2005. Distribution and downward movement of Pasteuria penetrans in field soil. J Nematol 37: 155-160. 
Chen, S.Y. 2007. Suppression of Heterodera glycines in soils from fields with long-term soybean monoculture. Biocontrol Sci Technol 17: 125-134.

Chen, Z.X., Dickson, D.W. 1998. Review of Pasteuria penetrans: biology, ecology and biological control potential. J Nematol 30: 313-340.

Cook, R.J. 1981. The influence of rotation crops on Take-All decline phenomenon. Phytopathology 71: 189-192.

Cook, R. J., and Baker, K. F. 1983. The Nature and Practice of Biological Control of Plant Pathogens. The American Phytopathological Society, St. Paul, MN.

Crump, D.H., Kerry, B.R. 1987. Studies on the population dynamics and fungal parasitism of Heterodera schachtii in soil from a sugar-beet monoculture. Crop Prot 6: 49-55.

Dabire, K.R., Mateille, T. 2004. Soil texture and irrigation influence the transport and the development of Pasteuria penetrans, a bacterial parasite of root-knot nematodes. Soil Biol Biochem 36: 539-543.

Dackman, C. 1990. Fungal parasites of the potato cyst nematode Globodera rostochiensis: isolation and reinfection. J Nematol 22: 594-597.

Dandurand, L.M.C., Knudsen, G.R. 2002. Sampling microbes from the rhizosphere and phyllosphere. In: Hurst C.J., Crawford R.L., Knudsen G.R., McInerney M.J., Stetzenbach L.D. (Eds.), Manual of Environmental Microbiology, ASM Press, Washington DC (2nd ed), pp. 516-526.

De Boer, W., Verheggen P., Gunnewiek, P.J.A.K., Kowalchuk, G.A, Van Veen, J.A. 2003 Microbial community composition affects soil fungistasis. Appl Environ Microbiol 69: 835-844.

Eberlein, C., H. Heuer, S. Vidal, and A. Westphal. 2016. Population dynamics of Globodera pallida under potato monoculture. Nematropica 46: 114-120.

Gair, R., Mathias, P.L., Harvey P.N. 1969. Studies of cereal cyst nematode populations and cereal yields under continuous or intensive culture. Ann Appl Biol 63: 503-512.

Gowen S.R., Channer A.G. De R. 1988. The production of Pasteuria penetrans for the control of root-knot nematodes. Proceedings of the Brighton Crop Protection Conference on Pests and Diseases. British Crop Protection Council, Surrey, pp. 1215-1220. 
Heijbroek, W. 1983. Some effects of fungal parasites on the population development of the beet cyst nematode (Heterodera schachtii Schm.) Meded Fac Landbouwwet Rijksuniv Gent 48: 433-439.

Heinrichs, C. 2013. Der Acker lebt auch in der Tiefe. Zuckerrübenjournal 02/2013, 14-15.

Jaffee, B. A. 1999. Enchytraeids and nematophagous fungi in tomato fields and vineyards. Phytopathology 89: 398-406.

Jaffee, B.A., Muldoon, A.E. and Westerdahl, B.B. 1996. Failure of a mycelial formulation of the nematophagous fungus Hirsutella rhossiliensis to suppress the nematode Heterodera schachtii. Biol Control 6: 340-346.

Jaffee, B. A., Santos, P. F., and Muldoon, A. E. 1997. Suppression of nematophagous fungi by enchytraeid worms: A field exclosure experiment. Oecologia 112: 412-423.

Janvier, C., Villeneuve, F., Alabouvette, C., Edel-Hermann, V., Mateille, T., \& Steinberg, C. 2007. Soil health through soil disease suppression: which strategy from descriptors to indicators?. Soil Biol Biochem 39: 1-23.

Kaemmerer, D., Meinecke, A., Hermann, A., Anselstetter, M., Göbel, E., Bürcky, K., Ziegler, K. and Westphal, A. 2014. Nematodenvermehrung und Ertragslesitung verschiedener Zuckerrüben-Genotypen. In: Maßnahmen zur Schadensminderung von Heterodera schachtii im Zuckerrübenbau. Bayerische Landesanstalt für Landwirtschaft. FreisingTüntenhausen, Germany. pp. 44-54.

Kerry, B.R. \& Andersson, S. 1983. Nematophthora gynophila och Verticillium chlamydosporium, svampparasiter pa cystnematoder, vanliga isvenska jorda med forekomst av strasadescystnematoder. Vaxtskyddsnotiser 47: 79-80.

Kerry, B. R. 1990. An assessment of progress toward microbial control of plant-parasitic nematodes. Supplement to Journal of Nematology 22: 621-631.

Kluepfel, D.A. 1993. The behavior and tracking of bacteria in the rhizosphere. Annu Rev Phytopathol 31: 441-472.

KWS SAAT. 2015. http://www.kws.de/go/id/dxgr/ (revised on 13.08.2015).

Mankau, R. 1962. Soil fungistasis and nematophagous fungi. Phytopathology 52: 611-615.

Mazzola, M. 2004. Assessment and management of soil microbial community structure for disease suppression. Annu Rev Phytopathol 42: 35-59. 
Meier, U., Bachmann, E., Buhtz, H., Hack, H., Klose, R., Märländer, B.\& Weber, E. 1993. Phenological growth stages of beta beets (Beta vulgaris L. spp.). Nachrichtenbl Deut Pflanzenschutzd 45: 37-41.

Montfort, E., Lopez-Llorca, L.V., Jansson, H.B., Salinas, J. 2006. In vitro receptivity assays to egg-parasitic nematophagous fungi. Mycol Prog 5:18-23.

Morgan-Jones, G., Gintis, B.O. \& Rodriguez-Kabana, R. 1981. Fungal colonization of Heterodera glycines cysts in Arkansas, Florida, Mississippi and Missouri soils. Nematropica 11: 155-163.

Müller, J. 1980. Ein verbessertes Extraktionsverfahren für Heterodera schachtii. [An improved method for the extraction of Heterodera schachtii.] Nachrichtenbl Deut Pflanzenschutzd 32: $21-24$.

Müller, J. 1998. New pathotypes of the beet cyst nematode (Heterodera schachtii) differentiated on alien genes for resistance in beet (Beta vulgaris). Fundam Appl Nematol 21: 519-526.

Niblack, T.L., Hussey, R.S., and Boerma, H.R. 1986. Effects of Heterodera glycines and Meloidogyne incognita on early growth of soybean. J Nematol 18: 444-450.

Noel, G. R., Atibalentja, N., \& Bauer, S. J. 2010. Suppression of Heterodera glycines in a soybean field artificially infested with Pasteuria nishizawae. Nematropica 40: 41-52.

Olatinwo, R., Yin, B., Becker, J. O., \& Borneman, J. 2006a. Suppression of the plant-parasitic nematode Heterodera schachtii by the fungus Dactylella oviparasitica. Phytopathology 96: 111-114.

Olatinwo, R., Borneman, J., \& Becker, J. O. 2006b. Induction of beet-cyst nematode suppressiveness by the fungi Dactylella oviparasitica and Fusarium oxysporum in field microplots. Phytopathology 96: 855-859.

Schlinker, G. 2010. Die Anzahl der nematodentoleranten Sorten wächst. Zuckerrübe 59: 50-51.

Schlinker, G. 2012. Zuckerrübensorten werden ständing besser. Zuckerrübe 61: 38-41.

Sikora, R. A. 1992. Management of the antagonistic potential in agricultural ecosystems for the biological control of plant parasitic nematodes. Annu Rev Phytopathol 30: 245-270.

Stirling, G.R. 1991. Biological control of plant-parasitic nematodes: progress problems and prospects. CAB International, Wallingford, UK, $282 \mathrm{pp}$.

Stirling, G. R. 2014. Biological control of plant-parasitic nematodes: soil ecosystem management in sustainable agriculture. CAB International, Wallingford, UK. 
Stirling, G. R., McKenry, M. V., \& Mankau, R. 1979. Biological control of root-knot nematodes (Meloidogyne spp.) on peach. Phytopathology 69: 806-809.

Talavera, M., Mizukubo, T., Ito, K., Aiba, S. 2002. Effect of spore inoculum and agricultural practices on the vertical distribution of the biocontrol plant-growth-promoting bacterium Pasteuria penetrans and growth of Meloidogyne incognita-infected tomato. Biol Fertil Soils 35: 435-440.

Thielemann, R. Steudel, W. 1973. Nine years of experience with monocultures of sugar beets in soil contaminated with Heterodera schachtii. Nachrichtenbl Deut Pflanzenschutzd 25: 145-149.

Weller, D.M., Thomashow, L.S. 1994. Current challenges in introducing beneficial microorganisms into the rhizosphere. In: O’Gara, F., Dowling, D.N., Boesten, B. (Eds.) Molecular Ecology of Rhizosphere Microorganisms, VCH, New York, NY, pp. 1-18.

Weller, D. M., Raaijmakers, J. M., Gardener, B. B. M., \& Thomashow, L. S. 2002. Microbial populations responsible for specific soil suppressiveness to plant pathogens. Annu Rev Phytopathol 40: 309-348.

Westphal, A. 2005. Detection and description of soils with specific nematode suppressiveness. J Nematol 37: 121-130.

Westphal, A. 2013. Vertical Distribution of Heterodera schachtii under Susceptible, Resistant, or Tolerant Sugar Beet Cultivars. Plant Dis 97: 101-106.

Westphal, A. and Becker, J.O. 1999. Biological suppression and natural population decline of Heterodera schachtii in a California field. Phytopathology 89: 434-440.

Westphal, A., and J.O. Becker. 2001. Soil suppressiveness to Heterodera schachtii under different cropping sequences. Nematology 3: 551-558.

Westphal, A. and L. J. Xing. 2011. Soil suppressiveness against the disease complex of the soybean cyst nematode and sudden death syndrome of soybean. Phytopathology 101: 878-886.

Yang, J. I., Benecke, S., Jeske, D. R., Rocha, F. S., Becker, J. S., Timper, P., Becker, J.O. \& Borneman, J. 2012. Population Dynamics of Dactylella oviparasitica and Heterodera schachtii: Toward a Decision Model for Sugar Beet Planting. J Nematol 44: 237-244. 
Yin, B., Valinsky, L., Gao, X., Becker, J. O., and Borneman, J. 2003. Identification of fungal rDNA associated with soil suppressiveness against Heterodera schachtii using oligonucleotide fingerprinting. Phytopathology 93: 1006-1013. 


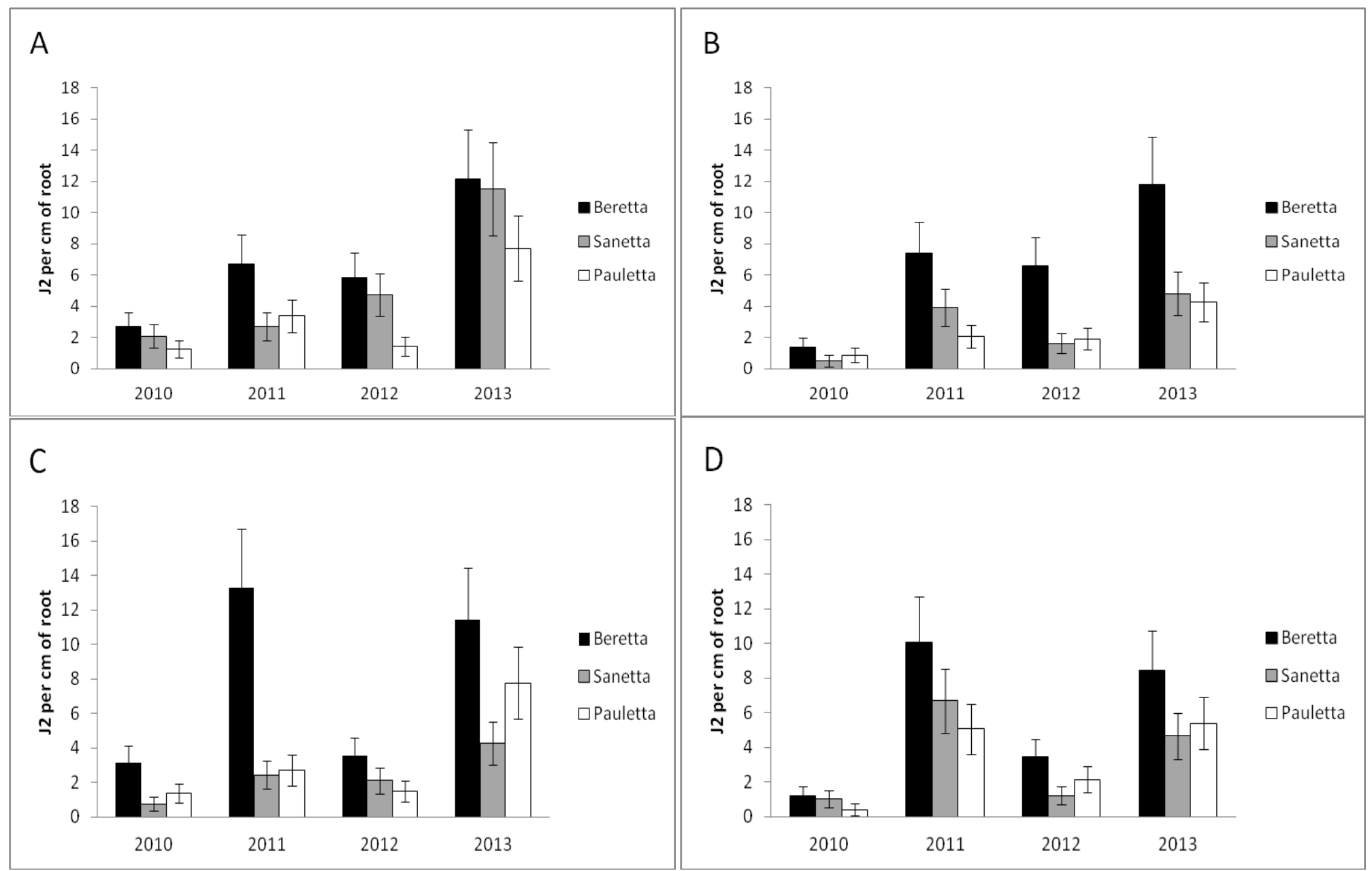

Fig. 4.1 Root penetration by second-stage juveniles (J2) of Heterodera schachtii Schach0 in a susceptible, resistant and tolerant sugar beet genotype at Münster, from 2010 to 2013 in (A) untreated control, (B) P. nishizawae, (C) D. oviparasitica (2 ${ }^{\text {nd }}$ inoculation in 2011), and (D) D. oviparasitica (single inoculation in 2011). 


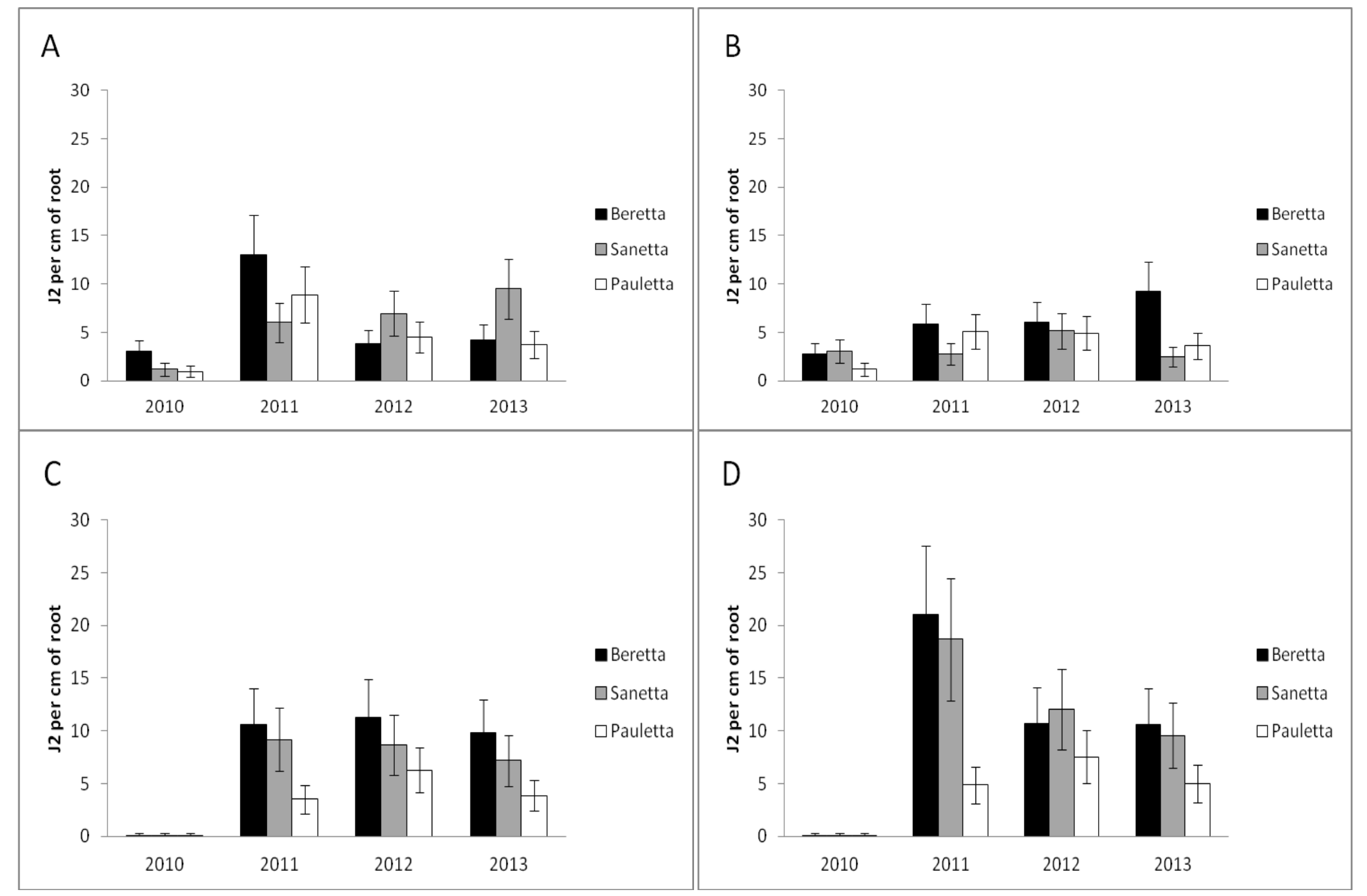

Fig. 4.2 Root penetration by second-stage juveniles (J2) of Heterodera schachtii Schach1 in a susceptible, resistant and tolerant sugar beet genotype at Münster, from 2010 to 2013 in (A) untreated control, (B) P. nishizawae, (C) Dazomet + D. oviparasitica, and (D) Dazomet - D. oviparasitica. 


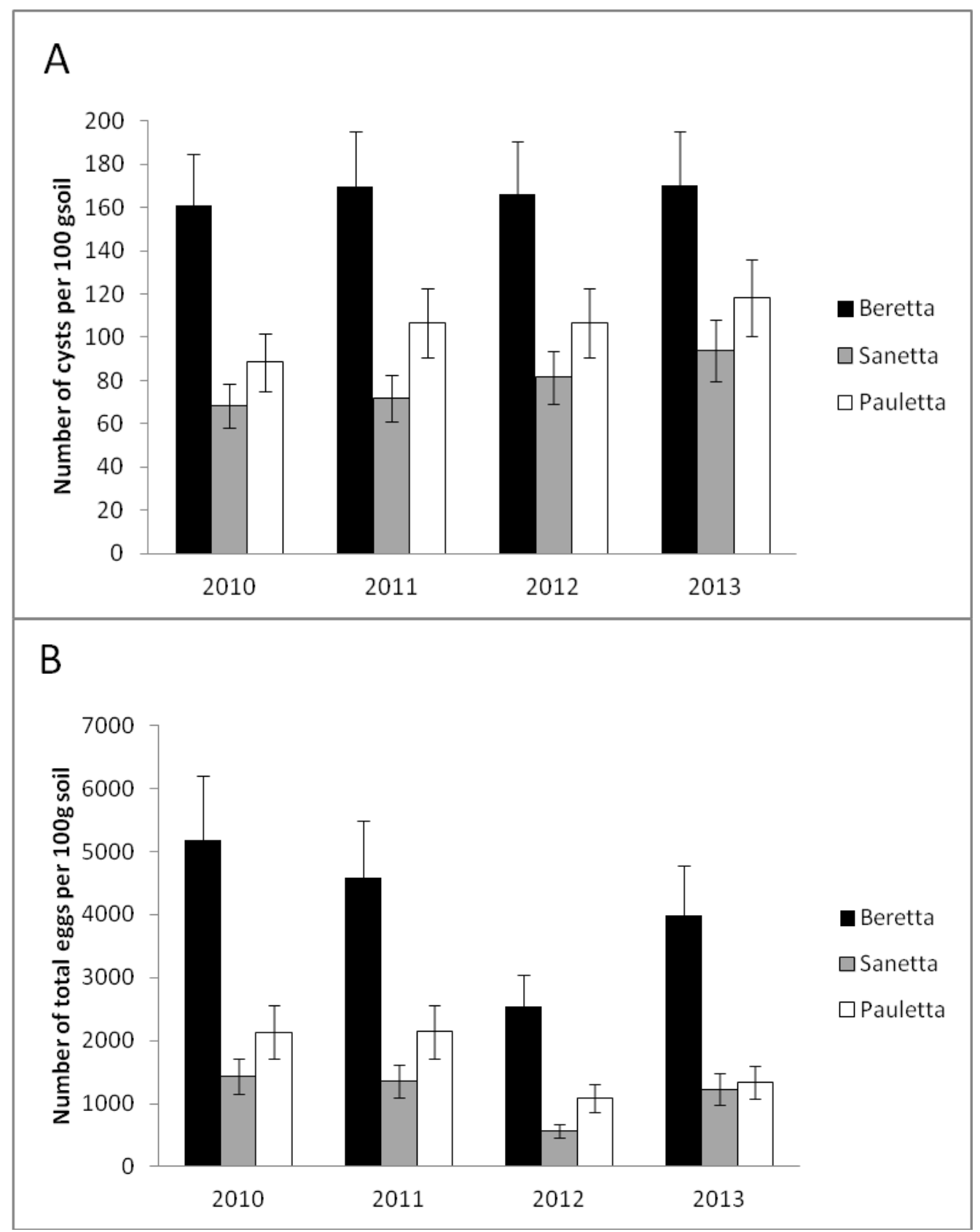

Fig. 4.3 Final population densities of Heterodera schachtii Schach0 at Münster, from 2010 to 2013, at 0- to 30-cm depth; (A) numbers of cysts and (B) total eggs. Data are presented as backtransformed lsmeans \pm lsmse. 


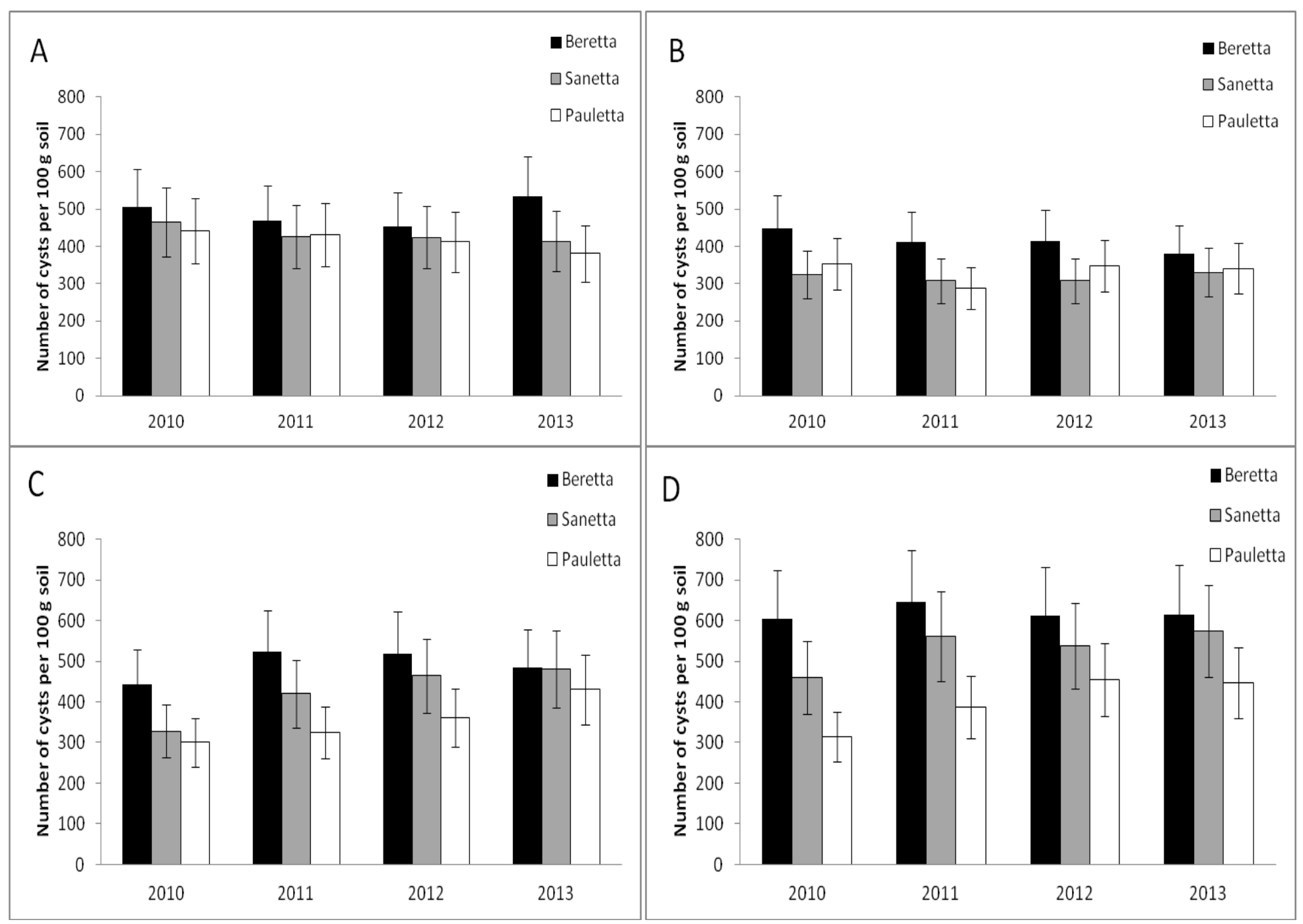

Fig. 4.4 Final population densities of cysts of Heterodera schachtii Schach1 at Münster, from 2010 to 2013, at 0- to 30-cm depth in (A) untreated control, (B) P. nishizawae, (C) Dazomet + D. oviparasitica, and (D) Dazomet - D. oviparasitica plots. Data are presented as backtransformed lsmeans \pm lsmse. 


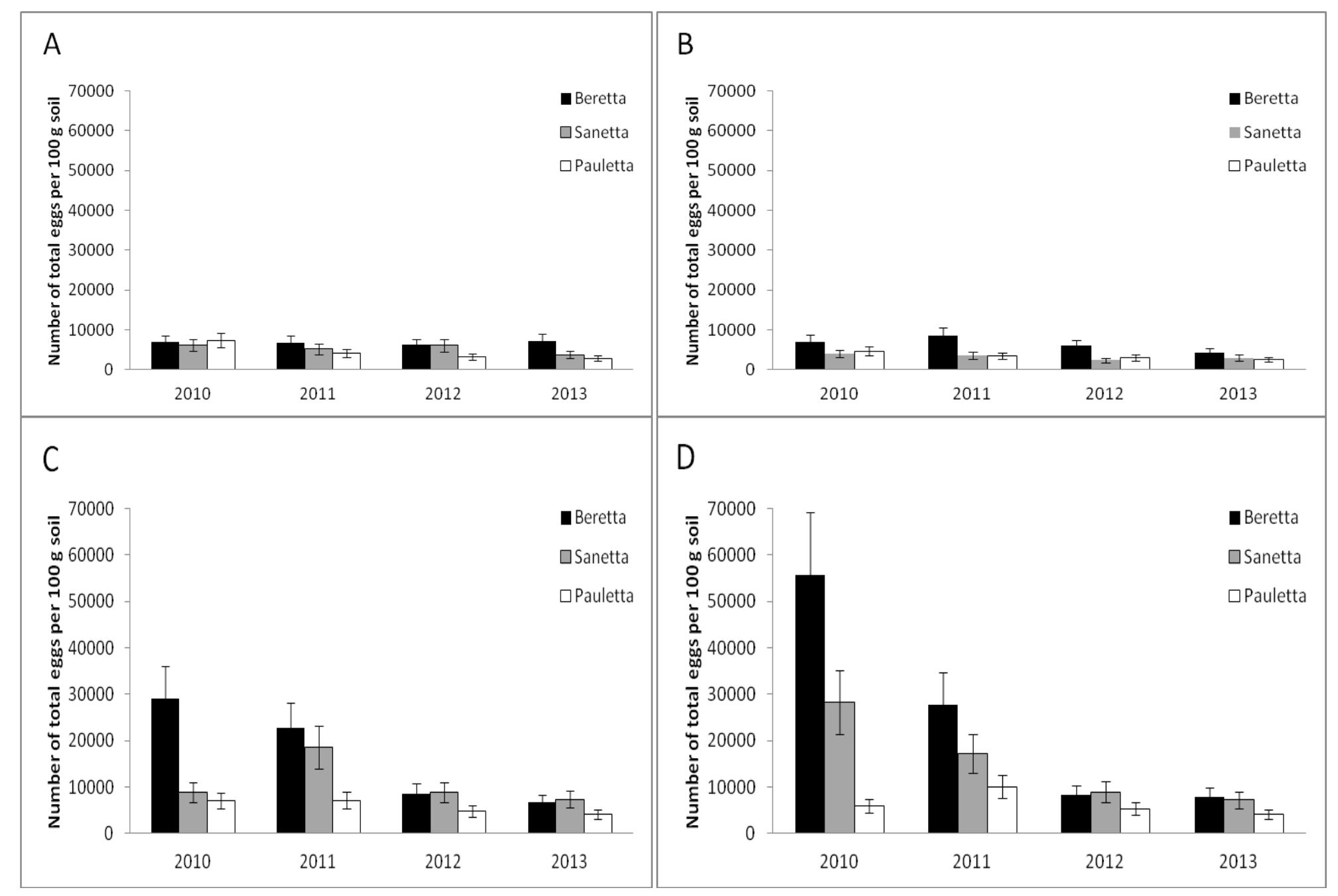

Fig. 4.5 Final population densities of total eggs of Heterodera schachtii Schach1 at Münster, from 2010 to 2013, at 0- to 30-cm depth in (A) untreated control, (B) P. nishizawae, (C) Dazomet + D. oviparasitica, and (D) Dazomet - D. oviparasitica plots. Data are presented as backtransformed lsmeans \pm lsmse. 


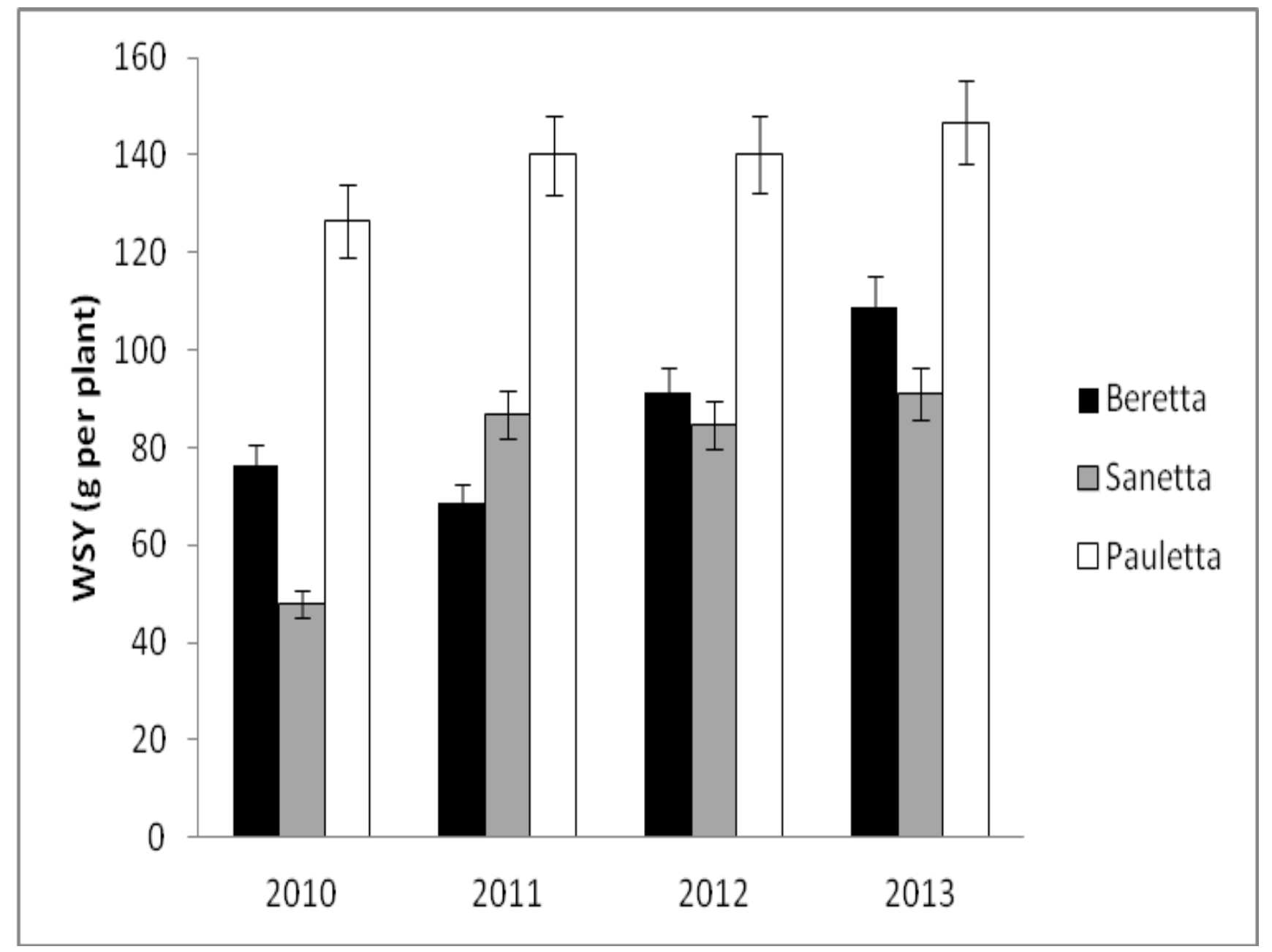

Fig. 4.6 White sugar yield (WSY) of Heterodera schachtii Schach0 at Münster from 2010 to 2013. Data are presented as backtransformed lsmeans \pm lsmse. 


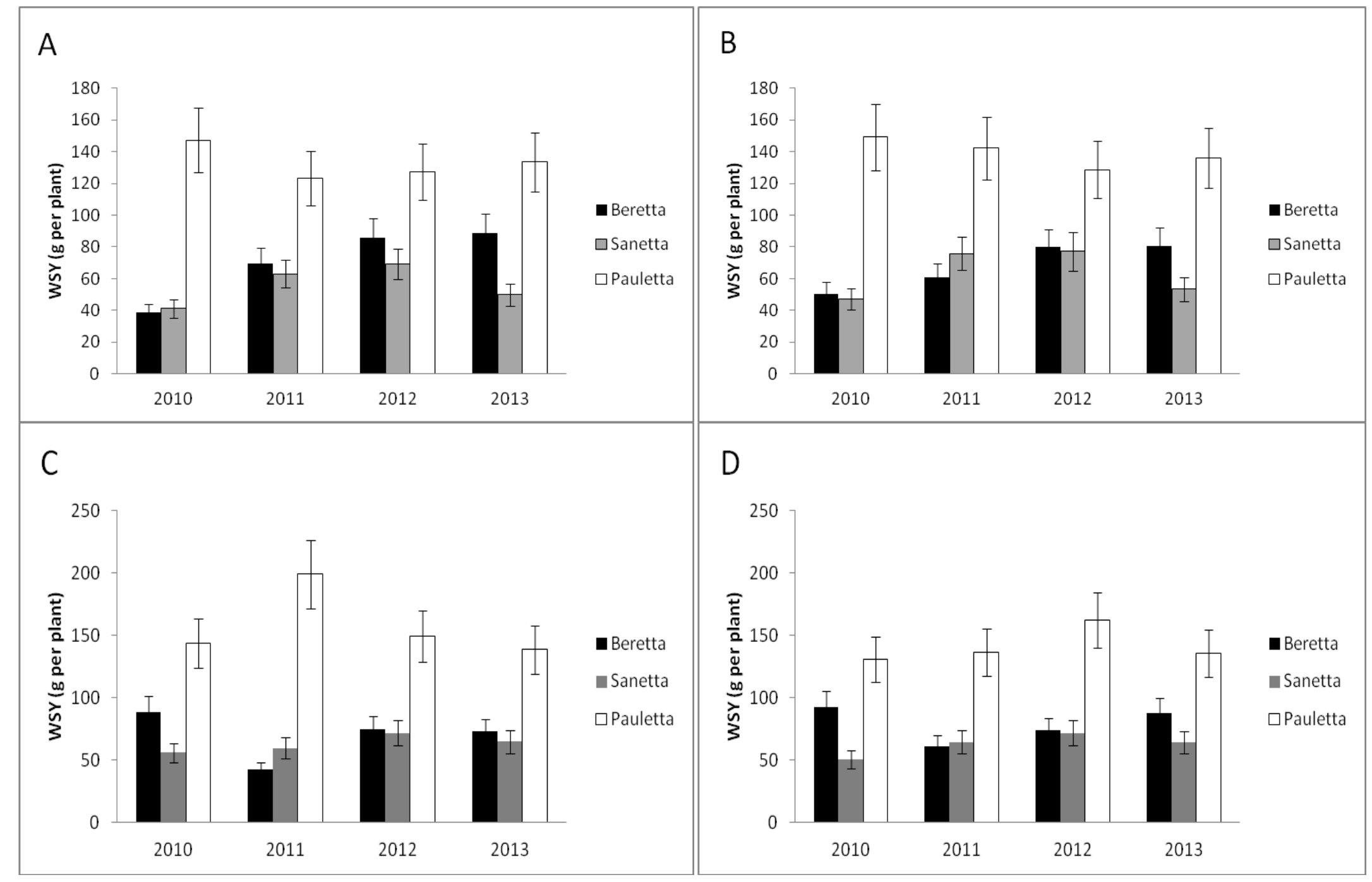

Fig. 4.7 White sugar yield (WSY) of Heterodera schachtii Schach1 at Münster from 2010 to 2013 in (A) untreated control, (B) P. nishizawae, (C) Dazomet + D. oviparasitica, and (D) Dazomet - D. oviparasitica plots. Data are presented as backtransformed lsmeans \pm lsmse. 


\section{GENERAL DISCUSSION}

Various soil ecosystems exhibiting the capacity to limit the development of different soilborne diseases and pests have been identified and termed suppressive soils. Several studies have been done to unravel the biological processes implicated in such soils (Weller et al., 2002; Borneman and Becker, 2007; Van Elsas et al, 2008). It has been proposed that implementation or modification of certain agricultural practices, such as organic amendments, cropping system (i. e. monoculture, crop rotation), input system (organic versus conventional), tillage regime, among others, can conserve or enhance resident microbial community involved in soil suppressiveness (Workneh and Van Bruggen, 1994; Van Bruggen 1995; Hallmann et al., 1999; Pankhurst et al., 2002; Van Elsas et al., 2002; Peters et al., 2003; Garbeva et al., 2006; Pérez-Piqueres et al., 2006; Mazzola 2007).

Findings of this study provide information on the effect of monoculture conditions on the dynamics of Globodera pallida, CCN (Heterodera avenae and H. filipjevi) and Heterodera schachtii cysts, healthy and diseased eggs. Although these monocultures did not lead to a severe and persistent decline as reported for other cyst nematode-suppressive soils (Gair et al., 1969; Westphal and Becker, 1999), a significant proportion of the nematode population became diseased, which suggest the presence of suppressive factors.

When comparing with other long-term experiments conducted with G. rostochiensis under susceptible potato monocultures in different European countries, the increase of egg populations in the here described project from the first to the fourth year are similar to the increases found by Jones and Parrot (1969) in the UK, and extremely below increases found by Zawiślak et al. (1989) in Poland and by Tiilikkala (1991) in Finland (Chapter 1). Under potato monoculture, a dramatic seasonal increase in the proportion of diseased eggs observed after the first cropping season in both G. pallida populations, along with fluctuations with a cyclic behaviour in the proportion of diseased eggs, especially in Chavornay (Chapter 1), suggested suppressiveness as the result of a density-dependent predator (parasite) - prey (host) regulation (Lotka, 1925; Volterra, 1926). When investigating the cause of the high increase of G. pallida diseased eggs, a greenhouse experiment with root observation chambers was conducted (Chapter 2). By eliminating most of the soil microbiota, biocidal or heat treatments have been used to 
demonstrate the biological nature of specific suppressiveness (Westphal, 2005). A lack of significant differences between numbers of females in non-heated and heat-treated soil (Chapter 2), could be explained by the fact that PCN generally complete only one generation per growing season, suggesting that a longer period of time may have been necessary for the development of measurable suppressiveness. The use of culture-independent methods demonstrated the presence of multiple microorganisms associated with females of G. pallida (Chapter 2). Next-generation sequencing complemented the diversity and abundance profiling of female's bacterial and fungal communities obtained by DGGE. Molecular tools have been of great importance on identifying key players of suppressive soils (Weller et al., 2002; Yin et al. 2003a, 2003b; Garbeva et al., 2004; Mazzola 2004; Borneman and Becker, 2007; van Elsas et al., 2008). Results obtained by pyrosequencing differed greatly from the species frequently found in other cyst nematodes. This difference may be mainly explained by the different procedures of determining cyst-colonizing microorganisms traditionally with culture-dependent methods. Considering the limited knowledge on the cyst-associated bacterial flora, and the reduced number of studies that have examined the fungi associated with PCN (Morgan-Jones and Rodriguez-Kabana, 1986; Roessner, 1987; Dackman, 1990; Crump, 1991; Yu and Coosemans, 1998), our study is an important contribution to this elucidation of cyst and egg colonizing microorganisms. Ribosomal sequences of the bacteria Burkolderia and Ralstonia were abundant on eggs. Sequences affiliated with the fungus Malassezia, especially $M$. restricta, were highly abundant (Chapter 2). Due to pathogenic abilities of Malassezia species on animal skin, a tissue that shares structural proteins with the cuticle of nematodes (Guého-Kellerman et al., 2011), the dominance of Malassezia spp. warrants further investigation. Sequences affiliated to Hirsutella rhossiliensis (a fungal pathogen of several cyst nematodes, including G. pallida; Chen and Liu, 2005), Microdochium bolleyi and Monographella cucumerina in G. pallida females, were also found in high abundance (Chapter 2). A relation of these organisms with the high levels of diseased eggs that were found in the potato monoculture microplots was suggested, though the application of Koch's postulates would be required to determine if these microorganisms were the causal agents of such large number of diseased eggs. Once the pathogenic abilities of these microorganisms can be proved, management strategies could take advantage of this specific microbiome occupying the microenvironmental niche within G. pallida females. 
In the CCN study, soil transfer of untreated oat monoculture soil into untreated soil did not have a measurable effect on the population densities of $H$. avenae and $H$. filipjevi, or in plant growth and yield (Chapter 3), most likely due to a buffering effect of the resident microflora that prevented the establishment of the potential antagonists of the introduced soil. The absence of common dominant bacterial and fungal ribotypes specific to the oat monoculture soil and plots with the non-heated portion of this amendment before and after cropping of susceptible oat, support this explanation. There are several examples of suppressiveness transfer that could be established successfully in microbially perturbed soils (Mankau, 1975; Kluepfel et al., 1993; Westphal and Becker, 2000), but in the few reports of the transfer of suppressiveness into untreated soils, higher amounts of amendment were needed for the successfully establishment of antagonists (Stirling and Kerry, 1983; Westphal and Becker, 2000). In spite of the failure of the suppressive transfer to facilitate the establishment of soil supressiveness, a significant increase in number of diseased eggs found in $\mathrm{CCN}$ populations during the three-year cereal cropping, suggested that cultivation of susceptible hosts alone, induced and supported the establishment of soil suppresssiveness by favouring resident antagonists present in the microplots (Chapter 3).

In order to test the suppressive potential of the oat monoculture soil and two soils from intensive cropping of cereal against $H$. avenae, a climate chamber experiment with root observations chambers was conducted (Chapter 3). Lower numbers of females in non-heated soils compared to heat-treated, indicated a suppressive effect of biological nature in the oat monoculture and the conventional farming (intensive cereal cropping) soil. In bacterial and fungal fingerprints, different patterns were observed for heat-treated and non-heated soils, with a larger number of dominant bands in the non-heated soils (Chapter 3). Whether these dominant ribotypes correspond to microorganisms responsible for reducing the number of females remained to be investigated. A similarity between the oat monoculture and the two soils from intensive cropping of cereal was observed in their ability to reduce $H$. avenae female populations in non-heated soils compared to the control (limited cereal cropping), and also at a fungal community level (Chapter 3). This suggested that the development of suppressiveness is not exclusive of a monoculture of the host. According to Cook and Baker (1983) the presence of the pathogen and a susceptible host is mandatory for suppressiveness to develop. However, rotation with favorable non-hosts crops may not only maintain the suppressiveness originated during cropping of susceptible hosts, but also lead to the build-up of suppressiveness by stimulating 
specific microbial antagonists within the soil microbial communities (Mazzola, 2004). Several studies have pointed out the importance of crop rotation compared to other management practices in influencing the microbial communities, and thereby the degree of soil suppressiveness (Van Elsas et al., 2002; Larkin, 2008; Larkin and Honeycutt 2006; Larkin et al., 2010). Although no extrapolations can be made from the data corresponding to a limited number of field samples, the lack of significant differences found between the soils from organic and conventional fields within the soils from intensive cereal cropping illustrate the importance of management practices, e.g. cropping system compared to the input system (conventional versus organic). Management practices can, play a key role not only in the population levels of the pathogen populations, but also in soil microbial communities (Van Elsas et al., 2002; Elmholt and Labouriau, 2005; Larkin, 2008; Larkin and Honeycutt 2006; Larkin et al., 2010). Results of this study suggest that control strategies should include the effects of cropping practices in the population densities of the pathogen and also in soil microbial communities that may complement the beneficial effect of crop rotation by enhancing potential suppressive agents.

Under a monoculture of a host, an inconsistent effect of the facultative fungus Dactylella oviparasitica or the obligate nematode parasite bacterium Pasteuria nishizawae was observed on the population densities of $H$. schachtii or in plant yield (Chapter 4). It is likely that a lack of soil receptivity prevented the organisms from their full potential. Through parasitism, competition for nutrients, and microbiostasis, the resident soil microbiota can negatively impact the establishment of introduced non-native microorganisms (Cook and Baker, 1983; De Boer et al., 2003; Monfort et al., 2006). Thus, perturbation of the resident microbiota by heat or biocidal treatments has been considered crucial for the successful establishment of antagonists (Mankau, 1962; Westphal, 2005). For that reason, D. oviparasitica was inoculated in basamid-previously treated soil in Schach1 plots (Chapter 4). Although this measure resulted in a reduction of $H$. schachtii final populations of total eggs under the resistant cultivar, compared to the corresponding control (basamid-treated plots without the fungus) after the first cropping cycle, no sustained suppression of the population densities or yield improvement was observed during the following cropping cycles. According to findings of Olatinwo et al. (2006), it seems much more important to introduce this fungus into non-suppressive soil before $H$. schachtii infestation instead of the simultaneous addition of the fungus and the nematode. Introduction of $D$. 
oviparasitica in plots already infested with the nematode, as it was the case in our study, may have prevented sufficient growth of the fungus before roots started to develop.

Despite the limited effect of $D$. oviparasitica or $P$. nishizawae, by the third cropping cycle of the four-year sugar beet monoculture, H. schachtii eggs became soon diseased, representing over $90 \%$ of the total eggs in both pathotypes (avirulent on any resistance sources, or virulent on sugar beet genotypes carrying the Hs1pro-1 gene for resistance Müller, 1998; Chapter 4). Interestingly, this phenomenon was observed under cultivation of susceptible, resistant and tolerant genotypes (Chapter 4), challenging the current concept of mandatory susceptible crop monoculture for the development and maintenance of soil suppressiveness. Westphal and Becker (2001) found that soil suppressiveness against H. schachtii was reduced after a double crop of the non-host Triticum aestivum, but preserved after cropping of resistant cultivars of sugar beet or oilseed radish. It had been also observed that soil suppressiveness has been induced by resistant cultivars. Katan et al. (1983) found that cropping of a cotton cultivar resistant to Fusarium oxysporum f. sp. vasinfectum resulted in reduced disease incidence of a susceptible cotton cultivar cropped afterwards on the same soil. Sneh et al. (1987) found that 810 years monoculture of melon varieties resistant to Fusarium wilt led to the build-up of soil suppressiveness, which was nullified after cropping of susceptible cultivars. Similarly, Hopkins et al. (1987) observed that a watermelon cultivar only moderately resistant to Fusarium wilt in greenhouse resistant tests was much more resistant to $F$. oxysporum f. sp. niveum in a monoculture soil, and the promotion of a suppressive factor by this cultivar was suggested. They also found that the suppressiveness that developed after monoculture of this cultivar was effective on all cultivars. It seems that resistant cultivars not only have the capability per se to reduce the population densities of a pathogen, but also indirectly by enhancing resident microbial antagonists to the pathogen, thus inducing the development of soil suppresiveness. It is known that through root exudates, plant species and genotype exert a significant effect on the composition of microbial communities inhabiting the soil and the rhizosphere (rewieved by Mazzola 2004). This is well illustrated in take-all decline of wheat, where the ability to support and enhance resident populations of 2,4-DAPG-producing fluorescent pseudomonads in the rhizosphere, which are responsible for suppresiveness to this disease (Raaijmakers and Weller, 1998), differ among wheat cultivars (Mazzola et al., 2004). 
In the tolerant cultivar, the highest white sugar yield (WSY) was observed in both $H$. schachtii pathotypes (Chapter 4). Such an outcome was expected, since it is known that under high but also under very low population densities, tolerant sugar beet cultivars are able to have a high yield, and almost identical to non tolerant cultivars (Heinrichs, 2013; Kaemmerer et al., 2014). The use of resistant and tolerant cultivars that can support the development of suppressiveness despite reduced populations of the pest nematode, could bypass the cost of generating soil suppressiveness by monoculture of susceptible hosts.

Findings of these studies provide additional evidence to the assumption that natural suppression should not be seen as a phenomenon that rarely occurs, but more often than we typically consider. Therefore, it is worthwhile to put more effort in recognizing these soils and the suppressive mechanisms involved, but also to give soils the chance to become suppressive. Virtually every soil possesses microorganisms that are able to constrain the pathogen to a certain extent (Stirling, 1991; Mazzola, 2004; Janvier et al., 2007), therefore more attention should be placed on adopting or modifying agronomic practices that support the antagonists that are already adapted to a particular ecosystem. A unique example that supports this claim are the results obtained after a 12-year research program undertaken in an effort to overcome the socalled yield decline in sugarcane, critical for the Australian sugar industry in the early 1990s. As a result of this investigation, a new sustainable and profitable farming system based on residue retention, minimum tillage, a leguminous rotation crop, and controlled machinery traffic, was implemented (Garside et al., 2005; Stirling, 2008). In relation to the two most important nematode pests of sugarcane, Pratylenchus zeae and Meloidogyne javanica, the introduction of a rotation crop, soil health improvements, and support and enhancement of suppressive mechanisms, reduced the population densitites of these nematodes, and the yield losses attributed to them. Due to the beneficial effects such as increases in sugar yields, cost reduction, improvements in soil health, and the additional income from profitable rotation crops, this system has being implemented by farmers. The positive outcome of this experience, illustrates the feasibility of such a goal, and can serves as motivation to evaluate the influence of cropping models and farming practices in the development or support of soil suppressiveness. 


\section{References}

Borneman, J., and Becker, J. O. 2007. Identifying microorganisms involved in specific pathogen suppression in soil. Annu Rev Phytopathol 45:153-172.

Chen, S., and Liu, X. 2005. Control of the soybean cyst nematode by the fungi Hirsutella rhossiliensis and Hirsutella minnesotensis in greenhouse studies. Biol Control 32:208-219.

Cook, R. J. and Baker, K. F. 1983. The Nature and Practice of Biological Control of Plant Pathogens. American Phytopathological Society, St. Paul, Minnesota.

Crump, D. H. 1991. Fungal species isolated from beet, cereal and potato cyst nematodes. Pages 58-64 in: Kerry, B. R., and Crump, D. H. eds. Methods for studying nematophagous fungi. IOBC/ WPRS Bulletin XIV.

Dackman, C. 1990. Fungal parasites of the potato cyst nematode Globodera rostochiensis: isolation and reinfection. J Nematol 22: 594-597.

De Boer, W., Verheggen P., Gunnewiek, P.J.A.K., Kowalchuk, G.A, Van Veen, J.A. 2003 Microbial community composition affects soil fungistasis. Appl Environ Microbiol 69: 835844.

Elmholt, S. and Labouriau, R. 2005. Fungi in Danish soils under organic and conventional farming. Agric Ecosyst Environ 107: 65-73.

Gair, R., Mathias, P.L. \& Harvey, P.N. 1969. Studies of cereal nematode populations and cereal yields under continuous or intensive culture. Ann Appl Biol 63: 503-512.

Garbeva, P., Van Veen, J. A., \& Van Elsas, J. D. 2004. Microbial diversity in soil: selection of microbial populations by plant and soil type and implications for disease suppressiveness. Annu Rev Phytopathol 42: 243-270.

Garbeva, P., Postma, J., Van Veen, J. A., \& Van Elsas, J. D. 2006. Effect of above-ground plant species on soil microbial community structure and its impact on suppression of Rhizoctonia solani AG3. Environ Microbiol 8: 233-246.

Garside, A. L., Bell, M. J., Robotham, B. G., Magarey, R. C., \& Stirling, G. R. 2005. Managing yield decline in sugarcane cropping systems. Int Sugar J 107: 16-26.

Guého-Kellerman, E., Batra, R., and Boekhout, T. 2011. Malassezia Baillon (1889). In: Kurtzman, C., Fell, J. W., Boekhout, T. (Eds.) The yeasts: a taxonomic study. Elsevier, pp.1807-1832. 
Hallmann, J., Rodrıguez-Kábana, R., \& Kloepper, J. W. 1999. Chitin-mediated changes in bacterial communities of the soil, rhizosphere and within roots of cotton in relation to nematode control. Soil Biol Biochem 31: 551-560.

Heinrichs, C. 2013. Der Acker lebt auch in der Tiefe. Zuckerrübenjournal 02/2013, 14-15.

Hopkins, D. L., Larkin, R. P., \& Elmstrom, G. W. 1987. Cultivar-specific induction of soil suppressiveness to Fusarium wilt of watermelon. Phytopathology 77: 607-611.

Janvier, C., Villeneuve, F., Alabouvette, C., Edel-Hermann, V., Mateille, T., \& Steinberg, C. 2007. Soil health through soil disease suppression: which strategy from descriptors to indicators?. Soil Biol Biochem 39: 1-23.

Jones, F.G.W. and Parrott, D.M. 1969. Population fluctuations of Heterodera rostochiensis Woll. when susceptible potato varieties are grown continuously. Annals of Applied Biology 63: 175-181.

Kaemmerer, D., Meinecke, A., Hermann, A., Anselstetter, M., Göbel, E., Bürcky, K., Ziegler, K. and Westphal, A. 2014. Nematodenvermehrung und Ertragslesitung verschiedener Zuckerrüben-Genotypen. In: Maßnahmen zur Schadensminderung von Heterodera schachtii im Zuckerrübenbau. Bayerische Landesanstalt für Landwirtschaft. Freising-Tüntenhausen, Germany, pp. 44-54.

Katan, J., Fishler, G., \& Grinstein, A. 1983. Short- and long-term effects of soil solarization and crop sequence on Fusarium wilt and yield of cotton in Israel. Phytopathology 73: 12151219.

Kluepfel, D. A., McInnis, T. M., and Zehr, E. I. 1993. Involvement of root-colonizing bacteria in peach orchard soils suppressive of the nematode Criconemella xenoplax. Phytopathology 83: 1240-1245.

Larkin, R. P. 2008. Relative effects of biological amendments and crop rotations on soil microbial communities and soilborne diseases of potato. Soil Biol Biochem 40: 1341-1351.

Larkin, R. P. and Honeycutt, C. W. 2006. Effects of different 3-year cropping systems on soil microbial communities and Rhizoctonia diseases of potato. Phytopathology 96: 68-79.

Larkin, R. P., Griffin, T. S., Honeycutt, C. W. 2010. Rotation and cover crop effects on soilborne potato diseases, tuber yield, and soil microbial communities. Plant Dis 94: 1491-1502.

Lotka, A.J. 1925. Elements of Physical Biology. Williams \& Wilkins, Baltimore, US.

Mankau, R. 1962. Soil fungistasis and nematophagous fungi. Phytopathology 52: 611-615. 
Mankau, R. 1975. Bacillus penetrans n. comb. causing a virulent disease of plant-parasitic nematodes. J Invertebr Pathol 26: 333-339.

Mazzola, M. 2004. Assessment and management of soil microbial community structure for disease suppression. Annu Rev Phytopathol 42: 35-59.

Mazzola, M., Funnell, D. L., and Raaijmakers, J. M. 2004. Wheat cultivar-specific selection of 2,4-diacetylphloroglucinol-producing fluorescent Pseudomonas species from resident soil populations. Microb Ecol 48:338-348.

Mazzola, M. 2007. Manipulation of rhizosphere bacterial communities to induce suppressive soils. J Nematol 39: 213-220.

Montfort, E., Lopez-Llorca, L.V., Jansson, H.B., Salinas, J. 2006. In vitro receptivity assays to egg-parasitic nematophagous fungi. Mycol Prog 5:18-23.

Morgan-Jones, G., and Rodriguez-Kabana, R. 1986. Fungi associated with cysts of potato cyst nematodes in Peru. Nematropica 16: 21-31.

Müller, J. 1998. New pathotypes of the beet cyst nematode (Heterodera schachtii) differentiated on alien genes for resistance in beet (Beta vulgaris). Fundam Appl Nematol 21: 519-526.

Olatinwo, R., Yin, B., Becker, J. O., \& Borneman, J. 2006. Suppression of the plant-parasitic nematode Heterodera schachtii by the fungus Dactylella oviparasitica. Phytopathology 96: 111-114.

Pankhurst, C.E., McDonald, H.J., Hawke, B.G., and Kirkby, C.A. 2002. Effect of tillage and stubble management on chemical and microbiological properties and the development of suppression towards cereal root disease in soils from two sites in NSW, Australia. Soil Biol Biochem 34: 833-840.

Peters, R. D., Sturz, A. V., Carter, M. R., \& Sanderson, J. B. 2003. Developing diseasesuppressive soils through crop rotation and tillage management practices. Soil Till Res 72: 181-192.

Pérez-Piqueres, A., Edel-Hermann, V., Alabouvette, C., \& Steinberg, C. 2006. Response of soil microbial communities to compost amendments. Soil Biol Biochem 38: 460-470.

Raaijmakers, J.M. and Weller, D.M. 1998. Natural plant protection by 2,4diacetylphloroglucinol-producing Pseudomonas spp. in take-all decline soils. Mol Plant Microbe Interact 11:144-52. 
Roessner, J. 1987. Pilze als Antagonisten von Globodera rostochiensis. Nematologica 33:106118.

Sneh, B., Pozniak, D., \& Salomon, D. 1987. Soil suppressiveness to Fusarium wilt of melon, induced by repeated croppings of resistant varieties of melons. Phytopathology 120: 347354.

Stirling, G.R. 1991. Biological control of plant-parasitic nematodes: progress problems and prospects. CAB International, Wallingford, UK, $282 \mathrm{pp}$.

Stirling, G. R. 2008. The impact of farming systems on soil biology and soilborne diseases: examples from the Australian sugar and vegetable industries-the case for better integration of sugarcane and vegetable production and implications for future research. Australas Plant Pathol 37: 1-18.

Stirling, G. R. and Kerry, B. R. 1983. Antagonists of the cereal cyst nematode Heterodera avenae Woll. in Australian soils. Animal Production Science 23: 318-324.

Tiilikkala, K. 199. Effect of crop rotation on Globodera rostochiensis and on potato yield. EPPO Bull. 21: 41-47.

Van Bruggen, A.H.C. 1995. Plant disease in high-input compared to reduced-input and organic farming systems. Plant Dis 79: 976-983.

Van Elsas, J. D., Garbeva, P., \& Salles, J. 2002. Effects of agronomical measures on the microbial diversity of soils as related to the suppression of soil-borne plant pathogens. Biodegradation 13: 29-40.

Van Elsas, J. D., Speksnijder, A. J., and van Overbeek, L. S. 2008. A procedure for the metagenomics exploration of disease-suppressive soils. J Microbiol Meth 75:515-522.

Volterra, V. 1926. Variazione e fluttuazini del numero d'individui in specie animali conviventi. Memmorie dell’Accademia Nazionale dei Lincei 2: 31-113.

Weller, D. M., Raaijmakers, J. M., Gardener, B. B. M., Thomashow, L. S. 2002. Microbial populations responsible for specific soil suppressiveness to plant pathogens. Annu Rev Phytopathol 40: 309-348.

Westphal, A. 2005. Detection and description of soils with specific nematode suppressiveness. J Nematol 37:121-130.

Westphal A, Becker JO. 1999. Biological suppression and natural population decline of Heterodera schachtii in a California field. Phytopathology 89: 434-40. 
Westphal, A. and J.O. Becker. 2000. Transfer of biological soil suppressiveness against Heterodera schachtii. Phytopathology 90: 401-406.

Westphal, A., and J.O. Becker. 2001. Soil suppressiveness to Heterodera schachtii under different cropping sequences. Nematology 3: 551-558.

Workneh, F., \& Van Bruggen, A. H. C. 1994. Microbial density, composition, and diversity in organically and conventionally managed rhizosphere soil in relation to suppression of corky root of tomatoes. App Soil Ecol 1: 219-230.

Yin, B., Valinsky, L., Gao, X., Becker, J. O., and Borneman, J. 2003a. Bacterial rRNA Genes associated with Soil Suppressiveness against the Plant-Parasitic Nematode Heterodera schachtii. Appl Environ Microbiol 69: 1573-1580.

Yin, B., Valinsky, L., Gao, X., Becker, J. O., and Borneman, J. 2003b. Identification of fungal rDNA associated with soil suppressiveness against Heterodera schachtii using oligonucleotide fingerprinting. Phytopathology 93:1006-1013.

Yu, Q., and Coosemans, J. 1998. Fungi associated with cysts of Globodera rostochiensis, G. pallida, and Heterodera schachtii; and egg masses and females of Meloidogyne hapla in Belgium. Phytoprotection 79: 63-69.

Zawislak, K., Tyburski, J. \& Rychik, B. 1989. Significance of crop rotation and cultivars resistant to potato cyst nematode on potato production. In: Vos, J., Van Loon, C. D., and Bollen, G. J. (Eds) Effects of Crop Rotation on Potato Production in the Temperate Zones. Springer, The Netherlands, pp. 111-119. 


\section{CURRICULUM VITAE}

Date /Place of birth: 26.11.1980 / Viña del Mar, Chile

School and University Education

\begin{tabular}{|c|c|}
\hline$\overline{2} / 2$ & $\begin{array}{l}\text { PhD in Agricultural Sciences - Georg-August-University of Göttingen, } \\
\text { Julius Kühn-Institute (JKI; Federal Research Centre for Cultivated Plants), } \\
\text { Münster/Braunschweig }\end{array}$ \\
\hline $4 / 2008$ & $\begin{array}{l}\text { Master of Science in Microbiology - Universidad Austral, Valdivia, Chile } \\
\text { - Thesis Title: "Pathogenicity to Meloidogyne hapla of ninety fungi } \\
\text { isolated from Meloidogyne spp. eggmasses from three regions in } \\
\text { Chile" }\end{array}$ \\
\hline $03 / 2002-12 / 2006$ & $\begin{array}{l}\text { Undergraduate studies of Biology and Natural Sciences Education - } \\
\text { Pontificia Universidad Católica de Valparaíso, Chile }\end{array}$ \\
\hline 03-05 1999 & Slaton High School, TX, USA \\
\hline$/ 1993-12$ & ducation), Villa Alemana, Chile \\
\hline
\end{tabular}

Research and Work Experience

10/2014 - 03/2015 Research assistant, Julius Kühn-Institut- Institute for Plant Protection in Field Crops and Grassland, Braunschweig, Germany

10/2010 - 09/2014 PhD studies at the Georg-August University of Göttingen, Department of Crop Sciences, Agricultural Entomology, and Julius Kühn-Institut, Münster/Braunschweig

06-092010 Volunteer at Julius Kühn-Institut-Institute for Plant Protection in Field Crops and Grassland, Münster, Germany

05/2010 Internship at the Nematology Laboratory, Servicio Agrícola y Ganadero, SAG [Agricultural and Livestock Service], Valparaíso, Chile

02/2007 - 02/2008 Biology Teacher, Colegio W.A. Mozart (High School), Santiago, Chile 


\section{National and International Meetings}

\begin{tabular}{|c|c|}
\hline $09 / 2014$ & 59. Deutsche Pflanzenschutztagung, Freiburg, Germany (Talk) \\
\hline $05 / 2014$ & $\begin{array}{l}\text { 6th International Congress of Nematology, Cape Town, South Africa } \\
\text { (Poster) }\end{array}$ \\
\hline $03 / 2014$ & $\begin{array}{l}\text { Jahrestagung } 2014 \text { des DPG-Arbeitskreises Nematologie, Görlitz, } \\
\text { Germany (Talk) }\end{array}$ \\
\hline $11 / 2013$ & $\begin{array}{l}\text { 6th Young Scientists Meeting of the Julius Kühn-Institute, Quedlinburg, } \\
\text { Germany (Talk) }\end{array}$ \\
\hline $07 / 2013$ & $\begin{array}{l}\text { 52. Annual Meeting of the Society of Nematologists, Knoxville, TN, USA } \\
\text { (Talk) }\end{array}$ \\
\hline $03 / 2013$ & $\begin{array}{l}\text { 41. Arbeitskreistagung des DPG-Arbeitskreises Nematologie, Bad } \\
\text { Salzuflen, Germany (Poster) }\end{array}$ \\
\hline $11 / 2011$ & $\begin{array}{l}\text { 4th Young Scientists Meeting of the Julius Kühn-Institut, Quedlinburg, } \\
\text { Germany (Poster) }\end{array}$ \\
\hline $03 / 2011$ & $\begin{array}{l}\text { 39. Arbeitskreistagung des DPG-Arbeitskreises Nematologie, Wageningen, } \\
\text { Netherlands (Poster) }\end{array}$ \\
\hline $8 / 2007$ & $\begin{array}{l}\text { Sixth International Conference of the European Science Education } \\
\text { Research Association, ESERA 2007, Malmö, Sweden (Poster) }\end{array}$ \\
\hline
\end{tabular}

\section{Publications}

$\overline{\text { Eberlein, C., Heuer, H., Vidal, S., Westphal, A. (2016). Microbial communities in Globodera }}$ pallida females raised in potato monoculture soil. Phytopathology 106,581-590.

Eberlein, C., Heuer, H., Westphal, A. (2016). Impact of cropping sequences and production strategies on soil suppressiveness against cereal cyst nematodes. Applied Soil Ecology 107,381-393.

Eberlein, C., Heuer, H., Vidal, S., Westphal, A. Population dynamics of Globodera pallida under potato monoculture (2016). Nematropica 46, 114-120.

\section{Abstracts}

Eberlein, C., Heuer, H., Vidal, S., Westphal, A. (2014). Population dynamics of Globodera pallida under potato monoculture. Julius-Kühn-Archiv 447,183-184. 
Eberlein, C., Heuer, H., Moos, J., Paulsen, H.M., Westphal, A. (2014). Suppressiveness of organic and conventional farming soils against Heterodera avenae. Journal of Nematology 46,156 .

Eberlein, C., Heuer, H., Moos, J., Paulsen, H.M., A. Westphal (2014). Development of soil suppressiveness against the cereal cyst nematode Heterodera avenae - Does the cropping system play a role? Presented at Workgroup Meeting 'Nematology' of the DPG at Görlitz, March 18-19, 2014.

Eberlein, C., Moos, J., Paulsen, H.M., A. Westphal (2013). Soil suppressiveness against the cereal cyst nematode Heterodera avenae. Presented at the Young Scientists Meeting, Julius Kühn-Institut, Quedlinburg, Germany, November 27-29, 2013.

Eberlein, C., A. Westphal (2013). Establishment of biocontrol against Heterodera schachtii under different sugar beet genotypes. Journal of Nematology 45,288.

Eberlein, C., Vidal, S., Becker, J.O., A. Westphal (2013). Population density suppression of Globodera pallida in a multi-year microplot trial with potato monoculture. Journal of Plant Diseases and Protection 120,142.

Eberlein, C., A. Westphal (2011). Suppression of Globodera pallida in monoculture cropping of potato. Presented at the Young Scientist Meeting, Julius Kühn-Institut, Quedlinburg, Germany, November 29-December 1, 2011. 


\section{DECLARATIONS}

1. I, hereby, declare that this Ph.D. dissertation has not been presented to any other examining body either in its present or a similar form.

Furthermore, I also affirm that I have not applied for a Ph.D. at any other higher school of education.

Göttingen, $17^{\text {th }}$ December 2015

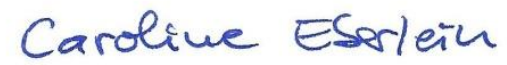

(Signature)

\section{CAROLINE EBERLEIN}

2. I, hereby, solemnly declare that this dissertation was undertaken independently and without any unauthorised aid.

Göttingen, 17th December 2015

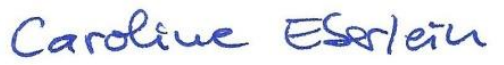

(Signature)

CAROLINE EBERLEIN 